\title{
Understanding Chinese American Parents: The Interplay of Chinese Tradition and Early Childhood Music Education in the United States
}

Juan Julie Yu

West Virginia University

Follow this and additional works at: https://researchrepository.wvu.edu/etd

\section{Recommended Citation}

Yu, Juan Julie, "Understanding Chinese American Parents: The Interplay of Chinese Tradition and Early Childhood Music Education in the United States" (2014). Graduate Theses, Dissertations, and Problem Reports. 568.

https://researchrepository.wvu.edu/etd/568

This Dissertation is protected by copyright and/or related rights. It has been brought to you by the The Research Repository @ WVU with permission from the rights-holder(s). You are free to use this Dissertation in any way that is permitted by the copyright and related rights legislation that applies to your use. For other uses you must obtain permission from the rights-holder(s) directly, unless additional rights are indicated by a Creative Commons license in the record and/ or on the work itself. This Dissertation has been accepted for inclusion in WVU Graduate Theses, Dissertations, and Problem Reports collection by an authorized administrator of The Research Repository @ WVU.

For more information, please contact researchrepository@mail.wvu.edu. 
Understanding Chinese American Parents: The Interplay of Chinese Tradition and Early Childhood Music Education in the United States

\author{
Juan Julie Yu \\ Dissertation submitted \\ to the College of Creative Arts \\ at West Virginia University \\ in partial fulfillment of the requirements for the degree of \\ Doctor of Philosophy in \\ Music Education
}

Janet Robbins, Ph.D., Chair

Molly A. Weaver, Ph.D.

Christopher Wilkinson, Ph.D.

Joy Faini Saab, Ed.D.

Paul Scea, M.A.

School of Music

Morgantown, West Virginia

2014

Keywords: Chinese American Parents, Early Childhood, Music Education, Acculturation Copyright 2014 Juan Julie Yu 


\begin{abstract}
Understanding Chinese American Parents: The Interplay of Chinese Tradition and Early Childhood Music Education in the United States
\end{abstract}

\title{
Juan Julie Yu
}

The purpose of this study is to examine the acculturation experience of first-generation Chinese American parents and the values that inform their expectations for their children's early childhood music education. A primary goal of this research is to gain a deeper understanding of the interplay of Chinese traditional culture and early childhood music education in the United States. The six participants for this study were first-generation Chinese American immigrants who at the time of the interviews had children under age eight and who resided in Philadelphia. As a qualitative multiple-case study, the primary data for this study were six sets of interviews, each set consisting of three different interviews with each of the six participants. Data were coded through the QSR NVivo software system and were analyzed and presented in the form of narrative portraits. The data analysis revealed four prominent themes that gave a voice to Chinese American parents. These themes included the importance of the traditional concept of guan in Chinese American parenting, the high value that Chinese Americans place on education, the function of music in Chinese culture, and the value of music education as moral cultivation. Considered within the context of the Chinese Americans' acculturation experience, these themes brought to light a number of tensions that Chinese American parents confront in providing for the music education of their young children. More awareness of these tensions will help both early childhood music educators and Chinese American parents build a reciprocal relationship that bridges this "cultural gap" and balances traditional Chinese values with early childhood music education best practices in the United States. 


\section{DEDICATION}

I dedicate this dissertation to my loving "tiger" parents and grandparents. 


\section{ACKNOWLEDGMENTS}

I am forever grateful to the members of my dissertation committee who were more than generous with their expertise and precious time. First, I would like to give special thanks to Dr.

Janet Robbins, my committee chair. She invested countless hours reading, revising, encouraging, and inspiring me throughout the long process of writing my dissertation. I appreciate most of all her patience. She is a mentor, a friend, and most importantly a loving American mom. I cannot sufficiently express my appreciation for her endless love and guidance. I would like to thank Dr. Molly Weaver for bringing me to the United States and providing me with this wonderful learning opportunity. Her amazing editorial skills taught me that even little things matter. I also want to thank Dr. Christopher Wilkinson for his wisdom and dedication, both of which touched me deeply. Finally, I must thank Dr. Joy Saab and Professor Paul Scea for their insightful advice on my dissertation revisions.

My dissertation would not have been completed without the support of my editor and good friend Dr. David Carpenter. The time that he invested in editing my work and the continued support, encouragement, and love from his entire family were much appreciated.

I would also like to thank all my participants for giving me their trust and for sharing with me their family stories. I hope that they enjoyed the process and sharing their stories as much as I enjoyed hearing them.

Furthermore, I want to thank my friends who were the best cheerleaders and provided me with fun study breaks that kept me going. I want to thank Dr. Jianjun He, who encouraged me to pursue my Ph.D. in music education at West Virginia University. 
Finally, I want to express my deepest gratitude to my parents and grandmother who supported me in pursuing my dream and allowed me time away from them to complete my Ph.D. They are living proof that "tiger" parents can be both strict and loving at the same time. My heartfelt thanks to them all. 


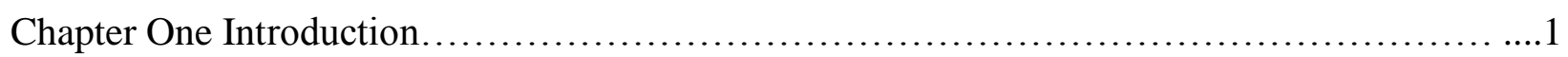

Statement of Problem........................................................................................

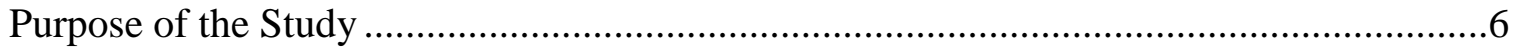

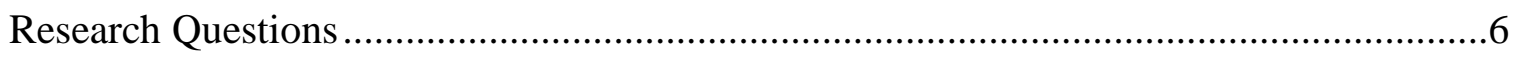

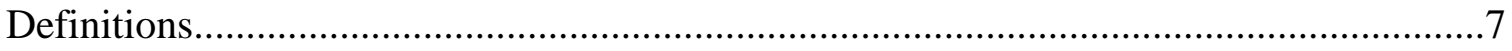

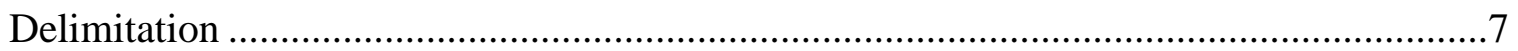

Chapter Two Review of Related Literature .....................................................................

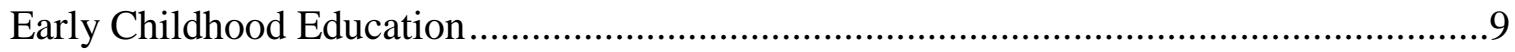

Parenting in Early Childhood..............................................................

Play in Early Childhood Education......................................................... 10

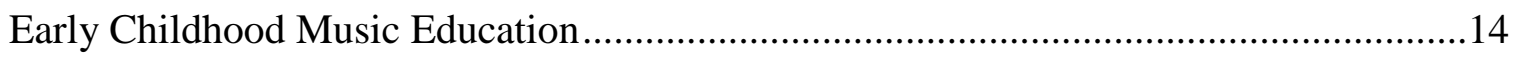

Parenting in Early Childhood Music Education ............................................15

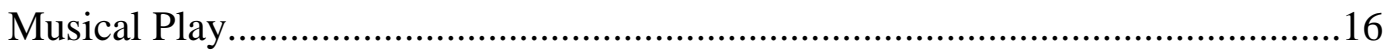

Traditional Chinese Values on Parenting and Music Education ...................................18

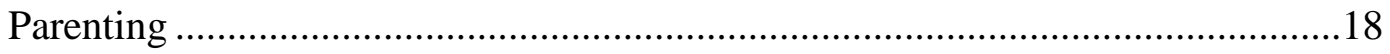

Confucianism and Music Education .........................................................22

The Acculturation Experience of Chinese American Parents..........................................24

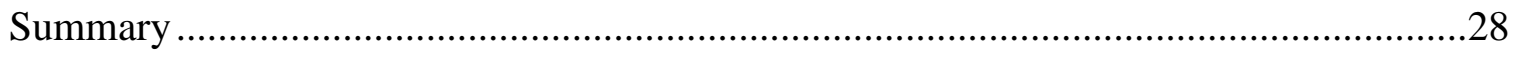

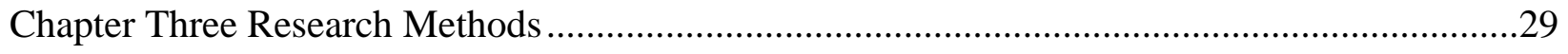

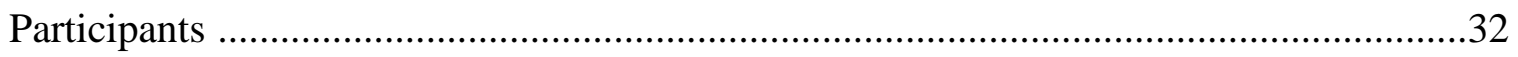

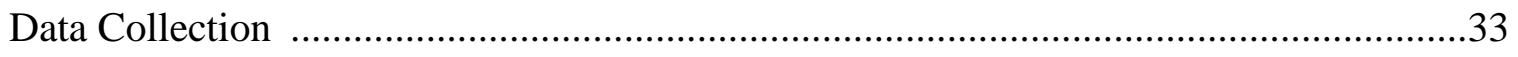

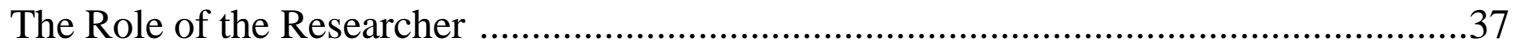




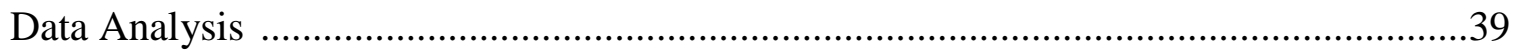

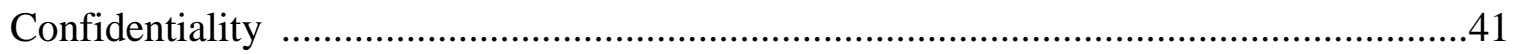

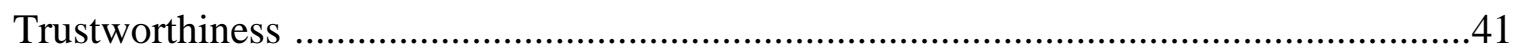

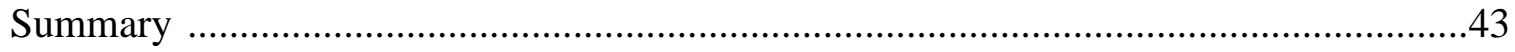

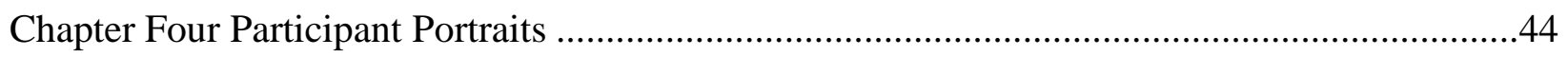

Jean

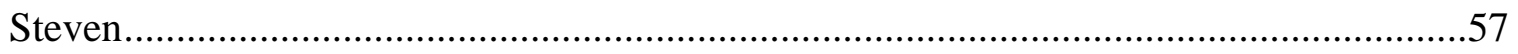

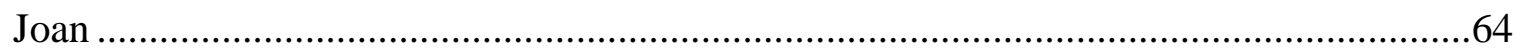

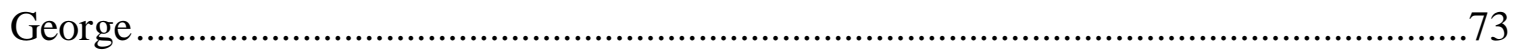

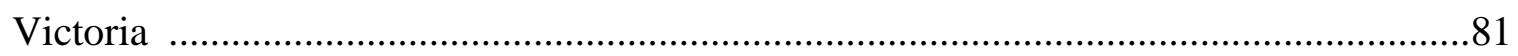

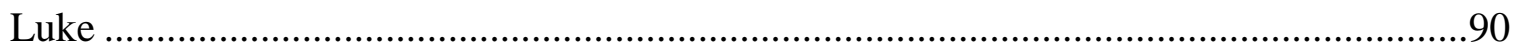

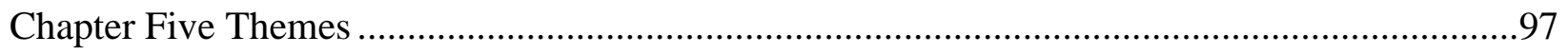

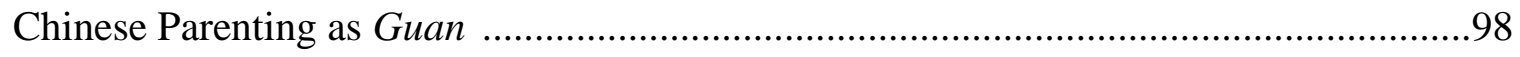

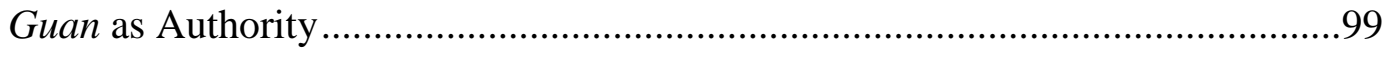

Guan as Mutual Respect ...................................................................... 100

Guan as High Parental Involvement .........................................................

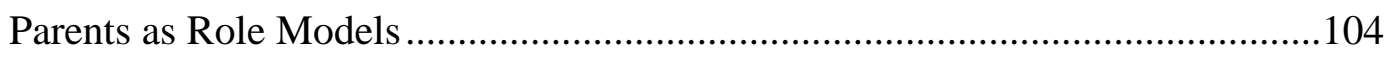

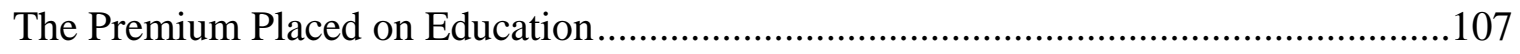

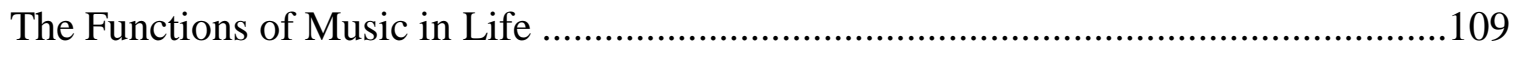

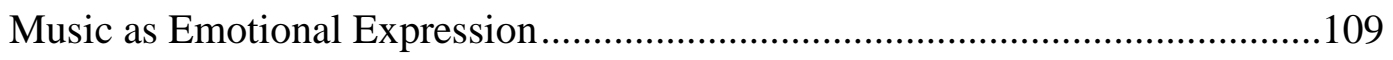

Music as Creative Self-expression .......................................................112

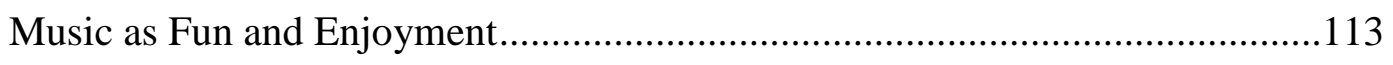

Music as a Moral Phenomenon ..............................................................118 
The Value of a Music Education

Music Education as Moral Cultivation ...........................................................120

Music Education and Social Status ................................................................123

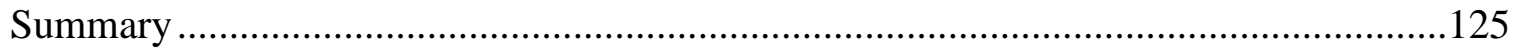

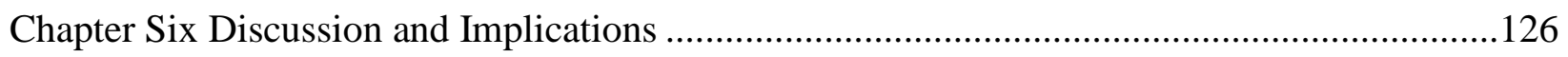

The Interplay of Culture Values ……………………...........................................127

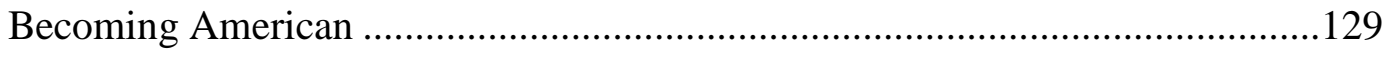

Dissatisfaction with Chinese Music Education .........................................130

Dissatisfaction with Aspects of Chinese Parenting ……….....................132

Selective Appropriation of American Culture …………..........................132

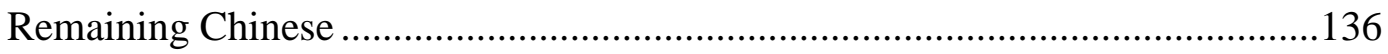

Dissatisfactions with American Culture …………………………….....137

Selective Preservation of Chinese Culture................................................137

Tension Arising through Interplay of Cultures .................................................141

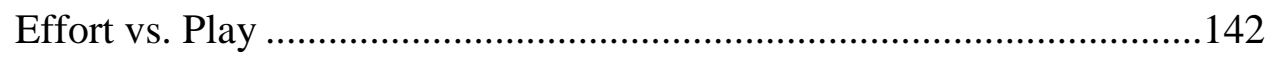

Guan vs. Independence ......................................................................143

Moral Cultivation vs. Creative Self-Expression .......................................144

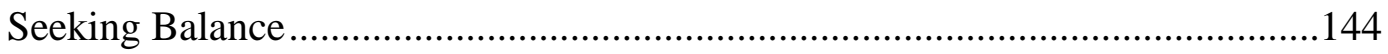

Implications for Early Childhood Music Education .......................................................145

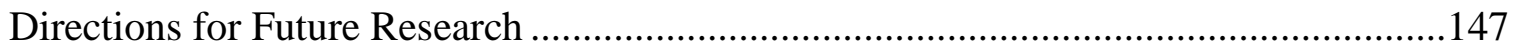

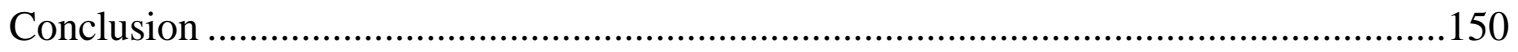


REFERENCES

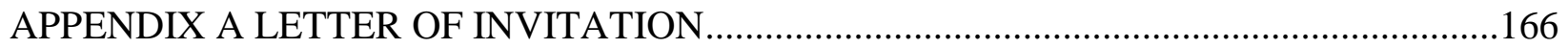

APPENDIX B INSTITUTIONAL REVIEW BOARD APPROVAL LETTER ......................167

APPENDIX C INTERVIEW PROTOCOL IN ENGLISH AND CHINESE ............................169 


\section{LIST OF TABLES}

page

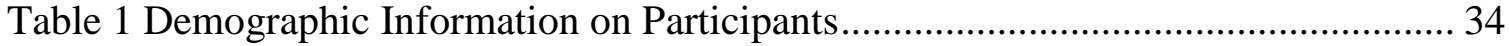




\section{LIST OF FIGURES}

page

Figure 1.2. Quadrants of Acculturation .............................................................. 26 


\section{CHAPTER ONE}

\section{INTRODUCTION}

The importance of parents in a child's early learning has been recognized by early childhood educators throughout the years. Parents are described as the first and closest teachers for their children (Pestalozzi, 1951). Interaction between parents and children is essential to the enhancement of children's achievement in early childhood. The way children's learning develops is strongly related to the learning environment, and it is parents who mediate the early environment of young children (Silverman, 1992). The dynamic interaction between the individual and the relatively rich early environment aids children's cognitive development and their ability to learn.

Music educators agree that parents are typically the first adults to provide a nurturing musical environment in which children will develop readiness for later music skill acquisition (Gordon, 1997). Music educators argue that parents, who are central in a small child's world, must be involved as much as possible in his or her musical education. A child's musical growth is a dual responsibility shared by music educators and parents (Ponick, 1999). The interactions between parents and children help young children not only in musical development, but also in all aspects of healthy social and emotional growth (Szabo, 1999). Parents can enrich their children's music development and cognitive development by creating a home musical environment (Gordon, 1995; Mallett, 2000).

While most agree on the importance of parenting in early childhood music education, there is less agreement about what kind of parenting is best. Parenting is one area in which the influence of culture is particularly apparent. Because parenting takes place within a cultural context, notions of what constitutes good parenting vary across cultures. Research suggests that 
parents with different cultural backgrounds may hold different expectations for their child's education, as well as have different values about music in their child's life (Wu, 2006), and such differences can lead to misunderstanding (Chao, 1994).

In January 2011, an article in the Wall Street Journal titled "Why Chinese Mothers Are Superior" put the spotlight on Chinese American parenting in particular. Amy Chua, a firstgeneration Chinese immigrant, described how she successfully raised two music prodigies - her daughters:

A lot of people wonder how Chinese parents raise such stereotypically successful kids. They wonder what these parents do to produce so many math whizzes and music prodigies, what it's like inside the family, and whether they could do it too. Well, I can tell them, because I've done it. (Chua, 2011a, p. 3)

Chua (2011) claimed that the Chinese American parenting style is a foolproof way of producing supremely intelligent and talented kids through sheer diligence, discipline, and long hours of practice. She details her strict approach to parenting and her unwillingness to accept anything short of academic excellence from her children. Chua (2011) thinks parents should have high expectations and demand excellence, and she argues that the so-called "tiger parenting" should be employed predominantly during a child's early years. She tells of doing so herself through the use of harsh pressure, such as threatening to take away her daughter's toys, holiday presents, and even lunch and dinner. Chua's "obsessive parenting" (Maslin, 2011) stands in contrast to the more nurturing and accepting parenting approach used by many Western parents. While Chinese American parents such as Amy Chua have often been negatively described as "authoritarian" and "controlling," such criticism is misleading (Chao, 1994). Chao argues that the portrayal of Chinese American parents as domineering, overbearing, and intrusive 
plays into a false and negative stereotype. She points out that Chinese American parenting does not typically include demeaning and unloving coercion. While the Chinese describe their parental role as guan — which literally means "to govern," or "control" - that word also denotes "to care for" and even "to love." Chao (1994) suggests that the concept of the authoritarian parent is somewhat ethnocentric and does not capture the important features of Chinese childrearing, especially features explaining their school success.

Chao argues that the Chinese concept of parenting as "training" (jiao shun and guan) is more useful in understanding Chinese American parenting. The Chinese concepts of jiao shun and guan denote the use of a standard of conduct growing out of parental concern for their children's well-being and successful adjustment. As Chao's critique suggests, the exact nature of Chinese American parenting is not well understood.

To better understand the expectations of Chinese American parents, music educators first need to understand the value of music in Chinese traditional culture. Music was an integral part of Chinese traditional culture, and culture influences the way people value music. Music in the ancient Chinese belief was meant not to amuse but to purify one's thoughts. Music was conceived in the highest sense as a means of calming the passions and of dispelling unrest and lust, rather than as a form of amusement (Smith, 1991). Traditionally, the Chinese have believed that sound itself influences the harmony of the universe. Music was believed to be a highly moral phenomenon, and music education was considered key to moral education, as well as a sign of social and economic status. This rich heritage is a significant part of an ancient civilization with a history of more than 5,000 years and continues to be important to Chinese Americans today. The result is an educational system with a strong emphasis on literacy and moral education in which there is little room for "play." 


\section{Statement of Problem}

In schools in the United States today, one in five children is an immigrant (Onchwari, Onchwari, \& Keegwe, 2008), with Chinese Americans being the fastest growing group in the Asian American community (United States Census Bureau, 2011). This changing demographic is an urgent call to develop a deeper understanding of Chinese American children and their families. With the increasing diversity of children in early childhood programs, it is vital for music educators to understand parental values within their socio-cultural context (Bronfenbrenner, 1979; Bronfenbrenner \& Morris, 1998). In order to develop reciprocal relationships with immigrant parents and support parents in providing musically enriching experiences for their children, music educators must understand who parents are, what they do musically, and what they think about music education for their children.

Early childhood music education is an area in which the challenge of cross-cultural understanding becomes especially evident. Parents bring their cultural beliefs and values with them when determining what is important for their child's development, as well as when considering appropriate approaches to help their children reach their goals. They may have different views of the role music plays in their child's life and of what constitutes best practice in music classrooms (Koops, 2011). The differences between parental expectations and the expectations of the educators can create challenges to mutual understanding.

An early childhood music curriculum that values individuality, spontaneity, and creativity, while highly valued in Western culture, often clashes with the traditional Chinese emphasis on conformity. Chinese traditional values still inform many Chinese Americans, which ill-prepare them for the play-based experiences they often encounter in their children's music classes. As they try to adjust to the society in the United States, they often experience a sense of puzzlement 
and bewilderment. This in turn leads them to question the value of the music education that their children are receiving and influences their decisions regarding their children's music education. Both parents and children will need to negotiate the differences between these two value systems. The strict approach to parenting described by Amy Chua runs counter to essential elements of current Western early childhood pedagogy. This makes it difficult for Chinese American parents to understand and value the teaching methods that they encounter in the United States, which sometimes strike them as anything but strict. In an attempt to negotiate the educational system in the United States and early childhood music education in particular, Chinese American parents sometimes encounter practices that may severely challenge their traditional Chinese values. This is particularly true when they encounter the use of play in the classroom.

Because Chinese parents have deep roots in traditional Chinese culture they often overlook or misunderstand the value of play in children's early learning. Such a lack of understanding has the potential to create challenges for both teachers and parents and can undermine the development of reciprocal relationships known to be vitally important for effective early childhood education. While Chinese American parents share many of the values articulated by Amy Chua, these same parents must accommodate themselves to the educational practices of their new home. The result is a conflict related to educational values and methods, one complicated by mutual misunderstanding.

Both in and outside the United States, even though there is an increasing amount of research on cross-cultural parenting styles and their influences on children's learning (Chan \& Moore, 2006; Wu \& Hart, 2002), there is still little research specifically focused on the parenting styles of Chinese Americans. Researchers have not yet provided a comprehensive description of 
Chinese American parenting. In addition, studies that examine the interplay of the Chinese immigrant experience and early childhood music education are scarce. It will benefit early childhood music educators to look more closely at this population in order to enhance their understanding of Chinese American parents and their children, as well as address challenges that these parents and children face when adapting to early childhood music education in the United States. Most important is the potential to build stronger reciprocal relationships between early childhood music educators and Chinese American parents.

\section{Purpose of the Study}

The purpose of this study is to examine the acculturation experience of first-generation Chinese American parents and the values that inform their expectations for their young children's early childhood music education. A primary goal is to gain a deeper understanding of the interplay of Chinese traditional culture and early childhood music education in the United States. Knowing what music means to Chinese American parents for their children's education and the role that music education plays in traditional Chinese culture will help early childhood music educators better understand Chinese American parents and their children. As well, this knowledge will help build reciprocal relationships necessary for bridging any cultural gaps that may exist.

\section{Research Questions}

1. How do cultural beliefs and life experiences influence Chinese American parents' views on music and music education?

2. What are Chinese American parents' expectations for their child's music education?

3. What roles do Chinese American parents believe music should play in the education of their children? 
4. What roles do Chinese American parents believe they should play in their children's music education?

5. How does acculturation influence Chinese American parents' expectations and decisions for their children's music education?

\section{Definitions}

First-generation Chinese American parents are defined as those who grew up in China but have migrated to the United States since 2000.

Second-generation immigrant children are defined as those who are born in the United States but whose parents were not born in the United States.

Early childhood is defined as the time period of children from birth to age eight as defined by the National Association for the Education of Young Children (NAEYC).

Young children is defined as children who are under age eight.

American is used to refer to elements of the culture of the United States.

\section{Delimitations}

The purpose of this study is to examine the acculturation experience of first-generation Chinese American parents and the values that inform their expectations for their young children's early childhood music education. The study is limited to parents who grew up in China, have lived in the United States since 2000, and are raising children under the age of eight. Children's musical training is not a focus of this study, nor is this study necessarily tied to children's participation in an early childhood music program. Descriptions of music programs and home environments are included only to provide contextual information about parents' acculturation experience, cultural beliefs, and values. In order to achieve an in-depth investigation of the Chinese American parents' acculturation experience, I will include a limited 
number of six participants in the study instead of a large sample or population of Chinese American parents with young children. 


\section{CHAPTER TWO \\ REVIEW OF RELATED LITERATURE}

This chapter is divided into four sections. The first focuses on early childhood education and highlights research on parenting and play in early childhood education. The second examines research in early childhood music education, specifically studies on parenting and musical play. The third discusses literature regarding traditional Chinese values on parenting and the influential role of Confucianism in music education. The fourth and final section focuses on the acculturation experience of Chinese American parents and the challenges they face as immigrants negotiating between traditional Chinese values and mainstream values in the United States.

\section{Early Childhood Education}

Parenting in early childhood. An important figure in education who recognized the importance of parenting in early childhood was Johann Heinrich Pestalozzi (1747-1827). He is known as the Father of Parent Education. "For children, the teachings of their parents will always be the core," and "as a mother is the first to nourish her child's body, so should she, by God's order, be the first to nourish his mind" (Pestalozzi, 1951, p. 26). Because of the important role parents play in the education of their children, he believed that teachers must be knowledgeable about what happens in the home in order to teach effectively.

Montessori (1912/1964) suggested that parents must collaborate with their child to create an interesting and attractive learning environment that is essential to the child's life and development. Vygotsky (1934/1987) was another who promoted the important role of parents in a child's early cognitive development. Parents' interaction with their children is part of the 
young child's "zone of proximal development," defined by functions that children are in the process of developing and cannot yet do without the aid of others (p. 266).

Current childhood education policies and practices in the United States continue to recognize the importance of parental involvement in a child's life. The National Head Start Association's agenda for improving children's readiness for school involves helping parents acquire the skills necessary to become their child's first and best teacher (2012). The Early Head Start National Resource Center (2005) identifies parent-child relationships as instrumental in children's overall development. The National Association for the Education of Young Children (NAEYC) guidelines suggest creating a stimulating environment with opportunities for discovery, active participation, and interaction with adults. Instead of focusing solely on educating the parent about what is best for the child, early childhood educators are encouraged to collaborate with parents.

Several studies by Berger highlight the importance of understanding students' parents and home settings. Berger (1987) argues that children are first shaped in their families and that the importance of the parents' role in a child's development should not be underestimated. The prevailing perspective of the growing child is powerfully influenced by the environment, especially the family and those who have an intimate relationship with the child. Parents have the ability to exert tremendous long-term influence on the growing child. For children of all cultures, the care and nurturing available in the early childhood environment is significant and essential to biological and social growth (Berger, 2008).

Play in early childhood education. In considering the value of play in early childhood music education, it is useful to briefly define play and to consider its role in young children's general learning and development. Play has been described as being "easy to recognize but very 
hard to define" (Johnson, Christie, \& Yawkey, 1999, p. 15). "Educators are unable to present a universally accepted criterion of play, especially when it is adopted as a teaching and learning strategy with pre-determined objectives" (Rogers, 2011, p. 104).

Niland (2009) recognized that children's play should be "spontaneous and flexible and most of all fun" and should involve "free choice, enjoyment, self-motivation, and a focus on process rather than on product" (Brock, Dodds, Jarvis, \& Olusoga, 2009; Frost, Wortham, \& Reifel, 2008, as cited in Niland, 2009, p. 18). He also argued that discussion of play often includes "creative behavior" as an important feature of "playfulness" in the creative process (Duffy, 2006; Moyles, 1995; Csikszentmihalyi, 2002; Duffy, 2006, as cited in Niland, 2009, p. 18). A study by Caldwell (1986) suggested that parents can help their children learn within the context of play by encouraging diversity within play rather than rigidity, and by emphasizing social roles as well as didactic or teaching-oriented behaviors.

When children play, they typically imitate the behavior of others and then use their own ideas to develop their play further. This is one of the reasons why play is central to children's learning. Children's play also reveals the developing use of imagination - the ability to think about events, people, or ideas that are not necessarily physically present. For all these reasons, play is regarded as being important to children's cognitive development, particularly their flexible thinking and problem-solving skills (Johnson, Christie, \& Yawkey, 1999).

The notion that young children learn through play is supported by a vast literature. Insights from theoretical and empirical studies provide powerful evidence that young children demonstrate an inherent capacity to play, and that play is central to their early learning (Rogers, 2011). The need for play in early childhood has long been acknowledged in the writings of educational theorists dating back as far as Amos Comenius (1592-1670). Comenius, known as 
the "father of modern education," was the first to recognize that play was a necessary component of the learning process in childhood. His continuing influence is apparent in the works of JeanJacques Rousseau (1712-1778) and Pestalozzi. Rousseau's concept of "discovery learning” is a development of Comenius's idea of play. He believed that children should play in a natural setting that allows them to give rein to their own curiosity. He suggested that early childhood education should be a time to be a child, as opposed to a preparation for adulthood. Swiss educator Pestalozzi believed that "work and play are all one for him (the child), his games are his work; he knows no difference" (Roopnarine and Johnson, 2000, p. 5). He also believed that experience and self-discovery in a natural environment are the best for educating children.

Pestalozzi's work influenced later educators and psychologists such as Friedrich Froebel, Jean Piaget and Lev Vygotsky. Froebel, a German educator and student of Pestalozzi, known as the father of the kindergarten, believed that play is a vital part of children's learning. In Froebel's kindergarten, musical experiences including free play, singing and movement games were at the center of early childhood education.

Swiss psychologist Jean Piaget, one of the major figures in 20th century developmental psychology, created the Theory of Cognitive Development. In his theory, Piaget identified three types of play in conjunction with three stages of cognitive development: 1) practice play, during the sensorimotor stage (ages 0-2), occurs when babies learn about themselves through physical senses consisting of repeated body movements, such as putting objects in the mouth, blowing spit bubbles, and playing peek-a-boo; 2) symbolic play, associated with the pre-operational stage (ages 2-7), is a more advanced stage when children engage in make believe games and fantasy role play and also use objects to symbolize something other than their intended function; and 3) 
games with rules, during the concrete operational stage (ages 7-11), is when rules are developed and more structured play takes on a social aspect (Follari, 2007).

Soviet psychologist Lev Vygotsky (1896-1934) discussed how play helps children develop abstract meaning separate from the objects in the world, which is a vital feature in the development of higher mental functions. In the words of Maria Montessori (1879-1952), Italian educator and founder of the Montessori Method of education, "Play is children's work; children need time to explore. It would be better to take advantage of the exploratory mind-set of very young children by having them make up their own songs, for example, and trying out different music activities at their own pace" (Britton, 1992, p. 55).

The work of these early educators and psychologists has greatly influenced present-day approaches to early childhood education (Jacobi-Karna, 2007). Play is at the center of contemporary early childhood pedagogy, and the recognition of its importance has directly contributed to a strong belief in the importance of a child-centered, emergent curriculum (Rogers, 2011; Saracho, \& Spodek, 1998). The National Association for the Education of Young Children (NAEYC) strongly supports early childhood learning environments that emphasize free choice, playfulness, creative behavior, spontaneity, and process rather than product (Brock, Dodds, Jarvis, \& Olusoga, 2009; Niland, 2009). The recognition of the importance of play has directly contributed to the strong position of the NAEYC on the importance of an emergent, childcentered approach to curriculum (Rogers, 2011).

In the second edition of Developmentally Appropriate Practice in Early Childhood Programs Serving Children from Birth Through Age 8, play was considered "an important vehicle for developing self-regulation and promoting language, cognition, and social competence" (NAEYC, 2009, p. 14), one of the 12 Principles of Child Development and Learning. Play was 
also recommended as an essential component of developmentally appropriate practice (DAP) and is at the core of educational practice. The DAP framework is designed to promote young children's optimal learning and development throughout early childhood (NAEYC, 2009).

\section{Early Childhood Music Education}

Humans are innately musical beings (Tarnowski \& Barrett, 1997), and as Alan Merriam (1964) has noted, "there is probably no other human cultural activity which is so all-pervasive and which reaches into, shapes, and often controls so much human behavior" (Merriam, 1964, p. 53). Merriam's outline of the ten functions of music across cultures, including such functions as emotional expression, aesthetic enjoyment, and entertainment, is a classic consideration of the subject.

Given the cultural preeminence of music, many early childhood educators argue that it is important to consider music as an integrated part of a young child's life and education (Campbell, 1998; Campbell \& Scott-Kassner, 2002). It is crucial that all children are given a musically enriched environment to bring out the musicality with which they were born. Many studies have found that the early years of life are a key time for musical growth as well as for overall growth in a child's life (Katz, 1986; Crosswhite, 1996). For nearly 50 years, the National Association for Music Education (NAfME) has worked to inform educators, policymakers, and the public about the importance of music education in the lives of young children (Berger \& Cooper, 2003; Trollinger, 2003).

Young children have a great capacity to learn new skills, including music (Denney, 2000; Billiter, 1993). Much research indicates that the earlier children are exposed to music education, the greater the influence on their musical development (McElwee, 2004). Well known $20^{\text {th }}$ century pedagogues Dalcroze, Kodaly, Suzuki, and Orff all agreed that music education should 
begin as early as possible (Flohr, 2005). Some early childhood music educators have found that children ages one to five years have the musical potential to become artistically responsive persons if provided with frequent opportunities for guided participation (Gardner, 1983; Gordon, 1995).

Parenting in early childhood music education. Much research supports the important role parents play in choosing early musical experiences for their children. Several studies looked specifically at parents' perceptions of early childhood music programs. Cardany (2004) conducted in-depth interviews with ten families regarding parental perceptions of preschool music education and concluded that these perceptions about music education affect their children's involvement and development in music. Koops (2011) conducted five interviews with parents who had participated in an early childhood program at a community music school, focusing on how their perceptions affected their involvement in their child's music learning. Several of the parents interviewed indicated satisfaction with their roles within the class and did not desire increased involvement in the class; others expressed a desire for more information about children's musical development and the teaching methods used. The perceptions that seemed to contribute to parents' involvement, both current and desired, were that enjoyment comes from musical interaction, their recognition of multiple roles of music in their children's lives, and their view of acquiring musical skill and knowledge as developmental.

Ilari's (2005) study of mother-child musical interactions led her to conclude that musical interactions are influenced by many factors, including parental beliefs about music. She went on to state that there is a need to include parent training in early childhood music experiences. Wu's (2005) survey of perceptions and attitudes of Taiwanese parents also underscored the impact of parental attitudes and perceptions on children's early childhood musical experiences and learning. 
She found significant correlations between parents' attitudes toward music and music instruction, and their children's participation in music instruction.

Several studies also looked the importance of the home environment. Mallett (2000) found a positive relationship between parental attitudes and the musical environment created in the home, yet another influence on children's musical development. According to Custodero's (2006) study of three-year-old children and their families, parents' use of music, both personally and with their children, affects children's musical experiences at home.

Musical play. Music educators have recognized the importance of free musical play in young children's musical growth and have provided guidance for parents to enhance children's musical play (Berger \& Cooper, 2003; Fox, 1989; Gordon, 1997; Littleton, 1991; Taggart, 2000; Tarnowski, 1999). Musical play can enhance parent and child bonding (Grätzer, 1999) and free musical play can lead to skill development (Smithrim, 1997).

In a study of free musical play of 3- and 4-year-olds, Berger and Cooper (2003) found that adult behaviors contributed to "play-extinguishing" and "play-enhancing" among children. Specifically, children's play was inhibited at times due to the physical proximity of an adult and when an adult criticized or corrected the child. Conversely, behaviors that enhanced children's play included adult comments showing their valuing of children's play and indicating acceptance of non-traditional interaction with the musical environment. The researchers suggested further research on adult behaviors that extinguish or enhance children's musical play.

Miranda (2009), in her article "Developmentally Appropriate Practice: Historic Roots and Evolving Paradigms," recommended that music teachers plan playful experiences in a stimulating environment in which children explore and express choice. "As a result of 
developmentally appropriate musical experiences, children should show curiosity about music and initiate musical play, both individually and collaboratively" (p. 8).

Musical play should include both structured and spontaneous experiences (Jacobi-Karna, 2007). Young children thrive on structure; they like routines - activities that begin and end in the same way that help them to develop a sense of competence because they know how a procedure goes and what happens next. Berger \& Cooper (2003) believe that spontaneity should be a dominant part of the approach with young children. Music educators have identified free musical play that is less structured as important for musical growth in young children and have suggested techniques for providing and enhancing musical play for practitioners and parents (Berger \& Cooper, 2003; Fox, 1989; Gordon, 1997; Littleton, 1991; Taggart, 2000). In addition, music education researchers have studied aspects of musical play such as how musical play enhances parent and child bonding (Grätzer, 1999).

Research has shown that child-centered musical play can be a powerful medium for young children's exploration of many musical elements and concepts (Berger \& Cooper, 2003). Observation of young children's free musical play provides considerable evidence of their skill development. For example, preschool children often use their head voices in vocal play even though they may not use them when singing composed songs. Studies of children's invented songs have shown use of tonal centers and clear tonal, melodic, and rhythmic structures (Tarnowski, 1999). Studies of children's free musical play have shown that children will be more deeply engaged over long periods of time and show greater persistence than is often evident in teacher-led group music making (Littleton, 1998; Smithrim, 1997).

Littleton (1998) categorized six styles of musical play that young children may engage in. These include "co-operative musical play," in which children are involved in sociable, 
interactive musical exploration; "functional musical play," in which children are exploring the sound-making potential of a range of materials and experimenting with techniques; "constructive musical play," in which functional exploration is extended into creative improvisation and composition; "dramatic musical play," in which children integrate music making with dramatic or pretend play; "kinesthetic musical play," in which children focus on movement or dance as a playful response to music; and "games with rules," in which children engage in group-oriented, structured musical games such as singing games or clapping games (Littleton, 1998, p. 25). This latter form of musical play is often part of early childhood music education curricula. However, all types of musical play should be considered foundational for an emergent, child-centered curriculum.

When music educators adopt a playful approach to music, they are valuing children's music making in its wider context. Increasingly, early childhood music researchers and practitioners are viewing young children's musical explorations as being distinct from those of adults, rather than being a primitive imitation of "real" music making (Barrett, 2003). Although many Western educators believe that play is an important way to teach children about the world, not all parents with diverse cultural backgrounds agree (Vandermaas-Peeler et al., 2001). Beliefs about play vary widely and must always be viewed within a particular cultural context (Caldwell, 1986). Few would dispute the importance of play in early childhood music classrooms, yet the challenges of practicing play exist in classrooms with students from diverse cultural backgrounds.

\section{Traditional Chinese Values on Parenting and Music Education}

Parenting. Chinese Americans brought with them one of the most ancient civilizations that many continue to cherish. Even after years of assimilation into society in the United States, Chinese Americans are nevertheless in some sense still in a transitional phase (Chen, 2004). 
While they continue to cherish their Chinese heritage, they also continue to adapt to culture in the United States. Verna and Campbell (1998) found that Chinese American parents tend to retain beliefs, attitudes, and values of their ancestral homeland. They stress education and they are very supportive, taking pride in their children's dedication and effort (Yang and Zhou, 2008). Research indicates also that play-based pedagogy in the United States contrasts quite strikingly with the traditional methods of teaching and learning in the Chinese community (Chen, 2001). Chao (1995) noted that Chinese American parents tend to have consistent attitudes toward education, expect their children to perform well based on their abilities, support their children psychologically and financially, and provide role models.

Most importantly, Chinese parents have been cited as emphasizing education as the “avenue to social mobility” (Chao, 1995, p. 341; Chen \& Uttal, 1988). In Chinese culture, education is highly regarded (Ho, 1989) and is considered an important means to a good job and economic prosperity. "Education is seen as a main vehicle for social mobility," and in Chinese society "parents pay more attention to their children's achievement-oriented activities and school work than to their social and cultural activities" (Pong \& Chow, 2002, p. 140).

Regardless of where Chinese immigrant families live, their child-rearing practices are still largely influenced by Chinese traditional culture. Research indicates that traditional Chinese parenting differs greatly from mainstream parenting in the United States in a number of ways. As noted in the introduction to this study, the tendency among Western scholars has been to view traditional Chinese parenting as controlling, restrictive, and authoritarian. In a highly influential article, Chao noted the paradox that such parenting is correlated in the psychological literature with poor academic achievement, whereas in fact supposedly "authoritarian" Chinese parenting correlates with academic success (Chao, 1994). She proposed a solution to this apparent paradox 
through a closer examination of the traditional Chinese concept of parenting as guan. While this term, which can be literally translated as "to govern" or "to control," would seem to refer to an authoritarian approach to parenting with an emphasis on the control of children, in fact the concept is more complex. Guan, as Chao explains, citing Tobin, Wu, \& Davidson (1989), has a more positive connotation and includes the idea of concern and even love (Chao, 1994, p. 1112). The stereotype of the "tiger mom" popularized by Amy Chua can thus be misleading and feed into what Chao views as ethnocentric stereotypes.

Chao's proposal that Chinese parenting be understood in terms of guan has been widely accepted. Initially concerned that Chao's study was limited to mothers of pre-school children and noting the tendency of Chinese parents to be more indulgent at this age, Gorman (1998) studied the mothers of adolescents but found results similar to Chao, concluding that "the motivation behind the seemingly strict childrearing practices of immigrant Chinese in this study reflected care and concern for their children's welfare, which is more in concert with Chao's (1994) notion of training (guan) than with traditional concepts of authoritarian parenting" (Gorman, 1998, p. 79).

Stewart et al. (1998) examined parenting styles as reported by Hong Kong adolescent girls and found that "characteristics associated with guan showed coherence, correlated significantly with parental warmth, and predicted well-being" (p. 345). In a subsequent study Stewart, Bond, Kennard, Ho, \& Zaman (2002) found that the "associations between parental guan and the outcomes of perceived health, relationship, harmony, and life satisfaction were significant for the Asian participants" (p. 74). Both Stewart et al. (2002) and Nelson, Hart, Yang, Olsen, \& Jin (2006) have suggested that rather than representing an "authoritarian" style of parenting, it may be better to think of guan as the "Asian face" of the Western concept of 
“authoritative" parenting (Stewart et al., 2002, p. 82; Nelson et al., 2006, p. 555), which combines high demands and firm control with democratic participation and warmth.

Chao (1995) also found a distinctive interpersonal orientation in Chinese parenting. In her research, Chinese mothers emphasized their children's relationships with others rather than their children's psychological attributes. This overall orientation, which emphasizes the interpersonal over the individual, is qualitatively different from views often associated with mainstream culture in the United States, in which individuality is stressed and individuals are viewed in terms of personality traits.

While Chinese parenting includes elements of concern, warmth, and a stress on interpersonal relationships, it remains true that a distinctive element of Chinese parenting is the focus on obedience and respect for authority (Chao, 1995; Ho, 1976; Ho, 1989). This same emphasis on authority is found in the Chinese understanding of education as well. The traditional Chinese view of both parenting and education is derived to a great extent from Confucius, whose philosophy for several thousand years has provided the Chinese with an understanding of education centered on the effortful, respectful, and pragmatic acquisition of an authoritative body of essential knowledge (Tweed \& Lehman, 2002). For Confucius, education served the purpose of moral formation and placed an emphasis on effort. Human nature was perfectible; a failure to excel was a moral issue and understood to be due to a lack of effort rather than to any unavoidable shortcoming of nature or talent.

Confucius claimed not to be an innovator but rather to base his teaching on the timehonored models of the past. The exemplars of the past and the teachers who transmitted their heritage in the present have been regarded as the authoritative representatives of the tradition to be treated with great respect. This in turn led to placing a high value on the mastery of an 
authoritative body of essential knowledge in terms of both the self-cultivation of the individual and the service of such sage individuals to society. This veneration of the past was manifested in a well-known emphasis on the appropriation, indeed the memorization, of the classics of the Confucian tradition, a trend that became especially prominent through the institution of the examination system based on the Confucian Classics. Hence a "tiger parenting" approach to education has deep roots in the Chinese tradition. The goal of the tradition at its best was always the deep appropriation of the tradition (Tweed \& Lehman, 2002).

Confucianism and music education. When it comes to understanding the use of music in Chinese culture, the influence of the Confucian tradition is crucial. Confucian notions of music are deeply embodied in Chinese musical life and converge with important intellectual streams in China and other Asian countries. In the Li Ji (Book of Rites), Confucius (as cited in Huang, 2012) is quoted as saying:

In music the sages found pleasure, and saw that it could be used to make the hearts of the people good. Because of the deep influence which it exerts on a man, and the change which it produces in manners and customs, the ancient kings appointed it as one of the subjects of instruction. (p. 165)

Music is an integral part of traditional Chinese culture and was considered second only to ceremony in the "six arts," which represent the most crucial knowledge and skills in ancient China, the others being — in descending order of importance - archery, charioteering, writing, mathematics (Yue, 2008). On the whole, music in Confucianism is regarded as a device for selfcultivation, a vehicle of self-expression, and a force of social stability. According to Confucius, "personal cultivation begins with poetry, is made firm by rules of ceremonials, and is perfected by music" (Huang, 1997, p. 29). In fact, this high valuation of music runs throughout the 
Confucian tradition. Lai (2003) has pointed out that "a significant theme in the Confucian classics, including Confucius's Analects, the Xunzi, the Book of Rites, the Book of Music, the Book of Poetry, and the Book of Filial Piety, is the connection between morality and music. In these texts, it is held that music is causally related to moral cultivation" (p. 107). Lai quotes the Book of Rites to illustrate this theme:

Ceremonies and music should not for a moment be neglected by any one. When one has mastered completely [the principle of] music, and regulates his heart and mind accordingly, the natural, correct, gentle and honest heart is easily developed, and with development of heart comes joy. (as cited by Lai, 2003, p. 107)

In his treatise on music, the Confucian philosopher Xunzi emphasized the social value of music, saying that "music properly employed leads to social harmony" (See Yuelun 5, quoted in Cook, 1997, p. 24). The connection between music and the individual moral life was presented directly in the Record of Music, dating from the Han Dynasty: "Virtue is the upright growth of one's nature, and Music is the flowering of virtue" (Yue Ji 6.4, quoted in Cook, 1995b, p. 59). And the great Confucian commentator Zhuxi pointed to the purifying power of music:

Music is characterized by the five tones and twelve pitches, sounding forth in a harmonious succession to bring regularity to song and dance and the eight timbres of instruments. It can be used to nurture man's nature and his sentiments, wash away his depravity, and dissolve his flaws. (Zhuxi's commentary on the Lun Yu, cited by Cook, 1995a, p. 127)

Such arguments that music is an important force for developing social harmony and moral purity suggest its vital role in the education of the young, especially for instilling the central Confucian virtue of ren. For Confucius, music education served the purpose of moral 
formation. Moral integrity is contained within the Confucian idea of ren, which translates as "humaneness." Confucius asks: "Is [music] merely bells and drums?" (Analects 17:11, cited by Huang, 1997, p. 86) Music is not merely a perfected form in which humaneness is characterized: according to Confucius, the essence of music is humaneness. In the Analects Confucius said, "A man who is not Good, what can he have to do with music?" (Analects 3:3; cited by Huang, 1997. p. 86) A man who is not virtuous cannot claim to be a musician nor have anything to do with music. He believes that those compositions that do not involve virtues or convey humanity are bad works, at best only the sounds of instruments.

Harmony (he) is another essential concept that is constantly emphasized in Confucian doctrines. Confucius believed that sound influences the harmony of the universe. Music (or at least what is regarded as "correct" music in the Confucian view) was acknowledged as being capable of bringing man and his family, society, and the universe into spontaneous harmony.

The particular importance of music and music education has thus been recognized by ancient Chinese society, and its importance continues to influence the formation of the character of the Chinese people and the values and expectations of Chinese Americans today. As a result, in the contemporary Chinese community, it is very common for parents to seek music education for their young children and have high expectations for their children's musical achievement. Chinese American parents are highly involved in their children's music education (Chiu, 1987), making an understanding of their role all the more important.

\section{The Acculturation Experience of Chinese American Parents}

Understanding the role of Chinese American parents involves recognition of cultural differences and acculturation. The challenge of acculturation is nowhere more keenly felt than in the education of children. Here cultural values inform parents' perspectives. When a family has 
resided in another culture for a long period of time, parental values may undergo a gradual change because of inevitable influences from the host culture (Li, 2001). No doubt the immigration experience influences Chinese immigrant parents' thinking and lifestyle. Therefore, it is important for music educators to be more aware of how Chinese American parents' values about music and music education have been shaped by their acculturation experience in the United States.

Yax-Fraser (2007) argues that no matter where they come from, immigrants who grew up in another culture with different social settings and in another language often stay strongly attached to their home culture. Although a new socio-cultural milieu puts pressures on many immigrant families, they have the desire to maintain their ethnic heritage. "The process of immigration can involve a period of dislocation and adjustment and has the potential to cause upheavals in one's identity and sense of belonging. A process of negotiation is required as immigrants welcome and support values and meanings, contest boundaries that render them as outsiders, and rearticulate their identity" (Yax-Fraser, 2007, p. 23).

Every immigrant faces a certain degree of cultural shock that begins the acculturation process (Lin, 2004). Acculturation is defined as the changes in behaviors and values that individuals make as they accommodate to their host culture (Graves, 1967). Acculturation brings challenges and changes to the immigrant's life (Thomas, 1995). Berry and Sam (1997) define four different consequences for individuals experiencing acculturation. They become either Integrated, Assimilated, Separated, or Marginal, as shown in their Figure 1.2. People in the Integrated quadrant pursue values of the mainstream culture and maintain values of the culture of origin at the same time. People who are in the Assimilated quadrant pursue values of the mainstream culture but identify less with the values of the original culture. People who are in the 
Separated quadrant primarily maintain values of the original culture and reject values of the mainstream culture, while those in the Marginalized quadrant reject values of both mainstream and original cultures.

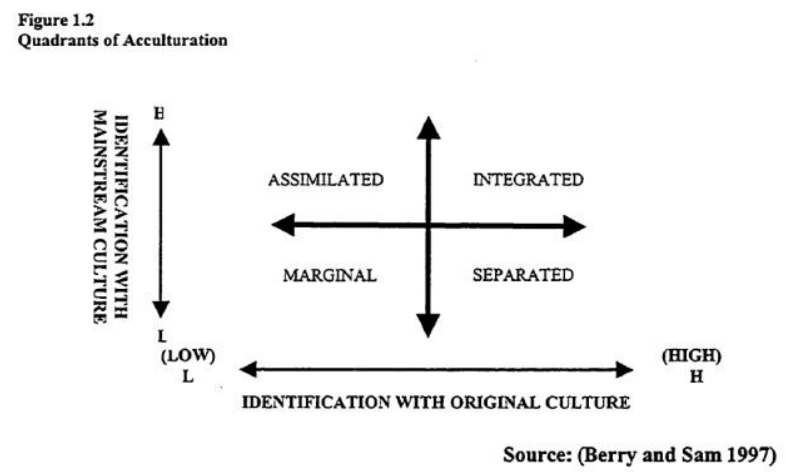

When facing differences between the original culture and host culture, immigrants begin to negotiate these differences. Lin (2004) defined "value negotiation" as a phenomenon of how immigrants cope with cultural shock by modifying their indigenous values, arguing that value negotiation is the internal process of the acculturation experience. Value negotiation involves a continuum of value modification, from complete preservation at one end to complete desertion at the other. The environment continually reinforces or reshapes the modified values until the individual either reaches a balance or gets exhausted and gives up on the negotiation process.

While all immigrants inevitably undergo some value negotiation process, the emphasis in Chinese culture on interpersonal harmony makes this process particularly difficult for Chinese Americans who may feel more compelled to negotiate and seek acceptance from the mainstream culture than do immigrants with other ethnic backgrounds (Gelfand et al., 2002). At the same time, Chinese immigrants may be reluctant to share their indigenous values with counterparts in the United States, fearing that doing so would invite misunderstanding, depreciation, and 
rejection. This hesitation may lead Chinese immigrants to feel isolated, which then may impede the value negotiation process that is part of acculturation.

The acculturation experience of Chinese immigrants in the United States is particularly complicated and diverse. As Bill Moyers stated in his Public Broadcasting Service documentary entitled "Becoming American: The Chinese Experience," “...the history of Chinese immigrants and their ongoing struggle to become American... is a compelling tale of struggle and triumph, progress and setback, separation and assimilation, discrimination and achievement. It is a collision of two cultures, and a saga that has largely been left out of history books" (Moyers, 2003).

Such experiences can cause high stress in Chinese immigrants, which may result in severe conflicts or even mental problems. Parent-child relationships are a common source of conflict and stress. Out of necessity Chinese American parents must modify their traditional way of raising children in accordance with a new way of life in the United States. They bring with them a wealth of beliefs and practices based on different philosophies including the family structure, value systems, methods of parenting, and socialization ideals (Yax-Fraser, 2007). The acculturation experience can involve upheaval and change as aspects of immigrant parenting become increasingly complex.

Research indicates that immigrant parenting requires negotiation between traditional Chinese values and mainstream values in the United States. Parents may have little opportunity for education. Since most Chinese American parents have established cultural identities as Chinese, they are less flexible in absorbing or assimilating mainstream values in the United States. Parents and teachers may find few connections and may be challenged to establish reciprocal relationships based on mutual understanding. 


\section{Summary}

This chapter reviewed the related literature in four areas. The first section examined research that centered on parenting as well as on play in early childhood education. The second section explored research on the roles of music, parents, and musical play in a child's life. The third section examined traditional Chinese values on parenting and the influence of Confucian values on music education. The last section of this chapter reviewed research on the acculturation experience specifically as it applies to Chinese American parents. 


\section{CHAPTER THREE}

\section{RESEARCH METHODS}

The purpose of this study was to examine Chinese American parents' acculturation experience in order to gain a better understanding of the ways it influences their experiences and expectations for their young children's music education. Because the phenomenon of acculturation is multi-faceted, I used a qualitative research methodology. According to Creswell (2007), qualitative research is selected when a complex, detailed understanding of a problem or phenomenon is required. Glesne (2010) explains that the goal of qualitative research is to "understand some social phenomena from the perspectives of those involved, to contextualize issues in their particular socio-cultural-political milieu, and sometimes to transform or change social conditions" (p. 4). Merriam (1998) observes that "qualitative researchers are interested in understanding the meaning people have constructed; that is, how they make sense of their world and the experiences they have in the world" (p. 6, emphasis in original).

Researchers suggest that the most important condition for choosing a research method is first to identify the research questions (Creswell, 2007; Maxwell, 2004; Reimer, 2002). The research questions of this dissertation entail understanding fundamental issues of cultural differences related to Chinese cultural values that inform parents' perspectives on education and influence their attempts to accommodate the Western education system and early childhood music education. Morse and Field (1995) further suggest that the types of questions that favor the choice of case study design are open ended, in-depth, descriptive questions, calling for views supplied by participants in a study. Such questions focus on developing an understanding about how different cases provide insight into an issue or a unique case. 
According to Creswell (2007), a case study "explores a bounded system (a case) or multiple bounded systems (cases) over time, through detailed, in-depth data collection involving multiple sources of information (e.g., observations, interviews, audiovisual material, and documents and reports), and reports a case description and case-based themes" (p. 73). Similarly, Merriam (1988) suggests that case studies are selected when the researcher is interested in examining a bounded system or case of a specific phenomenon. Case studies can be used for descriptive, explanatory, or exploratory purposes (Yin, 1993). Yin revised and restated earlier definitions of case studies in his fourth and most recent edition, breaking the definition of a case study into two components: the scope of a case study and the data collection and analysis strategies.

A case study is an empirical inquiry that investigates a contemporary phenomenon in depth and within its real-life context, especially when the boundaries between phenomenon and context are not clearly evident. The case study inquiry copes with the technically distinctive situation in which there will be many more variables of interest than data points, and so one result relies on multiple sources of evidence, with data needing to converge in a triangulating fashion, and as another result benefits from the prior development of theoretical propositions to guide data collection and analysis (Yin, 2009, p. 18).

I chose a multiple-case study design to analyze the complexities of the immigrant experience among multiple first-generation Chinese American parents. Through the use of a multiple-case study design, I attempted to gain a better understanding of the values they attach to the role of music in their young children's lives and the challenges they face when adapting to early childhood music education in the United States. 
Yin advises the use of multiple-case study design as opposed to single case study design to strengthen the analytic benefits of the case study, noting that "analytic conclusions independently arising from two cases, as with two experiments, will be more powerful than those coming from a single case (or single experiment) alone" (Yin, 2009, p. 61). A multiple-case (or collective) study is one that examines multiple cases illustrative of one issue or phenomenon. In exploring the acculturation experience of Chinese American parents, I studied six "cases" or families — what Yin (2009) refers to as an embedded case study design. An embedded case study design contains more than one sub-unit of analysis, which allows for a detailed level of inquiry. It is an empirical form of inquiry appropriate for descriptive studies, where the goal is to describe the features, context, and process of a phenomenon (Yin, 2009).

The choice of a multiple-case study method is based on the potential to understand a collection of cases more completely (Stake, 1995). Each case in a multiple-case study provides information that further informs a specific issue or theme. Yin (2003) also takes the position that when conducting a multiple-case study, each case should "serve a specific purpose within the overall scope of inquiry” (p. 52). A multiple-case study design seeks to examine several individual cases in context to "investigate a phenomenon, population, or general conditions" (Stake, 2000, p. 437). In this study, I used a multiple-case design to examine the experiences of six Chinese American parents in the context of early childhood music education. My task was to report the meaning parents ascribe to acculturation in sufficient depth that those who read the study can connect to the experience, learn how it was constituted, and deepen their understanding of the issues it reflects. To study a complex problem such as acculturation, I used an emerging qualitative approach to inquiry, which features collection of data in a natural setting sensitive to the participants and data analysis that was inductive and established patterns and themes. The 
final written report includes the voices of participants, the reflexivity of the researcher, and a complex description and interpretation of the problem that extends the literature.

\section{Participants}

Participants for this study were first-generation Chinese American immigrants who at the time of the interviews had children under age eight and who resided in Philadelphia, Pennsylvania, the place of residence of the researcher. Purposeful sampling was used to ensure the samples were suitable for the intent of this study. According to Patton (1990), "The logic and power of purposeful sampling lies in selecting information-rich cases for study in-depth.

Information-rich cases are those from which one can learn a great deal about issues of central importance to the purpose of the research" (p. 169). The goal of purposeful sampling is not to obtain a large and representative sample but rather to select persons, places, or experiences that can provide the richest and most detailed information to help us answer our research questions. Seidman (1998) and Yin (2003) suggest that six to ten participants, or cases, are adequate for a multiple-case study. My goal was to identify six immigrant Chinese American families, and interview one parent from each household. The parent's marital status was not a factor in selecting these families.

When seeking potential participants, I contacted the administrators at three local Chinese American schools that I knew to have early childhood music programs. Two of the schools are located in urban areas; the third is located in a suburb. I first emailed each of the teachers whom the administrators recommended with a brief introduction of the purpose and goals of the study. The major purpose of the email was to get contact information for Chinese American parents, who were then contacted directly by telephone about participating in my study. Being Chinese, I 
knew that Chinese parents are much more responsive to personal contact than to an impersonal email.

During the initial telephone contact with the parents, I read an invitational letter (Appendix A) to each participant that explained the nature of my study. As I spoke with parents I kept a record of those who seemed interested. A simple participant information form listing name, years of living in the United States, and ages of children was used to develop a database of potential participants to include contact information and notes about best times and locations to schedule interviews. I suggested that parents take some time to think about their interest in participating and phoned them a second time within a few weeks. Once I received West Virginia University Institutional Review Board approval (Appendix B), I sent the invitational letter that articulated the rationale for the study to those parents who agreed to participant in this study.

\section{Data Collection}

As a qualitative multiple-case study, the primary data for this study were collected through six sets of interviews, each set consisting of three different interviews with each of six individual, first-generation Chinese American participants. Each participant was a firstgeneration Chinese American immigrant who at the time of the interviews had children under the age of eight and who resided in Philadelphia, Pennsylvania. Although not intentional, all participants in this study were career professionals with advanced degrees. Participants' educational backgrounds and professions are included in the demographic information (see Table 3.1). 
Table 3.1: Demographic Information on Participants

\begin{tabular}{|c|c|c|c|c|c|c|}
\hline Name & Age & $\begin{array}{l}\text { Home } \\
\text { town }\end{array}$ & $\begin{array}{l}\text { Years in } \\
\text { US }\end{array}$ & Education & $\begin{array}{l}\text { Child's gender and } \\
\text { age }\end{array}$ & Profession \\
\hline Jean & 31 & $\begin{array}{l}\text { Guang } \\
\text { xi }\end{array}$ & 8 & M.A. & Son, 4 & Music \\
\hline Steve & 42 & $\begin{array}{l}\text { Shang } \\
\text { hai }\end{array}$ & 10 & Ph.D. & Son, 7 & Business \\
\hline Joan & 30 & Hunan & 7 & M.A. & Son, 3 & Business \\
\hline George & 37 & Ningxia & 9 & Ph.D. & Sons, $3 \& 7$ & Education \\
\hline Victoria & 33 & Hubei & 8 & Ph.D. & Daughter, 5 & Education \\
\hline Luke & 36 & $\begin{array}{l}\text { Jiang } \\
\text { su }\end{array}$ & 10 & J.D. & Daughter, 5 & Law \\
\hline
\end{tabular}

The primary form of data for my study came from these six sets of qualitative interviews designed to gain a deeper understanding of Chinese American parents' perspectives on music education for their young children and the acculturation process involved when adapting to contemporary music education in the United States. Interviewing provides "access to the context of people's behavior and thereby provides a way for researchers to understand the meaning of that behavior" (Seidman, 1998, p. 4). Specifically, I adapted Seidman's three-interview series approach of in-depth phenomenological interviewing that "combines life-history interviewing, and focused in-depth interviewing informed by assumptions drawn from phenomenology" (Seidman, 1998, p. 9). Seidman (1998) was one of the first to introduce Dolbeare's and Schuman's (Schuman, 1982) three-interview series approach to the field of education. The purpose of conducting a series of three interviews is to facilitate an in-depth exploration of a participant's experience; it allows the interviewer to investigate the meaning of an experience in context and in greater depth than would be afforded by a "one-shot" interview (Seidman, 1998, p. $11)$. 
Interview one: Focused life history. According to Seidman (1998), each interview in the three-interview series serves a different purpose. The first interview establishes a focused life history (Appendix C). In my study, interviewees were asked to share their life experiences, providing as much detail as possible, in order to provide the context for the study. Participants were asked to share past music experiences in China prior to moving to the United States. I asked questions such as "How were your parents involved in your music education when you were growing up?" "What do you recall about your parents' expectations for your music education?" By asking questions like these I hoped to have them reconstruct a range of constitutive events from their past music experiences that placed their current parenting decisions about early childhood music programs in the context of their lives.

Interview two: The details of experience. The second interview allowed participants to concentrate on and reconstruct concrete details of their present experiences (Appendix C). In my study I asked parents what involvement they actually have in their children's music learning. I did not ask for opinions but rather for the details of the experiences upon which their opinions may be built. In order to put their experience in context, I asked the Chinese American parents to talk about any challenges they face regarding their children's participation in the music program and their relationship with their children and the teachers. I also asked parents to recall the music activities they do with their children in school and at home. I encouraged them to tell stories that bring out details of their experiences.

Interview three: Reflection on the meaning. The third interview encouraged the participants to reflect on the meaning of their experiences (Appendix C). These questions took on a future orientation: "Given what you have said in earlier interviews, what are your expectations for your children in the future?" Seidman (1998) points out that making meaning 
requires that participants examine how the factors in their lives interact to bring them to their present situation. It also requires that they examine their present experience in detail and within the context in which it occurs. The combination of exploring the past to clarify the events that led participants to where they are now and describing the concrete details of their present experience establishes conditions for reflecting upon what they are now doing in their lives.

The third interview was productive because the foundation for it had been established in the first two. The very act of putting experience into language was a meaning-making process (Vygotsky, 1934/1987). When participants told stories of their experiences, they framed some aspect of them with a beginning, a middle, and an end, thereby making them meaningful in all three interviews. Even though it was the third interview that focused on the participants' understanding of their experiences, all three interviews in combination contributed to the overall sense-making of participants' experiences.

The ultimate goal of the three-interview series was to understand how participants construct a consistent world of meaning from their experiences. In this study, the successful reconstruction of a cultural world of meaning on the part of the Chinese American parents was necessary to reveal any puzzlement that they had experienced when confronting early childhood music education in the United States.

As Seidman (1998) suggested, I kept the length of the interview to 90 minutes and spaced each interview from three days to a week apart, over a two- to three-week period. This allowed me, as the researcher, to have an opportunity to establish a substantial relationship with the participants over time. In order to capture as faithfully as possible what the participants wanted to say, the interviews were conducted in Chinese. 
The first two interviews took place in a quiet setting convenient to the participants - my on-campus office - in which parents felt at ease. The final interview took place in the participants' homes. Conducting the final interview in this fashion provided insight into the participants' life style and their home environment. The participants were able to freely discuss their experiences of early childhood music programs in China and the United States, which provided insight into their acculturation experience.

All 18 interviews were audio recorded using a Samsung Galaxy voice recorder. I made descriptive notes during the interviews that followed the sequence of the interview questions. An outline was created for each interview with annotations as to the time that each new topic was introduced. The quotations needed in the dissertation were thus quickly found and transcribed and translated during the course of drafting the text. After all data were gathered from the interviews, a file was created in rich-text Microsoft Word for each participant that included the three interview audio files, an interview outline, and my interview notes.

Research journal. Over the course of my research, I kept a research journal. "For qualitative researchers, the act of journal writing may be incorporated into the research process to provide a data set of the researcher's reflections on the research act” (Janesick, 1999, p. 505). My research journal helped me to reflect on the research process and make adjustments to the research design during the course of the interviews. This in turn allowed me to make my experiences, opinions, thoughts, and feelings a visible and acknowledged part of the research process.

\section{The Role of the Researcher}

To minimize the effects of bias on a study, a researcher should incorporate self-awareness and reflection into the research process by continually exploring his/her relationship with the 
subject matter (Conrad, Neumann, Haworth, \& Scott, 1993). In this study, my role as researcher was to ask questions, respond to the parents, and at times even share my own experiences. In qualitative research, the researcher is part of the "meaning-making" process. Seidman (1998) draws on Martin Buber's work when describing the relationship between the researcher and participants, suggesting that an "I-Thou" relationship instead of a "We" relationship must be established between interviewer and interviewee. In an "I-Thou" relationship, the interviewer keeps enough distance to allow the participant to represent himself or herself as independently as possible; whereas in a "We" relationship, the interviewer acts as an equal participant, which yields a discourse more akin to conversation than to an interview.

Because the researcher is inevitably part of the research process, she may end up hearing what she wants to hear rather than what the interviewee truly wants to say. Seidman (1998) promotes the three-interview series as a refinement of the traditional single interview method and maintains that it better compensates for this weakness. The in-depth three-interview series affirms the role of the human interviewer, who, as Seidman (1998, citing Lincoln \& Guba, 1985, p. 107) states, can be "a marvelously smart, adaptable, flexible instrument who can respond to situations with skill, tact, and understanding" (p. 16).

Throughout this study, every effort was made to minimize the impact of the interview process itself on the interviewees' representation of their own experiences. When I started this study, my identity as a female Chinese American graduate student in my early 30 s helped facilitate relationships with my research participants. Because of my race, ethnicity, gender, and educational background, I gained the trust of my participants and was able to relate to the participants when they put their experiences into a cultural context. Being bilingual, I was able to 
conduct interviews in Mandarin Chinese, which allowed my participants to express their ideas fully in their native language.

\section{Data Analysis}

In a case study, data analysis "consists of making a detailed description of the case and its setting" (Creswell, 2007, p. 163). The process of data analysis includes making the collected information meaningful and bringing major findings to light for the intended audiences. Analysis of the interview data was conducted at two levels: in-case and across the six cases. Because I conducted a multiple-case study, there was a need to "provide interpretation across the cases" (Stake, 2006, p. 39). First, the in-case analysis was used to identify emerging themes within each case. Second, the across-case analysis was conducted by means of a process that Stake (1995) refers to as "categorical aggregation" to compare emerging themes and to combine them into categories across cases. This categorical aggregation was used to understand the overall cultural beliefs and acculturation experience of Chinese American parents. QSR NVivo (2012), a qualitative software program, was used to help code, sort, file, and connect interview data. Because I conducted the interviews entirely in Chinese and took interview notes in Chinese, the Chinese version of QSR NVivo was used.

I analyzed the collected data thoroughly for themes. I carefully listened to the interview recordings and read my interview notes several times in order to obtain a sense of the data and identify possible codes for analysis. During this process, I developed a system for sorting the interview data. I used letters to indicate participants (e.g., J=Jean, S=Steven, V=Victoria). I used numbers after the letters to indicate the interview series $\left(1=1^{\text {st }}\right.$ interview, $2=2^{\text {nd }}$ interview, $3=3^{\text {rd }}$ interview) and the page number in my interview notes. For example, J112 represents Jean, $1^{\text {st }}$ 
interview, interview notes page 12 , and V308 represents Victoria, $3^{\text {rd }}$ interview, interview notes page 8 .

After listening to and reading the data thoroughly, I looked for patterns related to my research questions as well as deviations from the patterns and sought similarities and differences across individuals. Although some patterns that related to the research questions were anticipated, others emerged unexpectedly as data were compared across cases, which is characteristic of the reflexive nature of qualitative research.

An initial list of codes was generated through this process and then this list was further refined through reflection and re-examination of the data. I searched for connecting threads and patterns among the codes and categorized them into themes. For example, the codes "music as creative self-expression," "music as emotional expression," and "music as a moral phenomenon" were categorized into a broader theme, "functions of music." I also looked for similarities and differences present across the six cases. The QSR NVivo program helped code each excerpt with a notation that designated its original place in the interview notes and the audio recording. It also organized codes hierarchically, which helped deepen levels of analysis and clarify the relationships between the raw data and the broader themes. Through the analysis process I compared what I was finding with the related research literature.

I used two basic ways to present interview data. First, I created a profile for each participant; second, I organized the profiles using the themes that emerged across the six cases. In constructing the profiles I created brief sketches introducing each participant based on data from my research journal and interviews. During the writing stage, I reread the interview outline notes multiple times in order to better capture the meaning of the data and to translate specific excerpts from Mandarin Chinese into English. I had an editor who is a native English speaker 
with a knowledge of Chinese; I also had a reader who is a native speaker of Chinese with an advanced degree in English literature who checked the English translation to strengthen the clarity and authenticity of the presentation of my research. I relied upon the audio recordings of the interviews to ensure the accuracy of direct quotations from each participant. As I considered it essential to present the narratives in the participants' own voices, I made every effort to include direct quotations in the portraits. Doing so enables the reader to hear the voice of an individual participant, thus giving the reader an opportunity to "see for themselves" (Wolcott, 1990, p. 129).

\section{Confidentiality}

To ensure the confidentiality of the collected information, all data were coded and kept in two secure locations: a Window-based computer system and Dropbox (a file hosting service on iCloud). An identification number was assigned to each participant, and pseudonyms instead of real names were used. At any time during the study, participants had the right to drop out and withdraw any information given. Coded identifiers were removed following analysis and before representation in any public reports. Data will be retained for five years and then will be destroyed.

\section{Trustworthiness}

Establishing trustworthiness is critical during the research design, data collection, and analysis processes in a qualitative research (Glesne, 2010). The purpose of trustworthiness is to verify that the qualitative research findings are "worth paying attention to" (Lincoln \& Guba, 1985, p. 290). Creswell (2009) recommends that any research study employ at least two of eight procedures that he identified to improve trustworthiness. In my dissertation, trustworthiness was enhanced through the strategies detailed below. 
Triangulation. Triangulation is a process that protects study findings from distortion caused by relying on a single method, a single source, and a single investigator's biases (Creswell, 2007; Denzin, 1978; Eisner, 1998; Glesne, 2010; Merriam, 1988; Stake, 1995). I began this study by conducting an intensive literature review as a way of obtaining multiple theoretical perspectives. The literature review continued throughout the analysis of data and writing of the document. I used a three-interview series for data collection and kept a research journal. I consulted multiple reviewers, including my advisor and colleagues, to review drafts of the reports.

Member checking. In member checking, the researcher takes the final report or specific descriptions or themes back to participants to determine the accuracy of the findings and interpretations (Creswell, 2009). This procedure provides an opportunity for participants to comment on the findings. In the process of member checking, I first emailed to each of the research participants the draft portrait that I had created for each individual with an explanation of the process and rationale of member checking. I asked each to read the portrait and make comments or suggest changes. Some participants responded promptly, such as Steven. Others took a bit longer to respond, such as Victoria. Luke never replied because he went to China after the third interview; his work requires him to be in China for four months every year. Most participants found it interesting and enjoyable to read their own portraits. For example, Jean said, "It's so interesting to read about my own stories." Joan also commented, "I liked reading about myself. It brought back my childhood memories." Some of the parents made minor corrections to spelling errors and wrong dates on events. Accordingly, I made changes in my document. None of them took exception with their portrait or my descriptions of their accounts. 
Peer review and debriefing. Peer review helps ensure that the research is honest and enhances the accuracy of the account. It provides external checks of the research process by reviewing and asking questions about research methods and analysis so that interpretations are broader than the individual researcher's perspective (Creswell, 2009). I sought feedback from my advisor and committee members in the music education program by reviewing the research design, reviewing the questions of the three-interview series, and submitting drafts of the narratives to get their impressions of my interpretations of the data. I revised the report accordingly. I also invited several colleagues to read my drafts. Although these colleagues were in many ways critical of my interpretations, their comments and questions helped me to focus on writing for my intended audience: early childhood music teachers.

\section{Summary}

Having discussed the research methods that were implemented in this dissertation, the next three chapters will present and discuss the findings. As a multi-case qualitative study, this dissertation examines the backgrounds and experiences of participants and the meanings they make of their lives in the context of their acculturation to life in the United States. In order to represent a richly detailed picture of each participant, Chapter 4 provides a narrative portrait for each of the six participants. Chapter 5 then discusses the most important themes that emerge from these portraits across cases. These themes taken together represent key aspects of the cultural backgrounds of the participants and the understandings of music education that they bring with them, as Chinese Americans, to their newly adopted culture. Chapter 6 focuses on the interplay of Chinese cultural values and early childhood music education encountered in the United States through a focus on their acculturation experience as they strive to become American while remaining Chinese. 


\section{CHAPTER FOUR \\ PARTICIPANT PORTRAITS}

This chapter synthesizes the content of the interviews in the form of six narrative "portraits" of Chinese American parents who participated in this study. The portraits introduce participants' backgrounds and views on a range of issues targeted by the three-series interview questions. Each portrait is organized in terms of eight areas: the participants' life experiences, their own parents' involvement in the music education they received as children, their parents' expectations for that education, the participants' cultural beliefs, the expectations that they themselves now have for their own children's education, their views on the role of music, their role as parents, and finally the impact of acculturation on all of this. In the course of listening to the participants discuss these different aspects of their backgrounds, experiences, beliefs, and expectations, common themes began to emerge. The following narrative portraits lay the foundation for the cross-case analysis to be undertaken in Chapter Five.

\section{Jean}

When I arrived for our interview, Jean greeted me with a big smile and invited me to sit at her kitchen table. After learning that I grew up in the same province as she did (Hunan), she eagerly switched to speak in our local dialect. Jean is an only child. Her mother is an architect who is also an adept musician who sings and plays several instruments. Her father is a government official. Jean affectionately refers to them both as music lovers:

My mother has music in her genes. She really likes "big songs" like the songs that Peng Liyuan sings. My mother makes me accompany her on piano when she sings. She is very active musically. I got my music genes from my mom. ( $1^{\text {st }}$ interview, May 9,2013$)$ 
As for her dad, it is a different story. He likes to listen to music, but Jean joked that when he sings he is "out of key, out of tune and out of feeling" ( $1^{\text {st }}$ interview, May 9, 2013). Despite their disparate levels of ability, Jean attests that her parents were equals in their enjoyment of music and is grateful to this day to have been raised in a home where music was cherished.

Jean's music values were instilled in her and cultivated under her parents' authority, but her devotion assumed a vibrant independence long after her childhood, so much so that Jean made a career of teaching music. She taught piano for a number of years in China and has been teaching in the United States for eight years.

Life experiences. Jean's earliest memory of music was when she was six years old and received a toy piano as a birthday present. "My initiation into early childhood music education was when I played my toy piano for a year. Every day when I came home from kindergarten I played the songs that I had learned in class on the toy piano using my right hand. No one taught me" ( $1^{\text {st }}$ interview, May 9, 2013). Jean's earliest experience with formal piano lessons, however, did not provide as fond a memory as her toy piano did. Specifically, Jean characterizes her first piano teacher as "a nightmare."

I remember that my first piano teacher was very fierce. She sat next to me on the piano bench cradling a cat in one hand and brandishing a ruler in the other. The slightest mistake in my playing incurred a sharp slap of the ruler across the back of my hand. The result was a red welt. One time she extended my one hour class to two just because I could not play one eighth note correctly in Little Thompson Second Volume. I had practiced that piece for hours at home and could play it very well. But when I played it in front of her my hand started shaking and I became nervous. The more nervous, the worse I played. Then she went to eat and told me to continue to practice on my own. After she 
returned she continued to use harsh words. After a half year of this my mother decided that this could not continue because it would discourage me. At that point I already thought that piano lessons were terrifying. My mother was worried that continuing under these conditions would break my spirit, so she found me another teacher. $\left(1^{\text {st }}\right.$ interview, May 9, 2013)

Although Jean developed a justified fear of piano classes based on her first teacher, her second piano teacher was quite the opposite. If anything, she was too indulgent, not strict enough, and praised her all the time, regardless of how well she played. This did not work, either. Finally, and fortunately for Jean, her mother found a third teacher. This teacher was kind and encouraging, more inclined to praise her only when she played well, and did not strike her when she did not. Jean's third piano teacher would become a deep influence in her life, inspiring Jean to become a music teacher and establishing a model in Jean's mind and in her own practice as a music educator as to how a teacher treats and develops the talents of her students. Jean described this teacher, teacher Lin, in detail:

Teacher Lin had a great influence on me. She was extremely patient. Whenever I did not understand something, she would be very patient; she would not stop until I understood it. Now my students' parents think I am a patient teacher. I think this is the influence of teacher Lin. $\left(1^{\text {st }}\right.$ interview, May 9, 2013)

Jean said that teacher Lin also taught her some important moral lessons:

Teacher Lin was a person with high moral standards as a teacher. She was very considerate. She understood that paying for piano lessons was a big expense for a normal family. She asked all of her students not to give her presents on traditional holidays. 
Instead, she asked them to give her a signed greeting card. She would hang these up in her piano room. I think that was very creative. $\left(1^{\text {st }}\right.$ interview, May 9,2013$)$

Jean studied with this beloved teacher from her childhood until she went away to college.

Jean stated that her most memorable music class at school was when she was taught sight-singing and musical note dictation (solfeggio) sometime during the fourth or fifth grade. That music could be not only heard but also notated was a transforming revelation for Jean:

I remember the two musical notes that were dictated were si ( $t i)$ and $r e$. My teacher called eight students up to the blackboard to take dictation. Only three of them got it right. I remember the feeling that I had vividly. It felt like an epiphany. Wow! Music can not only be sung and listened to, but can also be notated! I did not get it right on that occasion, but it stimulated my interest in learning solfeggio. Later I became one of the best in my class. As a result, I entered a class for musically talented students. $\left(1^{\text {st }}\right.$ interview, May 9 , 2013)

In connection with this class, Jean attended many piano competitions, performed recitals twice a year, and studied the Chinese zither and traditional Chinese folk singing.

Jean's parents' involvement. Jean remembers her parents' unyielding commitment to her study, recalling that for the full eight years of her agreement with her parents, her father would take her on his bike every week to her music teacher's home, no matter the weather, no matter his health. She recalled one vivid memory:

My teacher's house was more than an hour's bike ride from my parents' home. One day it was pouring rain. As usual my dad biked up the big hill that we had to cross en route. I was holding a big umbrella and we almost lost our balance and fell off the bike. $\left(1^{\text {st }}\right.$ interview, May 9, 2013) 
Jean's mother was by her account what we today would call a "tiger mom," very strict and domineering. Yet, she would always make herself available to sit and listen to Jean's playing and provide supportive feedback. Jean's mother also arranged "mini-recitals" in their home, during which Jean would accompany her mother playing on the phoenix zither. Jean believes that she must have inherited her mother's love of folk music. Although her father also loved music and fully supported Jean in her studies, he never played an instrument.

Jean explains her parents' commitment to her music education by recounting how her parents stopped watching television entirely when she was a little girl so as to entirely remove her favorite childhood distraction from her home environment. Jean practiced on a strict schedule, one closely maintained by her parents, even when she was on vacation. Her parents communicated routinely with her teacher and sought her advice on Jean's future, including advice on her career path. Even though her mother had ideas of her own, she ultimately deferred to and supported Jean's decision to pursue her dream of studying music in college.

Jean's parents' expectations for her. Jean's parents expected that her study of piano would build her character in a number of ways. For instance, they expected her to learn the discipline that comes from sitting at a piano for hours of practice and sticking with the same regimen and instrument for many years. Jean's parents also expected her to develop the virtue of persistence, believing that music education teaches children that progress and skill are hardearned and most worthwhile.

My parents believed that music is an important factor in a child's moral formation. They thought persistent piano study could shape my character. They asked me to sit at a piano for hours of practice. They also told me that kids who study music are more likely to be good kids. In their mind, children who devote their time to music lessons have less free 
time to get into trouble, and are less likely to end up in mischief. ( $1^{\text {st }}$ interview, May 9 , 2013)

Jean explains that, in addition to regulating a child's outward behavior, her parents believed that music education also fed and cultivated a child's artistic temperament. Jean's parents naturally expected that as a girl she would learn to play at least one instrument well, in accordance with the traditional Chinese view that well-educated girls master the "four arts": music, chess, calligraphy, and painting.

Jean said that her parents had different expectations for her at different stages of her music education. When Jean was young, her parents' expectations were very much in line with the traditional expectations just described, but as Jean's parents witnessed her music aptitude and unusual successes in high school, they began to expect Jean to develop a professional career in music, rather than merely possess familiarity with music as a sign of her proper education and upbringing. This expectation led Jean's parents to provide her with additional opportunities, such as attending a summer music camp at Shanghai Music Conservatory. She later went on to earn her undergraduate degree from this prestigious conservatory. After college, Jean pursued her music education in the United States, earning a Master's Degree in Music at Temple University.

Jean's cultural beliefs. Jean places a very high premium on education and harbors great esteem for teachers. She inherited both of these values from her parents. She explained that "her parents were willing to invest in education as much as they were able" $\left(1^{\text {st }}\right.$ interview, May 9, 2013). As far as respect for teachers, "my parents were very respectful to all my teachers. They always remembered to give presents to teachers on traditional Chinese holidays. The worth of the presents was not the point. The point was to show their willingness to work with the teacher and follow her guidance" (1 ${ }^{\text {st }}$ interview, May 9, 2013). 
Having now experienced music education in both countries, however, Jean confesses to wishing that her American students showed more of this kind of respect to their teachers. She has learned that American students are much more independent. For instance, when she once asked an American student to play a particular piece, the student replied: "Why would you want me to play this? You never mentioned this before" $\left(1^{\text {st }}\right.$ interview, May 9, 2013). Jean expressed that such an attitude can lead to a resistance to correction, and makes teaching difficult. "I believe that if a student gets angry easily when you point out his mistakes, he cannot make progress" $\left(1^{\text {st }}\right.$ interview, May 9, 2013). She noted that she had never encountered this sort of problem with Chinese students.

Jean's parents' values with regard to music greatly influenced her own, but her earliest experience with music was not imposed on her by her parents' expectations or authority. Rather, it was the result of a mutual agreement that the then seven year-old Jean made with them on the occasion of the purchase of a piano. Jean described the agreement they made, which she believes can serve as a good illustration of their guidance:

My parents had a serious talk with me before they bought the piano. They asked me if I could commit to eight years of piano study. If so, they would buy the piano for me. They told me that a piano would be a luxury for the family at that time. They hoped that I would study wholeheartedly and consistently to master the skills. I'm not the smartest person in the world, but I think my ability to "eat bitterness" (endure hardship) was nurtured through his eight years of practice. $\left(1^{\text {st }}\right.$ interview, May 9, 2013)

Jean recounts that, in the earliest years of her eight-year commitment, she often became bored and discouraged with the long hours of practice and sometimes felt like giving up. "I once really doubted my interest in piano, and wished that I had never agreed to the commitment" $\left(1^{\text {st }}\right.$ 
interview, May 9, 2013). Yet even as a child, Jean felt an obligation to honor her agreement with her parents and she continued her training. In the end, she not only satisfied the full eight years of the agreement but proceeded to study music formally for an additional six years, earning her bachelor's degree in one of the best music conservatories in China — the Shanghai Music Conservatory. Thinking back on the experience, Jean believes that her agreement not only helped her master the piano, but also helped develop her character and passions. Over many years of persistent study, Jean discovered herself through her love of the piano and music, and this instilled in her an abiding appreciation of her parents and their values, namely, never to give up in difficult situations and to appreciate the benefits of lifelong devotion. Although Jean considers these to be distinctly Chinese virtues, she endeavors to impart them to her American students.

Jean's expectations for her child. Like her parents, Jean believes that music education should build character by instilling discipline, persistence, artistic temperament, aesthetic appreciation and ability, and high moral standards. As she said:

I deeply appreciate that my parents supported my study of piano. Now, whenever I face difficulties in life, I can clench my teeth and persist until I overcome the difficulty. I think persistence is a great quality in a person. For that reason, I really appreciate my parents. Also, their expectation that I be artistic made me more of a well-rounded person. Experiencing the beauty of music also enriched my spiritual life. ( $3^{\text {rd }}$ interview, May 23 , 2013)

Jean's expectations for her own child are a little different from those of her own parents, due in part to her experience of living, studying, and teaching in the United States. She believes that every child is different and that parents should be attentive to each child's unique interests and talents. Jean has a 4 year-old son whom she has already begun to teach piano. Although he is 
young, Jean admits that she's begun assessing his future with music, stating that, "he seems to have interest, but it's too early to conclude if he is going to continue" $(2$ nd interview, May 16 , 2013). Jean selected the piano for her son rather than having him decide which instrument he would learn because, as she reasons,

First of all, I am a piano teacher. Second, the piano is the king of all instruments. Unlike string instruments, it always sounds nice and stays in tune even at the beginning stage of piano study. Music theory can also be learned through playing piano. It provides a comprehensive understanding of music as a whole. ( $2^{\text {nd }}$ interview, May 16, 2013) Yet even if her son's interest in piano continues, Jean states that she would never insist that he pursue a career in professional music.

I do not expect my son to become a professional musician, like Lang Lang. Such talents are rare. Making a living as a musician in America is very difficult unless you are very famous. I think music can be one of his hobbies, which can open up another door for him. Or it could be turned into a double major, like computer science and piano. After all, a boy has more responsibility for raising a family in the future. $\left(3^{\text {rd }}\right.$ interview, May 23 , 2013)

The role of music. Jean stated that music for her is a lifelong friend. "I once had doubts about my interests in music when I was in college. After I came to United States, it surprised me that I found out my love for piano was much deeper than I expected. It's part of my everyday life" $\left(3^{\text {rd }}\right.$ interview, May 23, 2013).

She further explained the benefits of music in a person's life by referring to the traditional Chinese concept of "self-cultivation." Jean often repeated that "music shapes a child's 
character and helps cultivate virtues, such kindness and the persistence that is earned from long hours of difficult practice" ( $3^{\text {rd }}$ interview, May 23, 2013).

Jean acknowledges that musical accomplishment is also a symbol of social status and is valuable in that regard as well, but she subordinates such considerations to the experience of joy. Jean wishes to induce her son to study music for the benefit of his own happiness, for the joy that music brings to our lives. She firmly asserted, "The value of discipline and hard work, and the benefit to one's own soul of experiencing the beauty of music, take precedence over material possessions. I believe that music purifies a person's mind and that people who study music tend to be happier, possess better character, and have more refined tastes" ( $3{ }^{\text {rd }}$ interview, May 23 , 2013).

Jean also wishes to promote music for her son and her students as a form of universal expression or "world language." Jean reasons that "if a person masters the language of music, that person can communicate the most profound of human sentiments to anyone in the world, making connections through shared emotional experiences" ( $3^{\text {rd }}$ interview, May 23,2013$)$. In a rare moment of pragmatism, she joked that "I also hope that my son will be more attractive to girls, later in life, if he plays piano well" ( $3^{\text {rd }}$ interview, May 23, 2013). She and I burst into laughter.

The role of parents. Jean's role in the musical education of her son began early. She stated:

I listened to music while I was pregnant, as a form of "prenatal music education." Once my son was born, I always encouraged him to listen to my playing the piano on my grand piano or on the upright. I have hired an American piano teacher to teach my son. I also spend a lot of time with him during his practice. So my son benefits from both Chinese 
and American teaching methods. I have not enrolled him in any early childhood music class other than what he already has in preschool. Because there are always ample musical activities in my home, I feel that he already has lots of musical exposure, so other early music education programs are unnecessary for him. $\left(2^{\text {nd }}\right.$ interview, May 16, 2013) Jean stated that parents must "guan" their children, using a Chinese word that is hard to translate but has a range of meanings from "manage" and "control" to "take care of" and "show loving concern for." "If parents spoil their kids, it harms them in the long run. Kids, especially the young ones, do not know much. So it's important for parents to help them make some choices in their inexperienced areas" ( $2^{\text {nd }}$ interview, May 16, 2013). She further explained that the Chinese concept of the parental role as guan seems at first to be a strict way of governing, but it is actually the way that Chinese parents show their love and care for their children. "I love my son, that's why I guan him" (2 $2^{\text {nd }}$ interview, May 16, 2013).

With respect to the governing and controlling aspects of guan, Jean prescribes that parents provide their kids with feedback, training, and discipline, oftentimes denying their child's wishes. Jean confides that, "kids love to go out and have fun. I fully expect my son to cry occasionally in front of me while practicing piano, because it's neither fun nor easy for a child to focus so single-mindedly on a task for so many years" ( $2^{\text {nd }}$ interview, May 16, 2013). Jean repeatedly claimed that "my son has too much fun at school, and accordingly, does not get much out of it" ( $2^{\text {nd }}$ interview, May 16, 2013). Jean explained that any child, left to his or her own devices, would prefer fun and games to long hours of practicing. Yet ultimately, Jean believes that a childhood devoted to the satisfaction of childish wants will not produce a fulfilled and happy adult. 
Although Jean does not enjoy seeing her son cry at times when he has to practice piano, she believes that "as my son matures, he will know greater joy than all his childhood frustrations combined, and find that his piano has become a true friend." "Only after having been taught the difficult lessons of character and responsibility as a child," Jean states, "can a maturing young person be entrusted with the freedom to choose for himself" ( $2^{\text {nd }}$ interview, May 16, 2013). Jean laments that American educators allow their students too much autonomy and too much decision-making authority too early.

I mentioned Amy Chua's book to Jean. She nodded and said, "I think tiger parenting is necessary especially in a child's early years." "However," she continued:

I have been thinking about the question of the extent to which parents should guan their kid. I think it's important to keep a balance between my dual roles as caring nurturer and authority figure. It's not easy, but I have become more permissive and open-minded since coming to America. $\left(2^{\text {nd }}\right.$ interview, May 16, 2013)

The acculturation experience. Although Jean earned her master's degree in the United States and has lived here for several years, she is convinced of the superiority of Chinese parenting, which emphasizes guan over the satisfaction of a child's individual wants or inclinations. In evidence of this point, she noted:

The parents of my own students avoid pressuring their children to learn and allow them freedom to learn at their own pace and do what they like. Such an orientation may be more fun or enjoyable for a child, but it's a waste of time and money. Their child's progress and educational advancement ultimately suffer without pressure to learn and parental authority providing such pressure. $\left(3^{\text {rd }}\right.$ interview, May 23,2013$)$ 
Nevertheless, because she resides in the United States, Jean has found herself having to adapt to aspects of the American approach and admits to having incorporated play into her classes and with her son. Having studied piano as a child herself, Jean acknowledges that practicing is not much fun for children and that there may be some value to the American approach after all. Jean confesses that she is generally more indulgent of her American students' want for fun than with her own son, who she says "gets enough fun at school" and for whom she wishes the acquisition of a truly cherished skill ( $3^{\text {rd }}$ interview, May 23, 2013).

Jean sees her son's musical path as being very different from her own, stressing that for her son, music is more purely a source of enjoyment and self-enrichment, as opposed to the subject of a personal commitment such as she made to her own parents. In fact, although her parents were strict and committed to her music education, Jean says:

I did not require much external motivation to pursue my studies. The initial agreement I made with my parents was all the motivation I required: my promise to my parents was inviolate, and once I received the gift of my piano, I did not stop playing for those eight years. Even as a child, it was unthinkable to break a promise to my parents—a violation of the Confucian ideals I have carried my entire life. $\left(3^{\text {rd }}\right.$ interview, May 23, 2013) Jean concluded her remarks by expressing her wish that American educators would promote the value and importance of music and better assert their authority as adults over the children they are endeavoring to teach. Jean thinks that "a lot of Americans believe that their children are fragile and, thus, must be coddled and over-indulged. Chinese believe that children are innately strong. Chinese parents believe that their child can take the pressure necessary to grow even stronger" $\left(3^{\text {rd }}\right.$ interview, May 23, 2013). 
To Jean, not only can children endure hard work and harsh words, they absolutely require them to grow. Jean concludes:

A teacher or parent must never be overly-deferential to a child's self-esteem, because a child learns best by accepting that she is lacking in skill and knowledge, and by committing to improve gradually through hard work and practice. A Chinese friend of mine practiced this approach and raised a child who ultimately ended up at Harvard University. Self-esteem is better appreciated and deserved in the light of such accomplishment, as opposed to during one's childhood. ( $3^{\text {rd }}$ interview, May 23, 2013)

\section{Steven}

Prominent displays of refined porcelain artwork greeted me, along with their proud curator Steven, when I visited his home. A man with an enthusiastic appreciation of art and beauty, prior to our interview Steven introduced me to his collections, assembled over many, many years from many, many places. He explained, "the appreciation of art is not only gained from knowledge based on books but from repeated experience. My accumulated experience with real porcelain shaped my ability to identify fine porcelains" ( $3{ }^{\text {rd }}$ interview, May 25, 2013). These collections and Steven himself reflect great knowledge of and admiration for the Chinese arts. Steven explains that his fondness for Chinese art is not limited to statuary or pottery but, rather, extends to all three of the distinct yet interconnected branches of the Chinese trinity of arts: music, visual arts, and dance. "The study of music, the visual arts, and dance, these three interconnected branches, aided my cultivation of the arts as a whole. For me, it is a kind of enjoyment" $\left(3^{\text {rd }}\right.$ interview, May 25, 2013).

Steven is forty-two years old and was born and raised in Shanghai, China. Having lived in the United States for almost ten years, Steven is currently an executive manager at an 
American consulting firm. A self-identified practitioner of Confucianism, Steven is also very interested in Western philosophy. Steven is the father of a seven year-old son who studied piano for all of three years before quitting it completely.

Life experiences. When Steven was a child, his music class was devoted exclusively to singing songs accompanied by piano or accordion. Despite its lack of enrichment, Steven told me that he enjoyed the singing very much, and that no other class was more fun than music class. $\mathrm{He}$ stated:

In general, I had one music class every week, which was held in music classrooms with accordion or piano. Singing was the only thing we did. My music teacher usually picked a song for us, and let us listen to it a couple of times with lyrics written down, before she asked us to sing after her. And then she would ask the more talented students to lead the other students in class. Then she would divide the class into boys and girls to sing different parts. Music class is my best memory of my elementary school. Compared to other classes, it was more fun. Other classes, such as chemistry and physics, were very boring. You know kids love to have fun. Opportunities for musical activities outside the classroom, such as singing in chorus and playing in band, were highly competitive and scarce, given the large number of students and limited resources at my school. I did not get a chance. I was not a particularly good student, and only good students got this kind of opportunity. $\left(1^{\text {st }}\right.$ interview, May 11, 2013)

Steven's parents' involvement. Steven told me that musical activities in his home were non-existent. Steven's family worked hard to secure the basic necessities of life and did not have the time or resources to provide a diversity of musical experiences for him either at school or in the home. Yet, although Steven's experience of music during his childhood was limited, it was 
nevertheless profound and had an enduring influence on him. Steven associates music with his family, and vividly remembers his father:

My parents had no involvement in my music education. My father was the main provider for the family. He was under a lot of pressure from work and was under financial pressure. He remains a mystery to me. He did not tell me a lot about himself. He went through the Cultural Revolution, and did not want to talk about that aspect of his life. I remember when I was little, every day I would look out through the window, waiting for my dad to come home. My mom and I would meet him at the door. My mom would take his coat and I would offer him a cup of tea. I have a lot of respect for him. He was very knowledgeable, but professors like him must have had a very difficult time during the Cultural Revolution. Although making a living for the family occupied most of his time, I did not realize he had deep musical skills, until one day he sang me a song after work. I was shocked, surprised, and touched. It was my first time to hear my father sing. I still remember the song and remember how surprised I was as a child to hear how beautifully he sang, how expressive his voice was, and how simple but touching the words were. Even now, long after his death, I still remember him best through this song, and the song itself serves as a profound emotional link to his memory. ( $1^{\text {st }}$ interview, May 11,2013$)$ Steven's parents' expectations for him. Steven said that his parents did not have specific expectations for his music education. "There was almost no musical activity in my family. Life was difficult and music was a luxury for me and my family. I could sense the pressure on my parents to make a living. They hardly had time to think about music" $\left(1^{\text {st }}\right.$ interview, May 11, 2013). 
Cultural beliefs. Steven is a lifelong student of ancient Chinese civilization and what is called "national culture"-a cultural movement committed to the preservation and promotion of traditional Chinese thought as represented by such thinkers as Confucius, Mengzi, Laozi, and Zhuangzi. Thus, Steven is an unusually ardent believer and practitioner of Chinese philosophy, despite his residing in the United States and his flirtations with Western philosophy.

Steven's philosophical dispositions have, as one would expect, greatly influenced his musical sensibilities. He discussed music largely within the Confucian framework of the six arts (Rites, Music, Archery, Charioteering, Calligraphy, and Mathematics). Steven regards music as perhaps the chief of the six arts, and fondly recounted the following passage from the Analects of Confucius (7:14, cited by Huang, 1997, p. 85), which he recited from memory:

While Confucius was in the state of Qi he heard the Shao music and for three months afterwards did not even notice the taste of meat. On this occasion Confucius said that he never imagined that music could be so sublime. $\left(1^{\text {st }}\right.$ interview, May 11,2013$)$

Steven explains that the story illustrates the primacy of music in its ability to affect us emotionally beyond any bodily sensation. Steven notes, paradoxically, that while the effects of music are sublime and otherworldly, it serves the practical purpose of providing people with inspiration and motivation in their ordinary lives. Specifically, Steven says that "just as the rural, agricultural laborers of northern China are sustained by singing traditional folk songs as they work in the fields, I, too, enjoy moving to music spontaneously when I'm taking a break from my work" (1t interview, May 11, 2013).

In addition to music's ability to sustain us through the mundane and repetitive events of our ordinary lives, Steven also emphasizes that, in accordance with the Confucian ideal, music purifies, ennobles, and elevates the human heart. By way of example, Steven stated: 
When I first heard a performance of the Chorale of the Yellow River-a sort of unofficial, Chinese national anthem-I was reminded all at once of the better aspects and potential of my own character, and my spirit was lifted. $\left(1^{\text {st }}\right.$ interview, May 11,2013$)$

In the same way, he recalled a story about the power of music to lift the spirit: Many years ago, when I first started to study English, I read a novel by John O'Hara. It was about a thief who is homeless and was put in jail because he repeatedly stole food. One day, after being released once again, he happened to pass by a church and heard hymns being sung. He was deeply moved and had an epiphany, realizing that he had to change his life. When I read this story I realized that music had the power to lift one's spirit. ( $1^{\text {st }}$ interview, May 11,2013$)$

This spiritual aspect of music makes it essential for the development of a noble and worthy character. Steven observed that music connects people emotionally to one another in the most profound and human of ways. He once again referred to a well-known traditional Chinese story:

Bo Ya was very accomplished on the qin (Chinese zither) and felt that only Zhong Ziqi could fully understand his playing. When Zhong Ziqi died, Bo Ya destroyed his qin, saying that without such an appreciative friend (zhiyin), there was no point in continuing to play. $\left(1^{\text {st }}\right.$ interview, May 11,2013$)$

Steven's expectations for his child. When I asked Steven about his expectations for his son, he said:

I did not harbor specific expectations for my son in terms of his musical education. I see no need to put pressure on my son to excel in music. In contrast, my wife's expectations were quite different. Her family background was very different than mine, and she 
received a lot of pressure to distinguish herself as a pianist. Accordingly, she is comfortable applying similar pressure to our son, insisting that he perform at an ' $A$ ' level in school and learn the piano, despite the fact that he never seemed particularly attracted to it and had a hard time sitting still for lessons. ( $2^{\text {nd }}$ interview, May 18, 2013) Steven expressed his frustrations with his wife's excessive and rigid expectations. He stated:

My wife would yell or scold David (my son) when he refused to practice piano. The more my wife forced him to play, the more resistant he became. He cried a lot during that time period. After a few years, my wife relented on insisting that our son study the piano and decided to take his own interests more seriously. As a result, David briefly studied the clarinet, before quitting music altogether. I noticed that he became so much happier after that. $\left(2^{\text {nd }}\right.$ interview, May 18, 2013)

The role of music. Steven believes that one major purpose of music in children's lives is to be a source of fun, similar to the music classes he so enjoyed as a child. "Music is fun and entertaining. It made me feel very bad when I saw my son suffering from piano lessons. That's not the way it is supposed to be" ( $3^{\text {rd }}$ interview, May 25, 2013).

Steven is aware that many contemporary Chinese people have a more practical interest in music, regarding musical accomplishment as a source of economic or social rewards. To him, the value of music education is more in keeping with the cultivation of the spirit as emphasized in the Confucian tradition.

The best aspect of Chinese culture with specific regard to music is that listening to and enjoying music, itself, is a form of moral instruction. According to Confucius, music 
makes a better person, and thus as a father, I want my son to grow to become a better person through music. $\left(3^{\text {rd }}\right.$ interview, May 25,2013$)$

The role of parents. Steven's parents did not have the time to manage his childhood closely in the fullest sense of the practice of guan. Now that he is a parent himself, Steven states: "I am a very supportive and encouraging parent. I allow my son autonomy in making decisions. However, my wife was not as lenient" $\left(2^{\text {nd }}\right.$ interview, May 18,2013$)$. Successful and self-made, Steven, like his wife, recognizes the value and importance of education although he concedes that he is probably less of a "tiger" parent than his wife. He states: "I am the farthest thing from a 'tiger dad'. My wife, by contrast, is much more the "tiger mom"” $\left(2^{\text {nd }}\right.$ interview, May 18,2013$)$.

The acculturation experience. Steven's experience of education in China was very different from what he has experienced in the United States. He sees "the merits to both the Chinese and American approaches" and tries to expose his son to "the best aspects of each, while also avoiding the worst excesses of each" $\left(3^{\text {rd }}\right.$ interview, May 25, 2013). He stated:

The Chinese approach to education is a form of "force feeding," which provides a solid foundation of basic knowledge, whereas American education is more oriented towards encouraging a child's creativity, providing freedom to explore and have fun. In my efforts to teach my son, I tried to combine both approaches. I am encouraging, supportive, attentive to the value of teamwork, and committed to making learning fun. Because my own father was somewhat stoic and uncommunicative, I always try to find ways to communicate openly with my own son. ( $3^{\text {rd }}$ interview, May 25, 2013)

Steven identifies lack of interest and commitment as the biggest challenges in dealing with his son's music education. Steven's experiences not only as a student in the United States but also as a teacher himself led him to see the value of play in education, in opposition to the 
traditional Chinese emphases on discipline and hard work. "One minute on the stage, ten years of practice backstage," Steven says, by way of explaining that American teachers would do well to understand that hard work is critical to success $\left(3^{\text {rd }}\right.$ interview, May 25, 2013).

Steven also wishes that American educators shared his Confucian conviction that music education is essential to proper moral formation, as he stated earlier. "Music leverages our spirit" $\left(1^{\text {st }}\right.$ interview, May 11, 2013). Steven understands that many Americans regard music as an unnecessary hobby or indulgence for children and, in turn, many American educators misunderstand the values of Chinese parents. Steven states that he would be heartened if his son's teachers attempted to better understand his culture and values, in particular the importance that his culture assigns to music in a child's moral development.

\section{Joan}

Joan is a Chinese woman in her thirties who has been living in the United States for seven years. Married with one son, Joan came to the United States with her family and currently works for her uncle's travel agency. My first impression of her was of a woman full of energy and with a positive attitude. She spoke quickly but precisely and was like a ray of sunshine when she walked into my office.

Life experiences. Joan describes her childhood as being "full of the joy of music" $\left(1^{\text {st }}\right.$ interview, May 14, 2013), despite the fact that her formal music curriculum at school was underdeveloped. Joan's earliest music class in school consisted exclusively of singing, and Joan feels that this limited the development of her musicality. She recalls a typical class as "a group of children, surrounding their teacher, singing to the accompaniment of an accordion" $\left(1^{\text {st }}\right.$ interview, May 14, 2013). She found that classes with such a simple format were not of much use for her early music education. 
In contrast to her school's threadbare curriculum, Joan's memorable private keyboard lessons and her music-rich home life were fundamental to expanding her musical horizons. "My mom played a variety of instruments, including the accordion and harmonica, and she loved to sing. She not only hosted musical events in her home, she also organized musical events at her place of work" ( $1^{\text {st }}$ interview, May 14, 2013).

Joan's mother sought to instill her passion for music in her children, encouraging Joan to begin keyboard lessons when she was five years old. And Joan noted, "I have a vivid image of me as a little girl carrying a keyboard and a musical score walking to my teacher's house. My keyboard teacher was a major figure in my early childhood music education. I liked her classes, because the one-on-one format was different from my music classes" ( $1^{\text {st }}$ interview, May 14 , 2013).

Although Joan enjoyed her piano lessons and a rich musical environment at home, she did not continue with piano lessons. As her interests in a variety of activities increased, she no longer had sufficient time to practice music. By the time Joan was in middle school, she was entirely focused on sports to the exclusion of music, and she distinguished herself as a table tennis player. She noted: "I really appreciate that my mom introduced me to a variety of activities, including keyboard, Chinese brush painting, martial arts, calligraphy, and sports, which opened so many doors for me. Although I am not particularly adept at any of these," she said it with a humble smile on her face, "and because my attention span is only about five minutes, they helped me expand my horizons" ( $1^{\text {st }}$ interview, May 14, 2013).

Joan's parents' parental involvement. In addition to her mother's inventiveness and enthusiasm for music, Joan received additional exposure to music outside the home. Specifically, Joan's mother registered her in local music competitions, which she would then "dutifully 
videotape for subsequent home viewings. My mom set a good example for her colleagues at work. Other parents of more limited means who sought to enrich their children's musical experiences eventually followed my mom's example and enrolled their children in music lessons and competitions" ( $1^{\text {st }}$ interview, May 14, 2013).

Although the keyboard studio where Joan took her music lessons was located a considerable distance from her home, Joan's mother insisted that she walk to her lessons on her own in order to develop independence. "My mom walked with me for the very first class. Then she insisted that I walk to my teacher's studio on my own, despite my reluctance. Years later, I learned that my mother had secretly followed me to my lessons to ensure that I was safe. I learned to appreciate how important independence is both to the study of music and to the development of good character" ( $1^{\text {st }}$ interview, May 14, 2013). Joan's commute to her lessons stands as a perfect example of guan, since it illustrates a parent's strict discipline and expectations for her child and evinces the loving, protective care at the very root of such discipline.

Joan's parents' expectations for her. Joan's parents expected her to learn one instrument as her "special skill," in keeping with the traditional Chinese expectation for daughters and well-educated girls in general. Although her parents expected Joan to possess competence and be able to play music for her own enjoyment or to entertain others, they had no expectation that Joan should distinguish herself with a career in music. Supportive of her efforts but also very firm, Joan's parents insisted that she discover her abilities and cultivate them.

Joan also noted that her parents always expected her to put in her best effort and be persistent in overcoming obstacles. Joan recounts a story that illustrates this: 
One night before a competition when I was seven years old, I was complaining to my parents that a passage in a piano piece I was learning was too hard to play smoothly without mistakes. It seemed to me that they were deaf to my cries of frustration and insisted that I continue practicing and seek new approaches to overcoming the obstacle, rather than simply give up on it. ( $1^{\text {st }}$ interview, May 14,2013$)$

As an adult woman, Joan reflects with gratitude now on what then appeared to be her parents' cruel indifference, explaining that she ultimately mastered the piece. "After all the frustrations, I was rewarded with a second prize at the competition. Now when I look back, I realize that I under-appreciated my parents' good intentions back then" ( $1^{\text {st }}$ interview, May 14, 2013).

Cultural beliefs. Joan's attitude toward music was shaped by her parents, who she recalls especially loved the patriotic "red songs" associated with the Cultural Revolution for the sense of unity and commitment to action that they inspired. She noted:

My mom is a "mic hog," [one who monopolizes the microphone at a karaoke party], she loves old songs like Chinese folk songs, Soviet Union songs, and red songs. I heard them so many times that I could sing along with her when she sang. My understanding of music was influenced by the power of music to inspire people and to lift their spirits, which is a notion with deep roots in Chinese culture. The motivating power of music can influence people's behavior for good or ill. ( $1^{\text {st }}$ interview, May 14, 2013)

Joan went on and explained how she categorized music as "good" and "bad" in terms of how it influences people's behavior. 'In my opinion, 'good' music serves to make people happy and inspires them to strive for higher or nobler things. 'Bad' music emotionally manipulates people towards ignoble ends and disables the capacity for critical thought" $\left(1^{\text {st }}\right.$ interview, May 14 , 
2013). Suffice it to say, Joan urges people to consume "good" music and avoid "bad" music, although she acknowledges that "it's no easy task sometimes to discern which is which" $\left(1^{\text {st }}\right.$ interview, May 14, 2013).

Joan's expectations for her son. Joan states that she has tried to pass the lessons learned from her parents on to her own child. Joan sees music lessons and practice as "a means of instilling the value of persistence" in her son, but more practically, she hopes that "music will be a source of joy in my son's life, as it has been in mine" ( $2^{\text {nd }}$ interview, May 21, 2013). Joan says that "I would never insist that my son become a professional musician, but it would be an acceptable option if my son's talents led him in that direction" ( $2^{\text {nd }}$ interview, May 21,2013$)$. Like her parents, Joan is open-minded regarding her son's future. Joan broadly expects her son to achieve excellence as expressed in good grades, awards in competitions, and the like. Joan states that such distinctions will secure him greater acceptance in society and help motivate him to succeed later in life. "Successful experiences in competitions are a good source of positive energy for a kid. It helps a kid gain confidence in himself/herself. I hope to create more opportunities for my son to be exposed to various activities at home and outside home" $\left(2^{\text {nd }}\right.$ interview, May 21, 2013).

The role of music. To Joan, the primary role of music in a child's life is to bring happiness and to provide fulfillment and enjoyment that cannot be had from any other art form. "Music can make us happy in a way that is different from any other art form, such as poetry or painting. I would like my son to learn an instrument so that he can entertain himself" ( $3^{\text {rd }}$ interview, May 28, 2013). Joan also sees music as "an effective way to letting off the pressures that young people so often experience, and as providing a good way for children to explore their feelings and develop their interests" $\left(3^{\text {rd }}\right.$ interview, May 28, 2013). 
Joan recalls that she never regarded piano practice as a chore. On the contrary, she found it to be a lot of fun, and as a result of her own experience she flatly claims that "music education should be fun" ( $3^{\text {rd }}$ interview, May 28, 2013). She qualifies this, however, by saying that "although education should be fun, fun is not the object of education" $\left(3^{\text {rd }}\right.$ interview, May 28 , 2013). Joan uses the Chinese idiom yu jiao yu le - a concept similar to the notion of "edutainment" - to describe her ideal of incorporating play into education. Joan notes that "beyond teaching basic skills and concepts, play-based education has the additional benefits of teaching teamwork, sharing, cooperation, and communication," all of which are traits she desires for her son $\left(3^{\text {rd }}\right.$ interview, May 28, 2013).

Joan holds to the traditional Chinese outlook that stresses the importance and value of music, but she laments that, "so often, music classes in China are subordinated to the studies of language, science, and math, and are generally not very interesting" $\left(3^{\text {rd }}\right.$ interview, May 28 , 2013). Joan notes, "I, like so many other Chinese people, was taught to love music without loving the experience of my actual music education" ( ${ }^{\text {rd }}$ interview, May 28, 2013). Joan sees similar problems with the American approach to music education and believes that music education could benefit from being "more relaxed, more entertaining, and more fun" ( $3^{\text {rd }}$ interview, May 28, 2013).

The role of parents. Joan sees a parent's role in music education as providing guidance, or guan, first and foremost. Joan noted that "I am against a parent forcing a child to study music, because to do so would make a child develop negative associations with the subject matter, which could ultimately kill his interest" $\left(2^{\text {nd }}\right.$ interview, May 21, 2013). Instead, Joan creates situations in which her son can discover his enjoyment of music for himself. She noted: "I hope to help my son discover his true interests and innate musical potential by providing him 
opportunities for a variety of lessons such as piano, voice, and dance. As a Chinese saying goes, 'interest is the best teacher.' No matter what his interest is, I support him" ( $2^{\text {nd }}$ interview, May 21 , 2013).

Joan sees a parent's role as providing exposure and fostering the environment for a child to discover music and its value for himself. "Once the spark is lit and a child develops the interest, it is a parent's duty to feed and nurture that interest because of a kid's naturally short attention span" (2 $2^{\text {nd }}$ interview, May 21, 2013).

One way for parents to do this, according to Joan, is to stay in close contact with their child's music teachers. Joan states, "Especially between Chinese parents and American teachers, cultural differences can lead to misunderstandings that impede a child's education" $\left(2^{\text {nd }}\right.$ interview, May 21, 2013). Joan advises that Chinese parents try different music teachers until they find one who understands their students' cultural sensibilities. Although Joan acknowledges that "the Chinese approach to music education is stricter and perhaps less enjoyable for a child," she does not conclude that the American approach is necessarily the best approach to education ( $2^{\text {nd }}$ interview, May 21, 2013). Joan holds that 'there is much to be said for the 'tiger mom' approach to parenting, noting that children need guan to correct for their childish inexperience and inclinations" ( $2^{\text {nd }}$ interview, May 21, 2013). Joan regards it as a problem for a parent to simply indulge a child's every want or comply with his every impulse. Accordingly, guidance, or guan, not only draws out a child's potential but also establishes the conditions for happiness later in life.

Although Joan sees the merits of the "tiger mom" approach, she also acknowledges its drawbacks. Specifically, she sees that too much guidance or oversight denies a child the freedom to make decisions for himself and learn from his mistakes. Joan asserts that she exercises her 
guidance and management mostly by providing experiences and environments in which her child has the freedom to act and even to make mistakes. Joan considers her parenting approach to be a synthesis of the stricter Chinese approach and the more permissive American approach, but she considers her parenting style to be consistent with the Chinese concept of zhongyong (Zhongyong, 2014), or the "Doctrine of the Mean," suggesting that she keeps a good balance while utilizing both approaches.

The acculturation experience. Joan earned a masters degree in finance in the United States, and thus has been educated in both China and the United States. Joan's earliest education was within the Chinese system, and because of her son's experiences in schools in the United States, she now has multiple perspectives on education. Joan's broad experience has led her to the conclusion that "there is no single, perfect way to educate a child, but rather a diversity of cultural approaches and techniques is to be desired" (3 ${ }^{\text {rd }}$ interview, May 28, 2013). In support of her view, Joan mentions that "the Confucian ideal is to adapt teaching to the ability of a student (yin cai shi jiao). Each student should be treated differently, in accordance with his or her abilities and expectations" ( $\left({ }^{\text {rd }}\right.$ interview, May 28, 2013).

After immigrating to the United States, Joan explains that her attitudes and viewpoints on music education changed. She notes:

In China, there was an excessive emphasis on status and attainment in music education, such as in class rank and winning competitions. As a result, a child's personal educational attainment could become tangled up in issues of a family's reputation. In contrast, in the United States there is greater emphasis on children enjoying music for its own sake, for sheer enjoyment. ( $3^{\text {rd }}$ interview, May 28, 2013) 
Also, Joan states that "there are abundant outreach programs and resources for parents to be involved with as partners in their child's education in United States, and that the programs themselves are less competitive and largely independent from issues of social status" ( $3^{\text {rd }}$ interview, May 28, 2013). Joan appreciates that "the American values of tolerance and inclusiveness are reflected in its music education programs" ( $3^{\text {rd }}$ interview, May 28, 2013).

Having discovered early childhood music education classes in the United States—which, as far as Joan knows, do not exist in China—she is convinced of their value. Joan claims that "research indicates that children start discovering their musical interests very early, as early as between the ages of three and six." Hence Joan's motto on the subject of music education: "the earlier, the better" $\left(3^{\text {rd }}\right.$ interview, May 28, 2013).

Joan recited a passage from the Three Character Classic (sanzijing), which translates as follows: "To feed a son without teaching him is the father's fault" ( $3^{\text {rd }}$ interview, May 28,2013$)$. Joan interprets:

The passage means that a parent is the most important player in a child's education. Although we educate children, no child can possibly know the value of an education; it is something that only an adult can understand. Thus, guan is essential because most learning occurs when a person is least capable of knowing its full purpose and consequences in later life. $\left(3^{\text {rd }}\right.$ interview, May 28,2013$)$

Joan integrates guan with her more American values by guiding and managing her child's education to include play. Joan sees no contradiction between providing guidance and management for a child (guan) and a child learning through play and through enjoying his educational experiences. Joan noted that "A parent's strict guidance need not necessarily entail a child's lack of self-expression, creativity, or enjoyment" ( $3^{\text {rd }}$ interview, May 28, 2013). 
Joan identifies the concept of a golden mean (zhongyong) as being the key to her building a happy second life for herself in the United States with her family. Joan thinks her son's American teachers would benefit from learning about the Chinese approach to education, and believes that all parties to music education - the child, the parent, and the teacher-will benefit from combining the best practices of the Chinese and American models. She explained:

Zhongyong is a traditional Confucius concept that I use to guide my second life here. I'm interested in learning more about American concepts and approaches to education and combining them with the Chinese approaches that shaped my own childhood. I hope my son's American music teachers will likewise be willing to make the necessary effort to understand their Chinese students' families' cultural values and traditions. $\left(3^{\text {rd }}\right.$ interview, May 28, 2013)

\section{George}

George arrived at my office at 3:00 p.m. sharp, attired every bit as smartly as he was punctual. When I offered him coffee, he explained that he not only does not drink it but has never even tried it, despite having lived in the United States for ten years. So instead, we had some tea and began the interview by discussing our shared fondness for the beverage. A tea aficionado, George told me that he maintains a broad selection of teas and invites friends to enjoy afternoon tea at his home on weekends. George's hobbies include jogging, biking, and fishing, as well as spending time outdoors with his two sons-ages 3 and 7. George earned his doctorate in education in the United States and is currently the director of an early childhood program located in Chinatown, Philadelphia. My immediate impression of George was that he was a very introspective person, a conclusion that would only be reinforced by the remainder of my interview. Although, like many Chinese immigrants, George's thinking has become more 
liberal or Westernized since coming to America, his capacity for reflection made him unusually self-aware of the changes he underwent.

Life experiences. George, the youngest of three children, grew up in a rural area of China. From a family of rather limited means, George's father was a teacher and his mother was a housewife. George would learn that his mother's pregnancy with him was unplanned and that she had gone so far as to attempt, unsuccessfully, to abort the pregnancy. George joked that, "as the Chinese saying goes, "if a catastrophe does not kill you, good fortune will follow" ( $1^{\text {st }}$ interview, May 19, 2013). The first of his family to attend college, George returned to his hometown after graduation and worked as a public school teacher for three years before enrolling in graduate school.

Inspired by English literature and American movies, George developed a deep interest in the English language and recalls waking up at 6:00 a.m. just to recite Shakespeare and entries from an English dictionary. "I have an amazing memory," George says, smiling. "I memorized exact definitions, and I may well have memorized the whole dictionary" $\left(1^{\text {st }}\right.$ interview, May 19 , 2013). George also describes how he would repeatedly watch English-language movies and imitate their dialogue, believing that to learn a language one must learn how to think and behave in the manner of native speakers.

Although George enjoyed and was appreciative of music as a child, one of his most vivid memories was of an incident in which his affection for music provoked his father to anger. George recounts how late one night during final exams, he wanted to work off some tension by playing the $e r h u$, the only musical instrument in his home. Unfortunately his playing woke up his parents. George's father became so angry at having been awakened that he smashed the instrument. George's father later apologized for the outburst, explaining that, in addition to being 
awakened by the music, he was worried that his son's playing would distract him from studying for his exams.

George had no opportunities to study music beyond the meager offerings at his school. He recounts:

Because my dad took a new job in Beijing, my family moved from a small town to the capital. I could not describe how happy I was at such a change, until one day at school. In my third year music class, my teacher asked me to go to the blackboard to perform sightsinging. I had never studied sight-singing, so I just stood there not knowing what to do. My teacher probably thought it was shameful that a student in the capital did not know how to read a musical score, so he kicked me! I felt so hurt, and it took me a long time to get over it. Fortunately, later incidents restored my confidence. Sometime after the kicking affair, at our Chinese New Year celebration, all my classmates recommended me to sing a solo, which I eventually did. I was a huge success, and my performance was considered the best in my class, and the teacher actually asked me to sing twice. I started to smile again and regained my love of music. Even today when I think of that kicking, I can still feel the hurt. For a long time, I did not even talk to my dad about it, but ultimately I was able to forgive the teacher and eventually pursue my music dream again. $\left(1^{\text {st }}\right.$ interview, May 19,2013$)$

Having recovered his love of music, George explains that he proceeded to enter singing competitions throughout his youth and young adulthood, and even formed a band when he was in college.

Cultural beliefs. George acknowledges that music education in China for young children as well as adults has been undergoing significant curricular reform for more than ten years. 
Nevertheless, he believes that the tendency to control children's musical interests persists to the detriment of personal expression and fulfillment. George reflects that "my own interest in music survived mainly because I never really received much formal music education" $\left(1^{\text {st }}\right.$ interview, May 19, 2013). George further laments:

The Chinese model presently over-emphasizes professional musical skills and discipline, turning music classes into strict training sessions. And in turn, they subvert the happiness and self-expression that music brings by turning the study of music into yet another form of rigid and repressive discipline. I am worried by stories that this is still happening, despite changes to the curriculum. Just like that kick I received, excessive structure and authority will eventually cause students to lose faith in music. $\left(1^{\text {st }}\right.$ interview, May 19 , 2013)

George acknowledges that, as in any art, skills are important. Yet, the experience of music as expressed in a child's musical interests and emotional health and happiness is more important than and more readily obtainable than technical mastery. George believes that discipline is better maintained by insuring the quality of a music program, by a teacher's charisma, and by the beauty of music itself than by threats, coercion, or authority.

George's expectations for his sons. George does not think it would be appropriate to dictate or meddle in his children's career paths. Rather, he believes that one of the best advantages he can provide his sons is to allow them to learn to make their own choices and pursue what interests them most:

For a little kid the most precious thing is his childhood. The experience of childhood is much more than the sum of the specific things he learns. You're only a child once, and once it's passed, you never have a second chance at it. In my case, I never developed any 
special talent as a child, and yet I turned out fine. I often tell my son that it is not necessary to compare yourself with your classmates. In fact, since it seems that so many kids these days are trying to specialize in a specific talent, special talents themselves become common and ordinary. To abstain from specialized, single-minded pursuits and to just be a happy, carefree, well-rounded kid is the exception today; that's what's special. Some of my Chinese friends may not agree with me. A lot of Chinese believe that children need to attain every competitive advantage possible for later in life, and they live by the saying, "You can not let your kids start at the starting line." This might be convincing to some parents, but to me, when there are thousands of kids on the same starting line all running in the same direction in competition with each other, most of them are predestined to lose. The only way to prevent this kind of almost inevitable failure is never to compete under such conditions in the first place. Today, there are many children studying music, and if you ask their parents why they want their children to study music, the most common response is that "other children are doing it, so my child has to do it too." How can a parent expect to nurture a child's individuality and help them discover his or her true interests if he's just "keeping up with the Joneses" vicariously through his children? ( $2^{\text {nd }}$ interview, May 27,2013$)$

George observes that just as he abstains from urging his younger son to pursue a career in music, he does not expect that his son will elect to pursue a career in it. George states that, "my wife and I hope that music will be one of his hobbies and can accompany him through life and help him live happily. We do not expect that he will become famous with music, but we will be satisfied just so long as he pursues what brings him joy, which is the best gift that a parent can give to a child" ( $2^{\text {nd }}$ interview, May 27, 2013). 
The role of music. George's understanding of the purpose of music in a child's life was influenced by his own painful formative experiences in the classroom as a child. For him, music should be studied without pressure or competition and serve primarily as a source of selfexpression and happiness. He noted:

Music education can contribute to every child's happiness. Music is meant to be enjoyed. The early childhood music education from my youth emphasized many things other than music itself. It turned music into a purely technical, specialized skill, devoid of beauty and creativity. I've always dreaded the thought that other children would have to go through what I did in my music class. I wish that every child could enjoy music for themselves, without competing with other children. ( $3^{\text {rd }}$ interview, June 2, 2013) George believes that music is important in the formation of the whole person. As an important source of beauty, music helps children develop good aesthetic sensibilities and emotional intelligence. He also believes that music aids in the formation of personal morality. George observes that music facilitates communication between people of all ages and backgrounds, and functions as a sort of "world language" that transcends linguistic and cultural divisions. George reasons that although a person living in Beijing may not know German, she can still respond to the emotions of German music. George is especially fond of the fact that the United States, a country of immigrants, maintains cultural cohesion through the blending and fusion of its constituent peoples' musics.

Finally, George explains that music has a spiritual dimension that purifies the heart, lifts the spirit, and nurtures a health personality. George sees music as essential to maintaining a positive attitude in life. 
The role of parents. George has devoted a considerable amount of thought to his philosophy of parenting, and explains:

In the traditional Chinese view, parents view their kids almost as possessions or property and are thus unable to show their children the same respect that they would show another adult. I believe this stunts the development of an independent personality in a child. In my home, though I cannot claim to be an expert, I try to create a democratic and equal relationship with my child based on mutual respect. For instance, whenever I email my wife, I will always include a few words for my son. I also ask my son to write back in order to nurture my communication with him. ( $2^{\text {nd }}$ interview, May 27, 2013)

George believes that parents should be as supportive as possible of their child's individual interests, including the study of music. George acknowledges that "it costs a lot to study music, and it requires a lot of parents' time and effort to support. But I support my child unconditionally. Even if it became a financial burden, we would still support him" $\left(2^{\text {nd }}\right.$ interview, May 27, 2013).

Despite his career as a professional educator, George regards a child's parents as the child's primary and most essential teachers. George stresses:

In my own teaching I educate parents because I believe parents are the first teachers of their children. They spend the most time with their kids, as well as the most important time. A parent's every word and action subconsciously influences the development of their children, so parents need to be as mindful about what they say and do as what they do not say. If parents create a nurturing musical environment at home, it will help with the child's healthy development. Therefore, parents are the foundation of a successful childhood music education. $\left(2^{\text {nd }}\right.$ interview, May 27, 2013) 
Although his own children are still young, George considers the changing roles that parents play at various ages and stages of their children's maturation. As he explains:

Parenting approaches must adapt to different stages of development, as a child matures. When children are young, parents take a more hands-on approach and focus on a child's acquisition of basic knowledge. But as their children grow older, parents should gradually loosen their grips and assume the role of facilitators and equal partners, encouraging open dialogue and exchange of ideas. ( $2^{\text {nd }}$ interview, May 27, 2013)

The acculturation experience. George confesses that his educational and parenting philosophies have undergone radical changes as a result of his residing in the United States for ten years.

In terms of his outlook on music education, George reflects that he no longer sees the acquisition of skills as paramount to learning or understanding music. Rather, George regards the cultivation of a child's personal interests and self-expression as the key to teaching music effectively. For George, a good early childhood music education program is merely an environment in which an individual child's creativity is engaged and fostered:

If a child who studies music has no passion for it, how can he possibly be devoted to its study? I remember when I was in college that we often had nothing to do and felt bored because we lacked passion for what we studied. In comparison to American college students, college students in China have less autonomy in choosing universities and majors, and their lack of choice and personal initiative is reflected in their listlessness. So, it is my belief that only if we nurture the passion in a child's heart can music work its magic throughout his life. As a parent and an educator, I've learned a lot, and I've largely been educated by my own children and by my students. I constantly reflect on my 
teaching, teaching methods, and parenting style. My sons and my students teach me how to fully respect their individuality in the choices that I make as a teacher and father. $\left(3^{\text {rd }}\right.$ interview, June 2, 2013)

George concluded my interview by suggesting that early childhood music educators in the United States should be sensitive in the way they interact with their students and their families, noting that many students come from very diverse cultural backgrounds, and these students' families often have very different expectations for their children and their children's teachers. A teacher can do a vastly better job of reaching a child as an individual learner if she better understands the cultural background of her students and fosters a diverse, yet inclusive, community of learners.

\section{Victoria}

Victoria greeted me at the door with a graceful smile and showed me around her house, appointed and furnished mainly in European style but with Chinese accents. Her home environment evinces an unmistakable thoughtfulness, consistency, and attention to aesthetic detail. We sat on a wide, comfortable couch and drank English tea as jazz played quietly in the background. Victoria had a gentle and friendly voice, and we established a rapport even before we discussed her experiences with music education at any length.

Life experiences. Victoria had a great deal to say about her musical journey, which she describes as "colorful and full of musical activities" ( 1 st interview, June 6,2013$)$. When she was only five years old, Victoria recalls spending a summer with her aunt and savoring her aunt's neighbor's piano playing: “After dinner every night the beautiful sound of piano playing emerged from the apartment upstairs, and I used to sit in the backyard of the apartment and just 
listen to it. Listening to this music under the evening stars is one of my fondest memories" $\left(1^{\text {st }}\right.$ interview, June 6, 2013).

Inspired by her love of the music, Victoria begged her parents to buy her a piano as soon as she returned from her aunt's home. Even as a child Victoria knew that a piano would be a significant expenditure for her family, and she resigned herself to the possibility that her family simply might not be able to afford it. Yet, she vividly remembers:

One night, I was awakened by my parents at my bedside. In excited whispers they kept asking me, 'Guess what we got for you?' as they led me outside to the stairwell of the apartment building. A huge box was stuck in the stairwell, and it was so big I realized that it could be only one thing: a piano! Despite my family's excitement, we could not actually get it into our apartment until the following day, and it took eight people to move it. $\left(1^{\text {st }}\right.$ interview, June 6,2013$)$

Victoria had three piano teachers during her childhood, and although they had different instructional approaches, she remembers them all with equal fondness and reverence. Her first teacher, Ms. Ji, was the music teacher from her elementary school. Victoria recollects: "Ms. Ji was very nice. She was an elegant lady with a gentle disposition, and I wanted to be just like her when I grew up" ( $1^{\text {st }}$ interview, June 6, 2013). Victoria learned rapidly under Ms. Ji's tutelage, so rapidly in fact that, after only six months Ms. Ji recommended to Victoria's mother that Victoria receive more advanced and rigorous training under Ji's own former piano teacher.

Victoria's second piano teacher was, as Ji recommended, a more advanced but no less gentle teacher. He also had a daughter who was Victoria's age, and the two of them often practiced together and became fast friends over their shared love of the piano. Their friendship motivated and drove them to practice and explore the piano in a manner unlike any piano lesson 
with an adult authority figure. After two years of instruction, however, Victoria's rapid acquisition of skills eventually led her to outgrow her second teacher, just as she had previously outgrown Ms. Ji. She was referred to an even more advanced teacher-Mr. Chan—who was renowned both for his strictness and for the high achievement of his students.

Victoria recalls that although Mr. Chan had a kind face his teaching style was exceedingly strict. Chan's reputation preceded him among children and parents as having often reduced children to tears with his disciplined teaching regimen. Naturally, Victoria recalls that she was very nervous to meet him and, true to his reputation, he assigned and demanded that she complete many homework assignments despite knowing that Victoria had many other responsibilities in addition to her piano studies. Victoria notes that of all the teachers she's ever had, Mr. Chan's expectations were the highest. Utterly uncompromising, Chan would not pass Victoria if her performance did not meet his exacting standards, and he would often make her redo assignments. Victoria acknowledges that despite her aptitude for music, she had to practice very hard to keep up with Chan's instruction. As an adult, she appreciates and admires his commitment to excellence, noting that she won many piano competitions as a child, which she attributes to her teacher's zeal.

All throughout her years of private lessons, Victoria warmly remembers that her music classes at school were full of fun: "We sang, we danced, and we played instruments. I always felt like I was one of the teacher's favorite students. I was very active in class and always raised my hand when the teacher asked a student to play an instrument, such as a cymbal, shaker, or triangle" $\left(1^{\text {st }}\right.$ interview, June 6, 2013).

Victoria was also selected for the school's highly-selective dance troupe, recalling that "[her] dance troupe even appeared on national television, and my parents were very proud when 
other parents would say that they saw me on TV — the kid in the middle with the big smile" $\left(1^{\text {st }}\right.$ interview, June 6, 2013).

Victoria's parents' involvement. Victoria's parents are both music enthusiasts, and although neither of them had any formal training, Victoria's mother's singing and dancing colors almost all of her memories of her home. Victoria also remembers that while many of her classmates' parents discouraged them from listening to music because they feared that music would distract them from their studies, her father supported her in purchasing audio cassettes of her favorite music. Because of her father's indulgence of her interest in music Victoria possessed the best, if not the only, Chinese pop music collection and became very popular among her peers. Victoria describes her father as "a tiger" with strict parenting but describes her mom as a fun and loving person. "Whenever my father tried to punish me for something I did wrong, my mother always stood behind me. I do not know how many times she saved me from getting hit by my father. I do not recall my mom ever getting angry at me at all" ( $1^{\text {st }}$ interview, June 6,2013$)$.

Victoria’s parents were highly involved in her early childhood music education: “My father has fine taste in music, and although he did not play himself, he was never shy about advising me as to the quality of my playing" (1 $1^{\text {st }}$ interview, June 6,2013$)$. Victoria's parents made music a priority in her life and arranged for her to devote as much time as possible to practicing piano. For instance, they would listen to her while she played piano at noon while most people were usually taking naps. "My dad listened to my playing after lunch, either sitting next to me or lying down on the couch. If I saw him starting to fall asleep, I would try to take a break from playing. But the funny thing is that, as soon as I did, he would be awake again," Victoria said it with an amazed look on her face, "My dad joked that he had a special talent" $\left(1^{\text {st }}\right.$ interview, June 6, 2013). 
Victoria further describes her parents' devotion to her music education:

I grew up in a small town where piano resources were very limited, but my father would always go searching for new piano scripts or recordings for me whenever he had a chance to go to a big city. And even though my third piano teacher lived in a city very distant from mine - two hours and half, one way, by car-my mom rode the bus with me to take piano lessons. Every weekend. Without fail. My dad once even drove nine hours just to take me to a piano competition in a neighboring province. $\left(1^{\text {st }}\right.$ interview, June 6,2013$)$ Victoria felt a bit overwhelmed by her parents' involvement in her childhood, especially because of her father's strictness. Not until she became a parent herself did she fully appreciate her parents' devotion and love.

Victoria's parents' expectations for her. Victoria explained to me that, although as a child she had assumed that her parents wanted her to become a professional pianist, she never actually understood what her parents' expectations concerning her music education were until she asked them about it directly, as an adult. As a child, Victoria concedes that, "my communication with my parents was limited. I just did what they asked me to do" $\left(1^{\text {st }}\right.$ interview, June 6, 2013). However, as an adult, Victoria learned from her parents that their motives in having her study music were premised on the simple hope that she would experience joy from music and develop the persistence and self-discipline that are essential to developing a strong work ethic.

Cultural beliefs. Throughout her life, Victoria has cultivated a special and sophisticated appreciation for Chinese musical culture and its long, varied history. Victoria notes that Chinese musical culture is as old as civilization itself, noting that the origins of the Chuzi-a romantic, colorful musical composition from China's Spring and Autumn Period — dates back to between 
770-476 B.C.E., whereas the lovely composition "Peacock Flying Southeast" can be traced to the Han Dynasty and thus was composed between 202 B.C.E. and 220 C.E.

Victoria explains that Chinese music is the product of an interplay and fusion between China's varied, ethnic musical traditions. Specifically, she observes that China has fifty-six ethnic groups, and each group has its own distinctive musical styles and features. The exchanges among ethnic group musical styles and signatures propelled the evolution of Chinese music. For example, Victoria recalls that:

In my music class alone we studied the Peacock dance, the cucurbit flute music from the Dai ethnic group, folksongs from the Tujia ethnic group from West Hunan, and bamboo instruments from the Li ethnic groups of the Hainan Province. Each of these musical traditions is very distinctive and so beautiful in its own right. What a person might broadly call the "Chinese musical tradition" is incredibly dynamic in its constituent traditions. $\left(1^{\text {st }}\right.$ interview, June 6,2013$)$

Victoria observes that music is as old as humanity itself, and that people have pondered the philosophical nature and purpose of music for ages. In Chinese thought and history, Victoria stresses that there are two main yet contrasting philosophies of music, one of which is derived from Confucianism and the other from the philosopher Mozi. Victoria explains:

Confucius emphasized the moral value of music. In the Analects he said that "a child's education starts with poetry, is built upon rites, and is completed in music" (Xing yu shi, li yu li, cheng yи yиe). Confucian rites, which were the backbone of society, were inseparable from music. Thus music had a political value and became associated with governance. Confucius also placed a very high value on the role that music plays in the formation of a person's character. Confucius was himself a skilled musician. The story is 
told that once, when Confucius was in Qi, he heard Shao music and for three months did not recognize the taste of meat. He said that he did not know that music could be so sublime. Mozi, on the contrary, was quite critical of the role that Confucius attributed to music. In his Feiyue [Against Music], he criticized the role of music in statecraft, which he thought was wasteful. Rulers, he charged, squandered their resources on music and neglected the welfare of the people. Therefore he proposed banning music. $\left(1^{\text {st }}\right.$ interview, June 6, 2013)

Although music still plays an important role in society, analogous to if not the same as the public role that was so important to Confucius and which was so harshly criticized by Mozi, Victoria thinks that it is nevertheless Confucius's emphasis on the enjoyment and moral value of music that best captures the positive role that music continues to have in Chinese life today.

Victoria's expectations for her daughter. Victoria misunderstood her parents' expectations for a long time. She thought they wanted her to become a professional pianist. Later she realized that although their parenting styles are different from hers, she and her parents have the same expectations for their children. Victoria expects her child to enjoy music and enrich her life through music. She believes that music should be an important part of everyone's life: Without music, life itself would be a mistake. I want my child to experience music as early as possible and as diversely as possible. I want my child to be exposed to music from all over the world, including Chinese traditional and folk music, of course. Music is culture, and it provides the best means to experience and learn about a culture. Most particularly, I hope that, through music, my child will be able to learn about and connect with her Chinese heritage. ( $2^{\text {nd }}$ interview, June 12,2013 ) 
The role of music. Victoria considers the prevalent Chinese understanding of music to be best expressed in the saying yue zhe le ye, which she interprets as "the role of music is to relax our tired bodies, entertain and make us happy, and lift our spirits.” Beyond this therapeutic function of music, Victoria maintains that music is important in helping a child become a wellrounded and cultured person: "A society expresses itself most directly and profoundly through its music. Through music education, my can child experience the best or truest expressions of a culture's values and can discover the spirit behind them" ( $3{ }^{\text {rd }}$ interview, June 18, 2013).

Victoria considers music to be a language of emotional expression, which she has relied upon in establishing an emotional connection with her child: "Starting when my child was only two years old, I would play music on my piano or sing songs to her, and I remember how she would either imitate me or respond to the music she heard in her own way. We bonded so closely in this way, more than I ever could have through spoken language" $\left(2^{\text {nd }}\right.$ interview, June 12 , 2013).

Victoria reflects that, despite her years of musical training and accomplishments, her thoughts on music are no more sophisticated or profound than those of her parents. With respect to the role of music and what she hopes her daughter will attain through its study: "Music nurtures the whole person. It purifies one's heart and strengthens one's character. I want for my daughter what my father wanted for his" ( $3^{\text {rd }}$ interview, June 18,2013$)$.

The role of parents. Victoria is deeply involved in her child's music education and actively seeks out and provides musical experiences for her child both at home and through early childhood music programs:

When my girl was only several months old, I discovered a music class for babies. It was the greatest fun that I had with my baby. She crawled everywhere, accompanied by 
beautiful music, while I interacted with her though movements and facial expressions. As she matured, I enrolled her in a series of music classes for different ages or developmental groups. As a mother, I see it as my responsibility to provide her with rich and varied musical experiences. $\left(2^{\text {nd }}\right.$ interview, June 12,2013$)$

Victoria acknowledges that although it is too early to think about a musical career for her daughter, she intends to provide the necessary guidance in accordance with her daughter's interests and abilities:

I would not force her into a field that she does not like, but if she develops an interest in music, I think it would be my responsibility to make sure that she sticks with it. Kids' interests are fickle. It is up to a parent to help a child stay on task and develop motivation and persistence, although I do not think it is wise to force a child to do anything. Before committing to any particular activity or instrument, I will make sure that my daughter is exposed to a wide variety of choices, so that she can choose something that she's passionate about. $\left(2^{\text {nd }}\right.$ interview, June 12, 2013)

The acculturation experience. Victoria has experienced the educational systems of both China and the United States. The biggest difference she experienced after coming to the United States was the attention to the developmental psychology of young children. "I was amazed by teachers' approaches in the different levels of music classes that I took with my child. I wish I had had the chance to experience that with my parents as well. Even a small age difference required a different type of parental involvement" $\left(3^{\text {rd }}\right.$ interview, June 18,2013$)$.

Victoria also reflects that the American model of education has made her more sensitive to and more tolerant of her child's behavior, noting that Chinese parents are generally less indulgent of their children: "I realize that kids develop at their own pace, so I should not expect 
her just to comply with my wants in terms of her behavior. Guan needs to leave space for a child's own choices, aptitudes, and predilections" ( $3^{\text {rd }}$ interview, June 18, 2013).

Another change Victoria experienced is that she became more tolerant of her child's behavior. "I realize that kids develop at their own pace, so I should not expect her always to follow my every lead. Guan needs to leave space for a child's own choices" $\left(3{ }^{\text {rd }}\right.$ interview, June $18,2013)$.

Victoria wants American teachers to know more about Chinese American parents’ cultural traditions. "Tiger moms" are still a common phenomenon. While this approach may be somewhat shocking to American teachers, in the context of Chinese culture it has its advantages and has proven effective. This is what is behind the status of the Chinese as a "model minority." Many Chinese immigrants are middle class with advanced education; they are high achievers. Rather than simply reject the "tiger mom" approach as a whole, Victoria thinks that American teachers should try to find aspects of it that they can incorporate into their own teaching.

\section{Luke}

Luke, a native-born Chinese man in his mid-thirties who has a five-year-old daughter, is currently employed as an attorney at a Philadelphia-area law firm. Luke arrived at my office punctually for our first interview, wearing the starched dress shirt and tie that function as the unofficial uniform of his trade. Succinct and direct in his speech, it was easy to conclude that he chose a career to which he is well-suited by disposition.

In our subsequent home interviews, however, Luke revealed a more colorful and casual aspect, both in his demeanor and his attire. His household environment was lively and always animated by jazz music playing on the radio. An aficionado, Luke showed me his extensive collection of jazz albums and CDs, and identified listening to live jazz as his favorite leisure 
activity. In addition, Luke's home is stocked with sufficient musical instruments to equip a band: two pianos - a red antique and a more modern brown upright, a drum set, and a saxophone. Luke explained that he spends a lot of time making art at his home: singing and playing instruments as well as drawing and painting in his leisure time. Upon request, he enthusiastically picked up his saxophone and improvised a short jazz piece that flowed with emotion.

Life experiences. In light of his passion for and collection of music, Luke's formal musical training was very limited, surprisingly. He recounts that his childhood music class was so boring that he rarely troubled to pay the faintest attention. Luke describes his school-aged self as a poor student and a troublemaker:

I disliked all those classroom rules, such as sitting straight and keeping your hands behind your back for the duration of a 50-minute music class. I could never keep that posture for more than a couple minutes. I remember one time that my music teacher refused to continue teaching the class unless I agreed to leave the room. $\left(1^{\text {st }}\right.$ interview, June 21, 2013)

Uninspired by school, Luke's interest in music was eventually aroused by three Chinese opera troupes that were located near his parents' home. Luke's parents were good friends of some of the opera performers, and they often received free tickets to the shows. Luke remembers that he was always thrilled to accompany his parents to those opera performances and, to this day, affectionately refers to the performers as his "teachers." In particular, Luke recalls that one of the opera performers had a daughter who was very talented at playing the pipa, a Chinese stringed instrument. He joked that he had a crush on her and, by a process of association, he developed an affection for and attraction to music. Later in his childhood, Luke occasionally studied piano 
with a friend who later became a musician. His informal yet friendly musical experiences initiated his interest in music.

Luke's parents' involvement. Luke's mother is an amateur musician who learned singing from the opera troupes near their family home. In addition to music, Luke's mother expresses herself through dance and taught others to do so professionally. In terms of her involvement in Luke's childhood with respect to music, Luke recollects:

My mom tried to teach me lots of 'red songs' and dances from the Cultural Revolution, but they always seemed a little bit boring to me, and I had no motivation to learn them. So, I guess my mom concluded that I lacked musical talent and just gave up on it. Maybe she figured I was more like my father, an engineer, who had no musical talent to speak of and could not possibly care less about my music education. Although my mom did not force me to learn music, I think I was indelibly influenced by her enthusiasm for music. Even today, my mom participates in musical events in her community, and when I go home she still likes to drag me along. Old habits die hard, I suppose. ( $1^{\text {st }}$ interview, June 21, 2013)

Luke's parents' expectations for him. Despite the fact that his mother was an ardent music enthusiast, Luke acknowledges that his parents never had any specific goals for him in terms of music education except that it entertain him and make him happy. Luke suspects that their lack of ambition for him and their simplistic attitude toward his musical experiences was influenced by the conditions of their upbringing:

When my parents were young, life in China was much more difficult and the resources for entertainment were similarly limited. The only songs to sing back then were limited to 'red songs.' I believe those songs, despite their shortcomings, provided joy and a sense of 
spiritual elevation for my parents' generation - for the people who lived through those very harsh and austere conditions. ( $1^{\text {st }}$ interview, June 21,2013$)$

Cultural beliefs. Luke asserts that he is proud that China has had a rich tradition of music that spans millennia. Luke has a special regard for traditional Chinese folk music, which he simply categorizes as "just good music." When pressed, Luke elaborates that "just good music" refers to simple and beautiful songs that resonate in the soul and touch one's deepest emotions: Traditional Chinese instrumental music is beautiful and it touches my soul. When you think about it, I'm amazed at how many different instruments we have, and how unique their sounds are. The dizi [lute], zheng [zither], pipa [a stringed instrument], suo na [trumpet] - I've learned that these, as well as any Chinese instrument, can be categorized into seven groups based on the material that they are made of: gold, stone, earth, silk, wood, bamboo, or leather. Further, they can be divided into four categories according to how they are played: whether they are blown, pulled, plucked, or sung. In traditional Chinese daily life, ensemble instrumental music is used mostly for folk customs and religious rites, but solo instrumental music is played mostly on the guqin [ancient zither], pipa, or xiao[pipe] by the literati, or improvised on suo $n a$ and dizi by folk musicians. ( $1^{\text {st }}$ interview, June 21, 2013)

In contrast to his notion of "good music," Luke allows that there is also such a thing as "bad music" in China, although he qualifies that it is not as common as "good music." Luke defines "bad music" with the example of music created for ignoble political reasons: "Music created during the Cultural Revolution was used purely for political reasons. It was composed for the sole purpose to aggrandize the government through 'singing and praise' (ge song). Its musicality was cheap and soulless" $\left(1^{\text {st }}\right.$ interview, June 21,2013$)$. 
Luke observes that Western music is infinitely more interesting to him compared to "red songs" from the Cultural Revolution because it expresses feelings in an intimate, personal, and direct manner: "For example, rock and roll directly expresses the rebellion, the anger and lust that animates every human heart. Jazz can transport me to another world, in every variety of human emotion" ( $1^{\text {st }}$ interview, June 21, 2013).

Luke explains that in China, professional musicians have been relegated to low social status since ancient times, noting that musicians in the Imperial Palace ranked at the very bottom of the social hierarchy. Luke concludes that to the Chinese, because music is predominantly considered to be a frivolous form of entertainment or diversion, it is not listed as a core subject at school.

Luke's expectations for his daughter. Luke states that he finds joy in "making music" with his child, and he expects to expose his daughter to diverse varieties of music and related experiences, noting, "I listen to all kinds of music, and whatever I listen to, my daughter listens to" ( $2^{\text {nd }}$ interview, June 26,2013$)$. Luke also believes in the importance of introducing his child to music education as early as possible in order to accelerate the development of her aesthetic sensibilities and to facilitate her experience of the happiness that music brings: "Music is beautiful, and I want my child to know this beauty as early as possible. I expect my daughter to be able to understand, appreciate, and create beautiful music. I spend most of my Saturday mornings playing music, and my child plays alongside me. We have fun together, and we bond through music in ways that no other activity seems to afford" ( $2^{\text {nd }}$ interview, June 26,2013$)$.

Luke expects his daughter to learn to play multiple instruments, including piano (which Luke regards as a foundation for learning music), 'cello, and Chinese instruments such as the dizi and the zheng. He jests that although he loves the violin, he "would never pressure [his] daughter 
to play violin, for fear of what a strong jaw would do to her beautiful face" $\left(2^{\text {nd }}\right.$ interview, June 26, 2013).

The role of music. Luke thinks the primary roles of music in children's lives are to show them beauty and to bring happiness, but he perceives differences between how music is studied and consumed in China and in the United States. Because of the fiercely competitive nature in the school system, Luke states that "children are under extreme pressure to distinguish themselves beyond their grades or exam results by mastering specialized skills such as playing an instrument" ( $3^{\text {rd }}$ interview, June 29,2013$)$. As a consequence, Luke reasons that "the true purpose or value of music is lost or de-emphasized. Joy, self-expression, and the experience of emotional truth are supplanted by technical mastery and ruthless competition" $\left(3{ }^{\text {rd }}\right.$ interview, June 29, 2013). Luke also laments that, "as an object of study, music is often subordinated to subjects such as math and science" ( $3^{\text {rd }}$ interview, June 29, 2013). Although Luke appreciates the value of math and science, he observes that the soul needs beauty as much as or more than it needs technological progress.

Luke sees the people of the United States, in contrast to the people of China, as having a more authentic interest and relationship with music, both in general and among those who play music. Luke regards Americans as being more attuned to the emotional content of music and less distracted by the trappings of competition and social status.

The acculturation experience. Luke thinks that he acculturated smoothly to America and has not faced many obstacles concerning the differences between his native and adopted cultures. He credits his parents' liberal parenting style and his personal love of American poetry, literature, and music for his easy transition: 
My parents are very liberal, and I grew up in a very liberal environment. However, China's political environment and limited resources limited my musical development as a child. For instance, I did not really like the "red songs" that were always so popular in China, and they never motivated my appetite for music education. Since moving to America, however, I've had access to a diversity of musical cultures and have been able to make friends through music from all over the world. I feel the freedom to indulge myself in the 'good music' that I so love. I've been spending much more time making music on my own and with my daughter than my parents did with me in China. Since music is perhaps the most meaningful expression of any culture, listening to that culture's music is the best way to come to understand it. My deep love of American poetry, novels, and music accelerated my acculturation experience, and I do not feel much of a conflict between my Chinese heritage and my new American identity, because I speak the language of American music. ( $3^{\text {rd }}$ interview, June 29, 2013)

Just as Luke reaped the benefits of smooth acculturation in the United States by enjoying American music, he reasons that American educators can similarly benefit from developing an appreciation for Chinese traditional musical culture. He explains:

I want American music teachers to incorporate Chinese traditional music into their music classes. Music serves as a bridge between cultures, and it can likewise help bridge the divide between American teachers and the Chinese families they work with. By learning Chinese music, American early childhood music teachers will better know Chinese culture and, thus, develop more successful and meaningful partnerships with Chinese families. Everybody wins. ( $3^{\text {rd }}$ interview, June 29, 2013) 


\section{CHAPTER FIVE}

\section{THEMES}

As is evident from the portraits in the previous chapter, for these Chinese American parents, education begins at home. In explaining their role as parents, the participants frequently made reference to the Chinese concept of guan, or "training." The first theme discussed in this chapter is parenting as guan, the distinctive Chinese approach to parenting deeply rooted in Chinese tradition going back at least as far as Confucius.

The participants also made clear that their role as parents in their child's education extends beyond their direct involvement through guan. It includes a strong commitment to and full investment in their child's lifelong education outside the home. The premium placed on education is the second theme to emerge, which, too, is an essential Confucian value, as several of the participants explicitly acknowledged.

The third theme that emerged from the interviews is music itself and the way it functions in participants' lives. How one teaches a child about music is dependent on how music should function in that child's life. The participants talked about the functions of music in fairly familiar terms: as a means for emotional expression, as a form of creative self-expression, and as just plain fun and enjoyment.

The fourth theme, namely the value of a music education, was woven throughout much of what the participants had to say. Parents shared their views on two aspects. First and most important was their endorsement of the traditional understanding of music education as a means of moral cultivation. Second was their recognition of the value of music education as a marker of social status. This final theme lies at the heart of this study and is particularly important for 
understanding the values that inform parents' expectations for their young children's early childhood music education.

These four themes together capture the essential elements needed for understanding the ways in which these Chinese American parents navigate the interplay between Chinese tradition and early childhood music education in the United States.

\section{Chinese parenting as guan}

Studies have consistently revealed striking differences between Chinese parenting and mainstream parenting in the United States. Since Chao's use of the term guan to critique earlier notions of Chinese parenting as "authoritarian" (Chao, 1994), this distinctively Chinese concept of guan has been used increasingly to frame the discussion about Chinese parenting. This new perspective has revealed the multi-faceted nature of Chinese parenting involving a constellation of priorities that Western researchers have categorized with such terms as control, authority, respect, and obedience on the one hand, and as parental involvement, concern, care, warmth, and love on the other (Chao, 1995; Cheung \& McBride-Chang, 2008; Gorman, 1998; Stewart, et al., 1998; Stewart, et al., 2002).

Both Chao (1994) and Stewart, et al. (2002) have connected this Chinese concept of guan with Chinese traditional culture, and with Confucianism in particular. Traditional Chinese parenting is derived to a great extent from Confucian philosophy that has been transmitted over generations. Although Americans are often shocked by the controlling aspect of guan, presented dramatically in Amy Chua's Battle Hymn of the Tiger Mom, Chinese American parents see guan as involving more than simple strictness and consider it as a way of showing their love, warmth, and care for their child. The Confucian concept of guan for several thousand years has provided 
the Chinese with an understanding of parenting that combines strict childrearing with care and parental warmth (Stewart, et al., 2002).

The diverse stories of the Chinese American parents in this study illustrate the richness of this concept of guan. The participants frequently used the term when describing parenting as both strict and loving. They often told stories that illustrated the following aspects of guan: as authority, as a form of mutual respect, as high parental involvement, and parents as role models. Although these aspects of guan are not well represented in the literature on Chinese parenting, they are present in literature on Confucian values. These four aspects of guan are now discussed in the following sections.

Guan as authority. One clear aspect of the concept of guan exemplified by the participants in this study is the element of authority. Researchers have also recognized this aspect of guan, which they have discussed in terms of authority, respect, and obedience (Chao, 1995; Gorman, 1998; Ho, 1976; Ho, 1989; Stewart, et al., 2002). Issues of authority, respect, and obedience frequently appeared in the participants' experiences with their own parents and with their children. For example, Jean's eight-year commitment to her parents is a perfect example of a child showing respect and obedience to her parents as the central authority in her young life. As she described it as not submission but respect. Jean also expects that her son will practice the same committed respect to her by following her guidance, training, and discipline. She readily admits that she would deny her son's wishes or override his preferences if they contradicted her assessments of what is best for him.

Regarding the governing and controlling aspects of guan, Jean confides that she fully expects her son to cry occasionally in front of her while practicing piano because it is neither fun nor easy for a child to focus so single-mindedly on a task for many years. She repeatedly claimed 
that her son does not learn much at school and has too much fun there. Jean explained that any child, left to his or her own devices, would prefer fun and games to long hours of practicing. Yet ultimately, she believes that a childhood devoted to the satisfaction of childish wants will not produce a fulfilled and happy adult. Jean laments that American parents allow their children too much autonomy and too much decision-making authority too early. She believes that only a mature young person can be entrusted with the freedom to choose for herself. She emphasizes the stricter aspect of guan and is exceedingly cautious not to indulge her son in such a way that would "spoil" him, reasoning that to do so would harm him in the long run. Jean thinks that young kids do not know much and, thus, parents' authority acts to counter a child's inexperience and poor decision-making skills. Despite this emphasis on the controlling aspect of guan, Jean nevertheless acknowledged that the parental role of guan is actually the way that Chinese parents show their love and care for their children. She stressed that, above all else, the reason she "guans" her son is because she loves him.

Guan as mutual respect. In contrast to Jean's unapologetic defense of the strict aspect of guan, Victoria combined a defense of guan with an appreciation of the importance of a child's own interests and free choices. She stated that as a parent she seeks to promote and accommodate her daughter's interests and abilities and opposes the idea of parents forcing a child to pursue her parent's interests. "Guan needs to leave space for a child's own choices, aptitudes, and predilections" ( $3{ }^{\text {rd }}$ interview, June 18). Similarly, George thought that parents should help children make their own choices and pursue their own interests. He incorporated values of democracy, equality, and mutual respect into his parenting and supported his child's interests. He noted that as a child gets older, a parent becomes more a facilitator and equal partner of his child, and less of an authority figure. Even though authority was important for the 
participants' understandings of their roles as parents, some participants emphasized it more than others. Despite these differences, however, the participants all agreed that guan requires that parents be involved with their children and their education.

Guan as high parental involvement. Chinese American parents are highly involved in their children's music education and regard it as a key to their child's success, making an understanding of their parental role all the more important. In Chinese culture, parents, rather than teachers or principals, are the primary force in a child's education, and the Chinese take parental involvement quite seriously (Chiu, 1987; Gorman, 1998). A well known passage from the "three character classic"-Elementary Chinese: San tzu ching (Wang, 1900)—illustrates this Confucian value well. It was quoted by Joan and can be translated as follows: To feed a son without teaching him is the father's fault. Joan explained that she interpreted the passage to mean that a parent is as morally obligated to teach a child as to feed her. Joan concluded that parents' involvement and commitment to their child's education is absolute. In the same vein, Victoria acknowledged that if her child developed an interest in music, it would be her responsibility as a parent to ensure that her daughter persists in her efforts.

While guan applies to all aspects of a child's life, it is particularly evident in the high value parents place on both education and music in Chinese culture. This value was evident as the participants discussed their own parents' involvement in their early childhood music education, as well as their involvement as parents with their own children.

The commitment that Victoria's parents showed toward her study of piano exemplified the Confucian notion of parental involvement. Not only did Victoria's parents make the significant financial sacrifice of buying her a piano and arranging for three progressively more demanding teachers as her skills improved, but also they were greatly committed to supporting 
her ongoing study: Victoria's mother routinely accompanied her on the two-and-a-half hour bus commute to her piano lessons, and her father drove nine hours to take her to piano competitions. Jean told similar stories about her parents' sacrifices for the sake of her music education. Like Victoria's parents, Jean's parents sacrificed greatly to purchase her a piano and rearranged their lives to ensure that she practiced and received lessons. In addition to demanding from her an eight-year commitment to study, Victoria's parents completely abstained from watching television so as not to distract her from her practice. Jean described it as an unyielding commitment to her study.

Jean also recounted her father taking her to her piano lessons on his bike each week, a journey that took over an hour. Victoria's parents maintained a strict schedule for her practice even when she was on vacation and kept in routine contact with her piano teacher in order to assist with her study. Joan likewise remembers her mother's commitment to her music education, recalling that her mother insisted that she learn independence by walking to her piano lessons by herself but eventually discovering that her mother had secretly followed each time to ensure that she was safe.

The commitment that the participants' parents showed toward their musical education is mirrored in the commitment that the participants show to their own children. Victoria relates childhood developmental theory to her own parenting activities, as when she decided to enroll with her child in a music class for babies and then continued with additional research-based, ageappropriate classes for her child as she matured. Jean's devotion to her child's music education commenced even earlier than Victoria's by listening to music while pregnant as a form of "prenatal music education.” 
George acknowledged that having a child study a musical instrument requires a lot of a parent's time and effort, as well as significant monetary investment. Nevertheless, he described his support for his children's music education as "unconditional," and said that he would support his child even after it became a significant financial burden. He emphasized that parents are a child's first teachers; a commitment to a children's education begins with the parents' commitment of time and effort.

Luke's parents were of limited means and led a hard life that prevented them from devoting much attention to his musical education; however, Luke's involvement in his daughter's education is extensive. He has provided a rich musical environment for her in his home and spends most of his Saturday mornings making music with her on a variety of instruments, a commitment of both time and financial resources. Luke also is committed to his daughter's ongoing music education, expecting her eventually to study not only the piano and the 'cello but also a variety of traditional Chinese instruments.

Another illustration of Chinese American parents' commitment to their child's music education is that not only do they create musical environments for their children at home, but they also provide their children many opportunities for musical enrichment outside of school in order to nurture their music aptitude. Victoria's parents created a rich musical environment in her home, encouraging her to listen to music, and her father would always advise her on the quality of her playing. Both parents traveled long distances to support her piano study and competition, and Victoria presently wants her child to experience music from all over the world. Her enrollment of her child in developmentally appropriate early childhood music classes reflects this same desire to provide optimal environments in which to experience music. 
Parents as role models. The final and, in some ways, most distinctively Chinese aspect of guan is that of parents as role models. Patterning behavior on ideal models rather than exclusively on rules and regulations is an important aspect of Chinese culture evident not only in parenting but also in Chinese history. Looking to figures from the past as guides for living in the present has long been an important aspect of the Chinese tradition. In Confucianism, the role model par excellence, the junzi, or "gentleman" or "sage," is the embodiment of virtue (de) and the model for the emulation of others (Tweed \& Lehman, 2002). The emphasis on exemplars as sources of moral guidance also influences Confucian views on education and parenting. Educators and parents "teach" not only through their explicit lessons but also, and perhaps most importantly, through their example.

It was clear from the interviews that one of the strongest influences on the participants' views on music and music education was the example set by their parents, who in most cases modeled a deep love of music. The example set by their parents is greatly valued and continues to influence their own involvement with their children's musical education. In most cases, participants modeled the same or similar role their parents had played during their childhood. In a few cases, however, parents' deep involvement in their children's musical education appears to compensate for a lack of involvement on the part of their own parents.

Jean clearly viewed her mother, and to a lesser extent her father, as role models in their love of music. She directly attributes her love of traditional Chinese folk music and her "musical genes" to her mother's influence. Jean models aspects of her parenting approach after her parents, especially her mother. For instance, Jean's parents provided her with private piano lessons as a child, and her mother changed her teachers twice in an effort to find the perfect teacher for Jean. Jean emulates her mother in her careful oversight and encouragement of her son's piano studies. 
Jean also credits her parents for instilling in her a respect for the value of education and for teachers. Jean stated that her parents were willing to invest in education to the fullest extent that they were able, and she notes that she and her husband are willing to support their child's musical interests "all the way." Jean also practices aspects of a "tiger mom's" strictness with her child. Notably, Jean chose the piano as the instrument to which her son would devote years of study, rather than letting him decide for himself, and in general asserts the superiority of the Chinese approach—-her parents' approach—to parenting.

Joan acknowledged that her parents — especially her mother—provided a model for her involvement with her child's music education and stated that she hoped to pass these practices on to her own child. Just as she learned the virtue of persistence from her parents' insistence that she never give up in the difficult work of learning music, she hopes to instill this value in her son. Joan also endeavors to model her parents' openness in exposing her son to a wide variety of interests (which eventually led her away from the piano) and providing him with ample opportunities to explore them.

Victoria's parents both were music enthusiasts and made music a priority in her life. So avidly did they support her study of piano and her interest in music generally that for years she assumed they wanted her to become a professional musician. It was only later that she realized the truth: they wanted her to experience the joy of music and to learn how to persist in her endeavors. Although her parenting style is different from her parents, Victoria realizes that her expectations for her own child mirror those of her parents, namely, to learn to enjoy music and allow it to enrich one's life. Victoria's deep involvement with her daughter's music education seems to model that of her own parents. As she explained: "I want for my daughter what my father wanted for his" ( $3^{\text {rd }}$ interview, June 18,2013$)$. 
Luke was most impressed by his mother's enthusiasm for music and, in particular, her love for the "red songs" and dances from the Cultural Revolution. Although he did not share her love for these particular songs, he was fascinated by her sheer enthusiasm, and in this sense she became an important model for his own love of music. Like his mom, Luke tries to model a love of music for his daughter and devotes time to making music with her. He also expects her to learn to play multiple instruments and develop an early appreciation for the beauty of music and the happiness it brings.

In the cases of Steven and George the role of parents in modeling music education was not as clear-cut. Steven's experience of his father as a role model is best exemplified in his recollections of his hard-working father returning home from a long day at work and bursting into song, an experience that left Steven with cherished and indelible memories. Steven's parents, however, were often too busy providing the basic necessities of life to worry about his music education. This may account for Steven's lack of specific expectations for his own son (in contrast to his wife's) and his discomfort at seeing his son struggle with his piano lessons. Steven's parents did not carefully manage his childhood (in the sense of guan), and accordingly, Steven takes a rather relaxed attitude toward his own son, allowing him as much autonomy as possible. Yet, in many respects, Steven attempts to redress his parents' shortcomings, most particularly his father's stoicism and distance, making a conscious effort to communicate as openly as possible with his own son.

George was reluctant to reveal much on the subject of whether and how he bases his parenting approach on his parents' example. Perhaps tellingly, George cited how his father smashed his erhu in the middle of the night as an important, formative experience in his 
experience with music, which may explain why George tries to create a democratic and equal relationship with his child, founded on mutual respect.

\section{The Premium Placed on Education}

One of the most important aspects of Chinese parenting as guan is providing for their child's education, and much of the parental involvement discussed above centered on this. Education is one of the most important values in traditional Chinese culture and is at the heart of the Confucian tradition. This value applies to both education in general and to music education in particular. In this section I present the participants' views on the premium placed on education.

Chinese cultural norms exert a heavy influence on Chinese American parents' expectations and values in terms of their children's education (Verna and Campbell, 1998). The Chinese in particular place an exceedingly high premium on education and commonly hold that it is the most important element of a child's life. Chinese American parents stress education and learning, are heavily involved in their children's education, and derive pride in their children's dedication and effort (Chao, 1994; Chen \& Uttal, 1988; Chen \& Uttal, 1988; Crystal \& Chen et al., 1994; Ho, 1989; Pong \& Chow, 2002; Stevenson \& Lee, 1990; Stevenson \& Stigler, 1992; Wong, 1995; Yang \& Zhou, 2008). Chao (1995) noted that Chinese American parents tend to have consistent attitudes toward education and, broadly speaking, expect their children to perform well academically, support their children psychologically and financially, and endeavor to model scholarly behavior.

Consistent with what other research has shown, the life stories of participants in this study make evident that Chinese American parents have a strong commitment to their children's education in terms of time, effort, and financial investment. Jean articulated this well, acknowledging that both her parents placed a very high premium on education and instilled this 
priority in her. She is well aware that her parents were willing to invest in her education to the fullest extent of their means and ability.

The Chinese American participants in this study were mindful of the many benefits of education, as their own lives and careers attest. For example, successful and self-made, Steven, like his wife and many other members of the emergent Chinese middle and upper classes, recognized how education transformed his life almost immediately in terms of affluence and social status. Steven cited the Chinese saying, "everything is subordinate to education" as a means of explaining that the Chinese regard education as essential to the goal of attaining security and personal prosperity. Later he put it more idiomatically, calling his education "his ticket to a better life" (2 $2^{\text {nd }}$ interview, May 18, 2013).

The Chinese American participants' advanced educational attainment has not only opened up opportunities for them to study in the United States, build meaningful careers, and achieve a high degree of socioeconomic status, but it has also given them the time and means to access a variety of enriching experiences. Not surprisingly, these parents expect that their children will be able reap similar benefits from their education. The participants shared the view that early childhood education is important for their children in order to better habituate and prepare them for many years of arduous, sometimes competitive, academic achievement. As Joan put it, "the earlier, the better" ( $3{ }^{\text {rd }}$ interview, May 28, 2013).

Participants also expressed their high regard for education by expressing their great esteem for teachers. Jean attributes some measure of her esteem for teachers to her parents, explaining that her parents were very respectful to all their teachers. They always remembered to give presents to teachers on traditional Chinese holidays. The worth of the presents was not the point. The point was to show their willingness to work with the teacher and to follow guidance. 


\section{The Functions of Music in Life}

Just as one's views on the role of music education are influenced by one's views on education in general, they are also determined in part by one's views on music. What a parent believes about music and its function in life will influence what kind of role she wants music to have in her child's life, and what kind of musical education she will seek for her child. In this section I will review the participants' views on the functions of music as a whole in preparation for subsequent discussion of their views on music education. A number of functions of music emerged from the interviews: a) music as emotional expression, b) music as creative selfexpression, c) music as fun and enjoyment and d) music as a moral phenomenon.

Music as emotional expression. An important function of music that has been identified by scholars in the field is the function of music as emotional expression. For instance, a wellrespected authority on the anthropology of music, Alan Merriam (1964), presented what has become a classic outline of the ten functions of music across cultures. First among these functions is music as an important vehicle of emotional expression, and this function was prominent in the interviews. All of the participants in this study shared their traditional cultural beliefs on the relationship between music and human emotion. A prevalent Chinese understanding of music was best expressed in the saying attributed to the Confucian philosopher Xunzi, yue zhe le ye, which was interpreted as, "the role of music is to make us happy and arouse our emotions" (Victoria, $3^{\text {rd }}$ interview, May 23, 2013). Victoria further described music as a language of emotional expression and as serving a therapeutic function. She felt that she established much of her emotional connection with her child through music. George considered music as a way to promote emotional health, asserting that it develops emotional intelligence and nourishes a healthy personality and a positive attitude about life. 
Joan also acknowledged the emotional power of music, but cautioned that it can be employed for good or ill. She thinks "good" music serves to make people happy and inspires them to strive for higher or nobler things. "Bad" music emotionally manipulates people toward ignoble ends and disables the capacity for critical thought. Luke also defined "good" music in terms of its emotional impact, citing deeply personal songs that resonate with the soul and stir one's deepest emotions — such as American jazz and rock and roll—as the epitome of "good music." To Luke, music has the highest purpose to enable joy, self-expression, and emotional truth.

Steven observed that music connects people emotionally to one another through feelings that are universal to the human experience. Steven explained the power of music to connect and bond people by reciting the traditional Chinese story about two dear friends who understood each other's feelings solely through the experience of one friend playing music for the other. According to the story, when one of the beloved friends died, the other smashed his instrument, reasoning that because his friend could no longer hear his music, he had been rendered emotionally mute. To Steven, this parable illustrates the function of music in establishing deep emotional bonds between people. Recall that Steven also told a more personal story of the emotional impact that his father's singing had on him as a child.

Of the variety of emotions that can be evoked by music, the ability of music to arouse happiness or joy was most commonly cited. For George, the most pragmatic reason to study music is because music makes people feel happy. Accordingly, George advised that children and adults alike should study music without pressure or competition. Victoria also noted that because music entertains and provides us with joy, music education ideally should be entertaining or fun, something more akin to recreation than to serious discipline. 
Like George and Victoria, Steven associated music with the enjoyment that it brought him in school as a child. He identifies music class as his fondest memory from elementary school and favorably contrasts the enjoyment of songs and singing with the cold formulas of chemistry and physics. Steven wants his son to have the same enjoyment that he experienced with music and frets that his son may not be enjoying his piano lessons. Even if his son is studying, Steven's priority is that his son enjoys the experience. Emphasizing that music is to be enjoyed, Steven noted that Confucius himself became oblivious to the taste of food after having tasted the sublimity of music.

Even Jean, whose early study of music was very regimented and serious in comparison to the others, desires that her son's musical education be pursued purely as a means of enjoyment and self-enrichment. Despite the rigors of her own music education, she observes that her parents enjoyed music, and considers that she benefitted as much from having been raised in a home where music was cherished as she did from her formal training in the subject. As an accomplished musician, Jean acknowledges that musical accomplishments are symbols of prestige and social status, and are valuable in that regard. But, in the final analysis, like George, she subordinates such considerations to the experience of joy.

To Joan, the primary function of music in a child's life is to bring happiness by providing the fulfillment and enjoyment that can be had only through musical expression. Joan also sees music as "an effective way of letting off the pressures that young people so often experience and a good way for children to explore their feelings and develop their interests." Joan maintains that music education can benefit from being "more relaxed, more entertaining, and more fun," a lesson she applies to her own son as she endeavors to provide opportunities in which he can discover his enjoyment of music for himself. Joan explained: "I hope to help my son discover his 
true interests and innate musical potential by providing him opportunities for a variety of lessons such as piano, voice, and dance. As a Chinese saying goes, 'interest is the best teacher,' but no matter what his interest is, I support him" (2 $2^{\text {nd }}$ interview, May 21, 2013). Like other participants, Joan's guiding motivation for having her son study music is for it to be a source of joy in his life, as it has been in hers.

Several of the participants likened their relationship with music to a dear friendship or love. Jean specifically referred to music as her lifelong friend, describing her love of the piano as integral to her everyday life. George similarly stressed that emotional passion is integral to the study of music, stating, "If a child who studies music has no passion for it, how can he possibly be devoted to its study? Only if we nurture the passion in a child's heart can music work its magic throughout his life" $\left(3^{\text {rd }}\right.$ interview, May 23, 2013).

Music as creative self-expression. Beyond talking about the function of emotional expression, the participants also highlighted a more specific function of expression, namely creative self-expression. This was a prominent theme that recurred throughout the interviews. For instance, Jean told a story from her childhood that illustrated a child's innate desire to express herself through music involving a toy piano that she received as a birthday present when she was six years old. Jean recalled that her earliest, formative experiences with music education were entirely self-motivated and self-taught. She trained herself to play songs she sang in kindergarten on her toy piano after school through a combination of trial and error, repetition, and memorization. In this manner, Jean described an inherent attraction to musical expression, which was a common characteristic of many study participants.

Similar to Jean's childhood hunger for musical self-expression, George flatly asserted that music is, foremost, a means of creative self-expression for children. George stressed that 
human beings learn language and music most adeptly as children, when the task of describing one's inner world and the world around them is new and wondrous. To George, cultivation of a child's personal interests and self-expression are essential to teaching music effectively. George defined a good early childhood music education program simply as an environment in which an individual child's natural interest in the musical language is stimulated and given voice. Luke's home in America is an excellent example of such an environment. He has filled it with both music and musical instruments, and he has acknowledged that he spends much of his leisure time playing piano and saxophone at home with his daughter.

Steven's early music education experiences and adult outlook on music were similar to Luke's. Steven, however, advanced that all artistic experiences and media—not just music— serve a similar, important purpose: "The study of music, the visual arts, and dance—-these three interconnected branches - put me better in touch with my humanity and made me a more complete person. For me, [art] is not simply a kind of enjoyment" ( $3^{\text {rd }}$ interview, May 25, 2013).

Jean shared Steven's and Luke's view that music is a form of deeply personal artistic expression but, more than that, she held that music serves as a universal language that transcends ordinary cultural and language barriers and facilitates understanding between people. She reasoned that, "if a person masters the language of music, that person can communicate the most profound of human sentiments to anyone in the world, making connections through shared emotional experiences" ( $3^{\text {rd }}$ interview, May 23, 2013).

Music as fun and enjoyment. The function of music as a form of fun and enjoyment emerged as an important theme in the interviews, a theme that evoked a variety of feelings and opinions from participants. Some of the participants emphasized that music should be fun and reported having had a lot of fun in their music classes growing up. Others were skeptical about 
whether music education could really be fun and emphasized the effort and hard work required to master a musical instrument.

Steven was outspoken about the fun he had in music class when young, in contrast to other classes that he found boring. While he did not have the opportunity to study an instrument when he was young, he learned to enjoy music nevertheless. His music class at school was devoted to singing, and he remembered it fondly: "Music class is my best memory of my elementary school. Compared to other classes, it was more fun. Other classes, such as chemistry and physics, were very boring. You know kids love to have fun" $\left(1^{\text {st }}\right.$ interview, May 11,2013$)$.

Steven today believes that music primarily should be a source of enjoyment in children's lives, similar to the music classes he so enjoyed as a child. He disapproves of demanding music lessons of the variety that Jean and Victoria endured, and regrets that his wife insisted on such lessons for his own son. He disparages the Chinese approach to education as a form of "force feeding" yet acknowledges that it provides a solid foundation of basic knowledge. To Steven, music education in the United States, by contrast, is more focused on creativity, exploration, and fun. He is receptive to the American approach that is committed to music education as something enjoyable. His experiences as a student in the United States and as a teacher himself have led him to see the value of play in education, in opposition to the traditional Chinese emphasis on mirthless discipline and hard work, and he hopes to combine the best of both approaches in his own son's music education.

As for Luke, he remembered his early music education as limited and boring. His interest in music was initially fostered through informal contacts with talented performers and friends while growing up in China, but is currently sustained by the exuberance of the American musical 
forms of jazz and rock and roll. He describes his typical recreation time as enjoying playing music with his daughter playing beside him. For him, this is a lot of fun.

Going beyond the boredom expressed by others, George characterized his formal, early childhood music education experiences in China in even more negative terms, noting that he endured humiliation and even physical violence in his music class. His experiences in the United States, by contrast, have convinced him that music education should be focused on enjoyment, creativity, and fun rather than on the rapid acquisition of technical skill.

Although there was a clear sense among the male participants that music itself is something enjoyable and that music education should be fun, the female participants in this study were more skeptical about the value of plain fun in education. Of the six participants, Jean and Victoria had the most intensive musical training during their childhoods, each achieving significant mastery of the piano under the guidance of watchful parents and skilled teachers. Both questioned the role of fun in music education. Jean did not characterize her music education as having been fun. She often found practice boring and reported that she was oftentimes discouraged and sometimes felt like giving up. Yet, her commitment to her parents pulled her through, and she believes that the persistence that developed from this process has served her well in life. Through all the hard work, Jean developed a genuine love of the piano and speaks of music as a source of joy and happiness; however, she remains skeptical about trying to make music education fun.

Jean acknowledges that children are fond of having fun, but she is critical of her son having too much fun at school. In a comment reflective of her own experience as a child, Jean claims that she fully expects to see her son cry in front of her while practicing piano, precisely because such practice is neither fun nor easy for a child. She cautions in her best Confucian 
manner that a childhood devoted to the satisfaction of childish wants will not produce a fulfilled and happy adult. Not surprisingly, Jean is outspoken in her defense of the Chinese concept of guan and is critical of the idea of giving a child the freedom to learn at his or her own pace. "Such an orientation may be more fun or enjoyable for a child," she says pointedly, "but it's a waste of time and money" ( $3^{\text {rd }}$ interview, May 23, 2013). She advocates the traditional Chinese approach that prioritizes guan over the satisfaction of a child's individual wants or inclinations.

Although Victoria placed a greater emphasis on the enjoyment of music, she found her own piano learning experiences to be demanding and difficult. Her third and most demanding teacher had a reputation for reducing children to tears, but she persisted in her studies and became accomplished enough as a pianist to win a number of competitions. She considered her study of piano as a means to self-discipline and the development of a strong work ethic.

Although Victoria's parents intended that she learn important moral lessons from her study of piano, their main hope was that she learn to experience the joy of music. Perhaps this difference in emphasis predisposed Victoria to have a more open and accepting perspective on the American model of music education, which she sees as more sensitive and tolerant in comparison to the Chinese model. Victoria stated that she was delighted to learn about the developmental theories of early childhood music education, which she uses to justify the fun she had with her daughter when she enrolled her in a music class for babies.

However, it was Joan who best articulated the ambiguities involved in describing music education as "fun." On the one hand, she was emphatic about the fun she had studying piano as a child, recalling that she never regarded piano practice as a chore. On the other hand, she admitted that music classes in China are often not very interesting, and she made the universal claim that "all music education should be fun" ( $3^{\text {rd }}$ interview, May 28, 2013). She went on to reveal an 
important nuance. She noted that "although education should be fun, fun is not the object of education" ( $3{ }^{\text {rd }}$ interview, May 28,2013$)$. Joan advocated incorporating play into education in a manner similar to the Chinese concept yu jiao yu le — which translates as a notion similar to "edutainment." She advocated a less authoritarian approach to education and argued that playbased education, "beyond teaching basic skills and concepts, teaches teamwork, sharing, cooperation, and communication," all of which are traits she desires for her son. Although she sees the merits of the traditional Chinese approach to music education, Joan concludes that music education could benefit from being "more relaxed, more entertaining, and more fun" ( $3^{\text {rd }}$ interview, May 28, 2013).

Looking back over the very different backgrounds of the participants, it is perhaps no surprise that success in formal musical study seems to correlate with an appreciation for the strict discipline that makes technical mastery possible. In this study, early negative experiences with strict music education tend to support a more relaxed attitude toward music education later in life, stressing the sheer enjoyment of music. Culture, upbringing, and a constellation of other societal factors have shaped the participants' acquisition and appreciation of music. All have experienced traditional Chinese and have closely observed contemporary American approaches to music education, in which the methodologies of the cultures sometimes appear to be fundamentally at odds with each other—pitting "mirthless discipline" against carefree fun, respectively. The participants are for the most part looking for ways in which the two approaches can be reconciled and synthesized to integrate the enjoyment inherent in the experience of music with the seriousness of purpose that underlies the traditional Chinese understanding of music as a moral phenomenon. 
Music as a moral phenomenon. The fourth function of music that emerged in the course of the interviews is music as a moral phenomenon, a distinctively Chinese emphasis that is less prominent in the West and that may be surprising to American early childhood music educators. Every participant in this study acknowledged an important moral dimension to music. Several stressed the importance of music in moral formation of children and of society at-large, and several explicitly linked their views on this matter to the Confucian tradition, which emphasizes the moral value of music.

It was Steven who perhaps expressed this most directly: “The best aspect of Chinese culture with specific regard to music is that listening to and enjoying music, itself, is a form of moral instruction. According to Confucius, music makes a better person" $\left(3^{\text {rd }}\right.$ interview, May 25, 2013). This linkage of music and morality has ancient roots in China. According to the Confucian view, music was associated with rites, the rules of propriety that held society together. Music thus had an important role to play in the ordering of society, and this order expressed through music was believed to reflect the order of the cosmos itself (Huang, 2012).

Confucius also placed a very high value on the role that music plays in the formation of personal character. As the Confucian philosopher Xunzi wrote in his treatise on music: "When music is central and balanced, the people will be harmonious and not indulgent; when music is solemn and stately, the people will be evenly uniform and not chaotic" (Yuelun 5, quoted in Cook, 1997, p. 23). The importance of music for the moral life was also noted in the Record of Music, dating from the Han Dynasty, according to which "Virtue is the upright growth of one's nature, and Music is the flowering of virtue" (Yue Ji 6.4, quoted in Cook, 1995b, p. 59). Steven echoed this ancient view when he spoke of music as purifying, ennobling, and elevating the human heart and told the story of how a performance of the "Chorale of the Yellow River" had 
reminded him, as he put it, "of the better aspects and potential of my own character" $\left(1^{\text {st }}\right.$ interview, May 11, 2013).

George also acknowledged that music has the power to purify the heart. Victoria and Jean expanded on this theme of the moral dimension of music. Victoria went into considerable detail in discussing the Confucian view on the moral value of music, contrasting it with the views of the philosopher Mozi. She quoted the Analects: "a child's education starts with poetry, is built upon rites and is completed in music" (Xing yu shi, li yu li, cheng yu yue, Analects 17:16, cited by Huang, 1997, p. 86), commenting that "Confucian rites, which were the backbone of society, were inseparable from music. Thus music had a political value, and music became associated with governance," adding that "Confucius also placed a very high value on the role that music plays in the formation of a person's character" ( $1{ }^{\text {st }}$ interview, June 6,2013$)$. She believes that it is this view that best captures the positive role that music continues to have in Chinese life today.

Jean's views were very similar. She recalled her parents' belief in the importance of music in a child's moral formation and felt that her study of the piano had shaped her own character. She explained the benefits of music in a person's life by referring to the traditional Chinese concept of "self-cultivation" and often repeated that "music shapes a child's character and helps cultivate virtue." Like George and Steven, she felt that music can purify a person's mind and added that "people who study music tend to be happier, possess better character, and have more refined tastes" ( $3^{\text {rd }}$ interview, May 23, 2013).

Two of the participants, Luke and Joan, made a distinction between "good' and "bad" music in unmistakably moral terms. As Joan put it: "In my opinion, 'good' music serves to make people happy and inspires them to strive for higher or nobler things. 'Bad' music emotionally manipulates people toward ignoble ends and disables the capacity for critical thought" $\left(1^{\text {st }}\right.$ 
interview, May 14, 2013). This view in fact echoes the view expressed centuries ago in the Yue $J i$, which contrasted "straightforward and upright" music that makes people "solemn and respectful" with music that is "indulgent and depraved" and makes people "licentious and chaotic" (Cook, 1995b, p. 57).

\section{The Value of a Music Education}

When considering the role of a music education, it is not surprising to see that the parents' views once again bear the imprint of the Confucian tradition. They acknowledged the importance of traditional Chinese attitudes towards music, especially those stemming from the Confucian tradition. For Confucians, music was an essential component of the traditional Chinese way of life. On a personal level it was important as a means of moral cultivation; it was also important for social status through its close association with ritual. This section will present the participants' views on these two important values of a music education: music education as a means of moral cultivation and music education as a marker of social status.

Music education as moral cultivation. The first and most important value is parents' endorsement of the traditional understanding of music education as a means of moral cultivation. This traditional view is something that clearly continues to influence their views on the music education of their own children. Five of the six participants addressed this notion. For example, George asserted that music aids in the formation of personal morality. Victoria mentioned the Confucian concept of the moral value of music, explaining that her parents told her they wanted her to study music so that she might develop persistence, self-discipline, and a good work ethic. Victoria adopted her parents' sensibilities, stating that "music nurtures the whole person. It purifies one's heart and strengthens one's character" $\left(3^{\text {rd }}\right.$ interview, June 18, 2013). 
In order to elaborate on how different aspects of her music education shaped her character and taught her persistence, Jean recounted the story of the eight-year commitment that she made to her parents to study piano, which she said taught her one of life's profound lessons in honor and duty. At that time owning a piano was a luxury for her family. With her parents expectation that she study wholeheartedly and consistently to master the skills, she developed the ability to "eat bitterness" (endure hardship) entirely through this eight years of practice.

Jean's parents correctly anticipated that her piano studies would instill discipline and willpower in her by means of concentrated practice at the piano for hours every day for many, many years. They also expected her to develop the virtue of persistence, believing that a music education teaches children persistence as a result of effort and hard work.

Jean recalled that in the earliest years of her eight-year commitment to piano study, she often became bored and discouraged with the long hours of practice and sometimes felt like giving up. Yet even as a child, Jean felt an obligation to honor her agreement with her parents, feeling that to break a promise would have been a violation of the Confucian ideals that she still values today. Reflecting on the experience, Jean believes that her agreement helped her master not only the piano but also her own character.

Like her parents before her, Jean currently holds that music education should build character by instilling discipline, persistence, artistic temperament, aesthetic sensitivity, and high moral standards. She describes the moral benefits by referring to the traditional Chinese concept of self-cultivation. She also feels that music should shape her own child's character and help him cultivate the virtue of persistence that is earned from long hours of difficult practice.

Joan also explained that her music education gave her more than the technical skill of playing an instrument; it also helped her build aspects of her character. She stated that these 
invaluable lessons were often supported and encouraged by her parents through their active involvement in her music education. For instance, Joan recounts that her mother insisted she walk to her lessons on her own in order to develop independence in meeting her responsibilities. Like Jean, Joan said that throughout her music education, her parents carefully promoted and cultivated in her a serious commitment to study, telling the story of her parents insisting that she not give up on mastering a difficult piano piece even when she was frustrated. As an adult woman, Joan reflects with gratitude on what then appeared to be her parents' cruel indifference, explaining that she ultimately mastered the piece. Not surprisingly, Joan now sees music lessons and practice as a means of instilling the value of persistence in her own son.

Steven agreed that music plays an important role in the development of a strong and moral character and, like George and Victoria, he traces this idea to the Confucian notion of the cultivation of the spirit. Namely, Steven stressed that it is a uniquely Chinese notion that listening to and enjoying music is, in itself, a form of moral instruction. According to Confucius, music makes a better person. Accordingly, as a father, Steven explains that he intends for his son to become a better person through music.

The prominence of the virtue of persistence in these participants' experiences is associated with the importance of effort in Confucian tradition. Both persistence and effort are keys in achieving moral cultivation. For Confucius, human nature is perfectible; a failure to excel is a moral issue and is understood to be due to a lack of effort rather than to any unavoidable shortcoming of nature or talent. The value of effort is reflected in the insistence of the parents of some of the participants on practicing their instruments for long hours and not giving up even when they are bored. In short, for some of the participants their music education was simply hard work. Several of the participants had expended years of effort mastering their instruments, 
clearly valued their accomplishments, and felt that it had taught them an important lesson for life, especially the virtue of persistence. Of course it is possible to appreciate music, even love music, without being a skilled musician. In some cases, music education can be limited to the free and easy group singing that Steven so much enjoyed as a child. But music education can also take the form of sustained effort and hard work needed to master a musical instrument.

Music education and social status. Parents also recognized the value of music education as a marker of social status, a reward that is accomplished through persistence. While some of the participants were critical of this social dimension, it was nevertheless acknowledged. The notion of music education as focused on the sustained effort to master an instrument is closely connected to the notion that music education can serve as a means of attaining social status and professional success. Technical mastery of music is rewarding, but just as importantly it reinforces an important notion held by many socially ambitious Chinese families: mastery of highly technical subject matter through discipline and hard study yields success in life. For example, Victoria remembered how important it was to her parents that she won piano competitions.

Many of the participants acknowledged that musical achievement is a positive indicator of social status, but none of them regarded social status as the primary reason for parents to invest in their children's music education. The participants' overriding view was that music was most fundamentally intended to enrich life and to be enjoyed for its own sake rather than used as a means of social or class advancement. Nevertheless, musical achievement as a marker of social status was mentioned frequently enough to warrant identifying it as a specific theme.

Jean frankly conceded that musical accomplishment is a symbol of social status and that she has benefitted from it in her life. She participated in many piano competitions, performed 
recitals twice a year, and acknowledged that such accomplishment was an indicator of her proper education and upbringing. She also repeatedly mentioned the traditional Chinese expectation that a well-educated young woman would be accomplished on at least one instrument.

Victoria, who like Jean was quite accomplished on piano, was also a member of what she described as a "highly selective" dance troupe. She received social recognition for her skills, winning many piano competitions. She noted that her family's status seemed to have been enhanced by her accomplishments. After an appearance in a piano competition on national television, she most remembers how proud her parents were when other parents acknowledged that they had seen her on TV.

Joan's experience differed from Jean and Victoria's in that she broke off her study of piano comparatively early, but her parents nevertheless regarded her study of piano as fulfilling the social requirement that well-educated girls have a "special skill." Joan remarked that her mother enrolled her in music competitions and went so far as to show video recordings of the proceedings to her friends and co-workers in pursuit of social prestige. Joan remembers that parents of more limited means followed her mother's example and, in turn, enrolled their children in music lessons and competitions.

However, Joan disapproved of viewing musical achievement as a status symbol—an excessive emphasis in Chinese music education - fearing that it too easily could get tangled up in issues of a family's reputation. George voiced similar concerns. He criticized this phenomenon of parents competing with each other using their child's music achievement. Rather, he believed that nurturing a child's individuality is more important.

Although Steven's family's circumstances prevented social status from being a pressing issue for him, he was nevertheless aware of the fact that many contemporary Chinese have a 
practical interest in music and regard musical accomplishment as a means of economic or social promotions. It is possible that such criticism of the competitive aspects of music education in China may be attributable to the more secure social and financial status of the participants in comparison to their parents.

\section{Summary}

The four themes that emerged during the interviews with six Chinese American parents provide insight into the research questions with which this dissertation began. Chinese American parents' views on music and music education, their expectations for their children's music education, and their understanding of their own role as parents seem to have been determined in large measure by the cultural background that these themes bring to light. However, as Chinese Americans, their views on these matters are also shaped by their experience in their new home. Through the process of acculturation they have been confronted with new values to which they must in some way adapt. The fifth and final research question addressed by this study concerns the issue of acculturation and its influence on Chinese American parents' expectations and decisions for their children's music education. It is this question that will be addressed in the final chapter. 


\section{CHAPTER SIX}

\section{DISCUSSION AND IMPLICATIONS}

This study has examined a specific aspect of the acculturation experience of firstgeneration Chinese American parents pertaining to their desire to provide for the music education of their children in the United States, where early childhood music education is informed by values sometimes at odds with the traditional values of their home Chinese culture. In the context of acculturation, two sets of cultural values come into contact, and potentially into conflict. Parents are required - by the necessity of providing for the education of their own children - to negotiate these differences and, if possible, integrate aspects of both sets of values in a meaningful way.

Music educators are facing increasingly diverse classrooms, including increasing populations of Chinese American immigrant children. Given the potential for misunderstanding on both sides, it is important that music educators better understand the values of Chinese American parents and be able to help these parents understand the principles of American early childhood music education. Better informed music educators will be better equipped to help these parents negotiate the challenges they face in providing for the music education of their children.

The foundation for the examination of the acculturation experience of participants in this study has been laid by addressing the first four research questions that guided this study:

1. How do cultural beliefs and life experiences influence Chinese American parents' views on music and music education?

2. What are Chinese American parents' expectations for their child's music education? 
3. What roles do Chinese American parents believe music should play in the education of their children?

4. What roles do Chinese American parents believe they should play in their children's music education?

These questions were addressed in the previous chapter, which presented the participants' views on parenting, education, music, and music education. It remains to examine the final research question specifically:

5. How does acculturation influence Chinese American parents' expectations and decisions for their children's music education?

This fifth question will be the focus of this final chapter, which will examine the interplay between the participants' traditional culture and their American experiences as they attempt to become American while remaining Chinese. On the one hand, dissatisfaction with elements of Chinese music education and parenting leads to selective appropriations of American culture. On the other hand, dissatisfaction with elements of American culture leads to the selective preservation of Chinese culture.

This chapter will also examine the tensions that arise through this interplay of cultures, examining the contrasting values of effort vs. play, guan vs. independence, and moral cultivation vs. creative self-expression as well as the challenge of seeking balance between two sets of values. A discussion of implications for early childhood music education and directions for future research follows.

\section{The Interplay of Cultural Values}

Modern acculturation theory provides an initial framework for understanding the dynamics involved in the interplay between Chinese and American cultural values. According to 
the Berry \& Sam (1997) model of acculturation introduced in Chapter Two, four patterns of acculturation can be identified and placed in one of four quadrants, depending on the consequences of the acculturation process: Integrated, Assimilated, Separated, and Marginalized. To review the nature of each of these four patterns briefly, in the Integrated quadrant are people who pursue values of the mainstream culture while maintaining values of their culture of origin. In the Assimilated quadrant are those who pursue values of the mainstream culture but identify less with values of the original culture. In the Separated quadrant are people who primarily maintain values of their original culture and reject values of the mainstream culture, and in the Marginalized quadrant are those who reject values of both mainstream and original cultures. Looking back at the portraits of the participants in this study presented in Chapter Four and the data analysis presented in Chapter Five, it becomes clear that all participants in this study are best characterized by the Integrated quadrant. All parents pursue the values of the new mainstream culture while preserving their culture of origin for the simple reason that they see both positive and negative aspects of both cultures. However, there is clearly a spectrum of degrees of integration, with some viewing Chinese culture more positively than mainstream American, and some viewing mainstream American culture more positively than that of China. The interview data also reveal degrees of tension among the participants that arise out of the acculturation process as they each in their own way negotiate the differences between the two cultures and seek to find a balance that they believe to be appropriate for their own children.

For these participants, neither assimilation nor separation is a real option. They identified some elements that they wish to retain from both cultures and others that they feel are best left behind. In the course of this complex process of appropriation and preservation, a number of tensions emerge between the values to be appropriated and the values to be preserved. 
In the following two sections I first examine these parents' appropriation of elements of American culture in the context of their dissatisfaction with contrasting elements of their original Chinese culture, and then their preservation of yet other elements of Chinese culture in light of their dissatisfaction with contrasting elements of American culture. These two sections will be followed by a third examining the tensions that emerge in the course of this complex interplay.

Becoming American. The Chinese American participants in this study were dissatisfied with several aspects of their own experience of music education during their childhoods in China and, accordingly, criticized what they continued to view as the traditional Chinese approach to music education. In many cases the participants found that what they most liked about the American approach to music education were those practices and characteristics that seemingly addressed most directly their dissatisfaction with the Chinese approach and represented for them an improvement. In a similar manner, they expressed criticism of specific traditional Chinese parenting practices and spoke favorably of the contrasting approaches they discovered in the United States. The consequence of this process of reflection on and evaluation of both cultures has been a selective appropriation of American culture.

However, this appropriation has not been uncritical. There has been a process of criticism of American culture and a preservation or re-appropriation of elements of Chinese culture. There are several reasons for this selective appropriation of specific American approaches to early childhood music education. They expressed dissatisfaction with the music education they experienced in China and dissatisfaction with traditional Chinese parenting practices. These two areas of dissatisfaction contributed to their openness toward alternative approaches to music education and to parenting and the appropriation of several features of American approaches as part of their new American identity. 
Dissatisfaction with Chinese music education. Several of the participants observed a common phenomenon in China nowadays to be that children love music but do not like their music classes. A number of participants recalled their musical experience in school as being uninteresting, and most participants recalled their early music education consisting almost entirely of singing. The participants pointed out that there are a number of reasons why Chinese music classes are often stifling or uninteresting, the main reason being that Chinese music education overemphasizes mastery of technique and neglects cultivation of a child's innate musicality and creativity. For example, Luke complained that his formal music education in China emphasized rote memorization and performance to the near total exclusion of stimulating his personal interests in the subject. In addition, he felt that the fiercely competitive nature of Chinese academics put children under extreme pressure to distinguish themselves through the mastery of specialized skills. As a result, Luke asserts that the creative aspects of music and even the mere enjoyment of the subject matter is lost and supplanted by a race for technical mastery and ruthless competition among students with aptitude. George similarly concluded that Chinese music classes overemphasized the development of professional musical skills to the point that classes became mere training sessions. Like Luke, George believed that there was too much competition to excel at special talents and thinks that acquisition of skills should not be the key purpose in music class. Steven voiced complaints similar to those of Luke and George, describing that he always felt pressured by the highly competitive musical activities in his early childhood, which arose as a result of the many students and limited resources at his school. At Steven's school, only students with excellent musical skills received opportunities for enrichment or to attend musical activities beyond the classroom. 
A second reason participants pointed out was that formal music education in China often tends to be rather regimented and emphasizes conformity. For instance, Luke disliked the overbearing classroom discipline and felt that his childhood music class was joyless and constricted by the rules that he was expected to obey as a child. Similarly, George criticized the Chinese music education model as tending to micromanage and control children to the detriment of personal expression and fulfillment, and he argued that the lack of choice and personal initiative in music classes fostered a lack of interest and detachment from the subject matter. He referred to the Chinese approach to music education as "force feeding" and still speaks bitterly of the rigid and repressive discipline and excessive structure and authority in his childhood music classes.

Many participants expressed concern about the objectives of Chinese music education and how the curriculum is geared toward the interests and abilities of the very talented few at the expense of all others. Steven was especially critical of the tendency in China to view music in terms of its practical benefits, as a source of economic or social rewards. Joan likewise complained about excessive emphasis in China on status (e.g., class rank) and attainment in music education (e.g., winning competitions). George similarly criticized many Chinese parents' motivations in providing musical training for their children purely as a means of enhancing their children's competitiveness for academic and professional opportunities. As a result, these participants explained how a child's personal educational attainment could become entangled in matters of family reputation and social status.

Finally, a few participants recounted receiving physical punishment in music class as the most negative aspect of the Chinese approach to early music education. For example, Jean described her first piano teacher as "a nightmare" and characterized her lessons as "terrifying" 
because of the verbal and physical punishments she received. Jean recounted that her piano teacher would slap her hand with a ruler if she did not play well, leaving welts, and George recalled the humiliation and pain of being kicked by his music teacher because he could not read music notation. He confessed that even as of late he feels traumatized by the incident. Such harsh treatment was yet another criticism of Chinese music education.

Dissatisfaction with aspects of Chinese parenting. The participants' attitudes toward traditional Chinese parenting were on the whole less critical than their views of Chinese music education, and were often expressed in terms of their assessment of parenting as guan and the phenomenon of the "tiger mom" among Chinese American families. George expressed the most critical views of traditional Chinese parenting, rejecting entirely the notion of parents as unquestioned authorities and children as a kind of property. He also felt that Chinese parents often tend to be overprotective in ways that stunt the development of a child's independent personality. Similarly, Victoria asserted that guan needed to accommodate a child's own choices, aptitudes, and predilections. Although Joan saw the merits of the "tiger mom" approach, she also acknowledged its drawbacks. Like George and Victoria, Joan acknowledged that too much guidance or oversight denies a child the freedom to make decisions and learn from mistakes.

Selective appropriation of American culture. Within the context of such specific dissatisfactions with their Chinese education and parenting, the participants found many aspects of early childhood music education in the United States attractive and preferable to the Chinese system they had left behind.

Enjoying music for its own sake. While a number of participants criticized Chinese formal music education as being too technical and too competitive, they appreciated the American educational value of enjoying music for its own sake. For instance, Joan explained that 
her attitudes and views of music education had changed since coming to the United States, and that she is enamored with the American practice of enjoying music for its own sake-for the sheer enjoyment of it. Luke values the focus on creative self-expression found in music education programs in the United States as more appropriate than the highly politicized "red songs" of the Cultural Revolution. He feels that the attitude toward music in the United States is more authentic - more attuned to the emotional content of music.

George's priorities in music education have become very “Americanized.” Since coming to the United States, he regards music education more in terms of the cultivation of a child's personal interests and self-expression rather than for the purposes of future educational or professional advancement. To George, "a good early childhood music education program is an environment in which an individual child's creativity is engaged and fostered." Steven agreed that, in comparison to the Chinese system, American education is more oriented toward encouraging a child's creativity and providing freedom to explore and have fun. He has endeavored to incorporate these values into the education of his own son.

Rich resources in music education. Upon coming to the United States the participants discovered that the diversity lacking in the Chinese system was a conspicuous strength of the United States system. Since immigrating to the United States, Luke has discovered his fondness for both jazz and rock and roll, interests that he shares and promotes with his daughter. Likewise, Joan likes the number of different opportunities in music education in the United States, remarking that a wide array of outreach programs is available for children as are resources for parents as partners in their child's education in United States. She also notes that, unlike in China, these music programs are less competitive and largely independent from issues of social status. 
As an immigrant, Joan especially appreciated that the values of tolerance and inclusiveness are reflected in American music education programs.

Having discovered early childhood music education classes in the United States—which, as far as she knows, do not exist in China—Joan has become convinced of their value. Experiencing both the Chinese and the American approaches to music education firsthand, the former in her own childhood and the latter with her son, has convinced her that while there is no single, perfect way to educate a child, a variety of approaches and techniques is most desirable. John believes that every child is different and that parents should be attentive to each child's unique interests and talents. Victoria also acknowledges that music education approaches in the United States are more sensitive and tolerant of children's individual behavior and therefore are more diverse than those in China.

The value of play in early childhood music education. Despite her strong advocacy of the values of guan, Jean admitted to incorporating play into her music classes in the United States, acknowledging that practicing an instrument for hours on end is not a fun experience for most children and that there may be some value in play-based approaches after all. She realized that it is important to keep a balance between her dual roles as caring nurturer and authority figure. Steven's efforts to deal with the challenge of his own son's lack of interest and commitment to music education has led him to the similar position of seeing the value of play in education, in contrast to the traditional Chinese emphasis on discipline and hard work.

Joan integrates the concept of guan into her parenting by guiding and managing her child's education to include play. She saw no contradiction between providing guidance and management for a child and fostering a child's learning through play and enjoyment of his or her educational experiences. 
Age-appropriate practice theory. Since coming to the United States, Joan has become increasingly aware of developmental theory in early childhood education and understands that children start discovering their musical interests very early, between the ages of three and six. Hence, Joan's self-declared motto on the subject of music education is "the earlier, the better" $\left(3^{\text {rd }}\right.$ interview, May 28, 2013). She has applied developmental insights to her understanding of guan, a subject upon which she continually reflects. Joan describes her current parenting philosophy as practicing different levels of guan in ways that are relative and appropriate to different stages of a child's development. Jean also noted that approaches to parenting must adapt to different stages of development as a child matures. According to Jean, when children are young, parents should take a more hands-on approach and focus on a child's acquisition of basic knowledge. As children grow older, she believes that parents must gradually loosen their grip and assume the role of facilitators and equal partners with their children, encouraging open dialogue and exchange of ideas.

Advantages of parenting in the United States. In addition to appreciating many facets of music education in the United States, some of the participants have found value in the parenting approaches they have encountered since coming to the United States. For instance, rather than assuming the role of an unquestioned authority, George said that in his home he tries to create a democratic and equal relationship with his child based on mutual respect. Victoria stated that children need to develop at their own pace, and that parents need to help their children develop independence by giving them freedom to make their own choices and develop their own aptitudes and predilections. Similarly, Joan has integrated American values such as selfexpression and creativity into her parenting. She now recognizes the importance of giving a child the freedom to act and even to make mistakes. 
Remaining Chinese. Although the participants had many criticisms of traditional Chinese culture, by no means did they wish to abandon the values of that culture altogether. On the contrary, they spoke at length about the strengths of Chinese culture and its values, and expressed hope that American educators would be open to learning more about the perspectives of their Chinese American students and their parents. As might be expected, they also expressed criticisms of parenting and education in the United States that can be traced directly to their high assessment of the Chinese models. While they appreciated and wished to appropriate elements of American culture, the appropriation process was cautious and careful to avoid adopting characteristics of American culture that they held to be inferior to those of their culture of origin. While wanting to become American, parents also wanted, in important ways, to remain Chinese. This section will discuss those aspects of American culture deemed so undesirable by the participants and then examine those aspects of traditional Chinese culture that the participants most widely regarded as being worthy of preservation and promotion.

Dissatisfactions with American culture: Too much fun, not enough guan. Even while adapting to their new culture in America, the Chinese American parents who participated in this study expressed some dissatisfaction with music education and parenting in the United States. Except for Luke, all believed that educators and parents in the United States allow too much freedom for their children and do not provide enough guan, or even any guan at all.

Several participants criticized teachers in the United States for not being sufficiently sensitive to the Chinese cultural background of their students. Steven stated that educators misunderstand the values of Chinese parents and wished that educators in the United States shared his Confucian view of the connection between music and the formation of character. Joan also expressed a desire that music teachers make the necessary effort to understand the cultural 
values and traditions of their Chinese students and their families. More broadly speaking, George emphasized the importance of teachers appreciating the diverse cultural backgrounds of all students.

Selective preservation of Chinese culture. The participants in this study shared many dissatisfaction with their home culture; their list of complaints about their host culture in the United States may seem rather short by comparison. As was already noted, none regards total assimilation to American life to be desirable. Or, to put it another way, none seeks to abandon the culture of their birth, regardless of their criticisms of it. As individuals who purposely chose to immigrate to the United States in search of new opportunities, it is not surprising that they tend to focus on the positive aspects of their new culture and are most sensitive to the faults of their original culture that they have in some respects left behind. However, the participants identified some specific shortcomings in the American approach to parenting and education and felt that there were several aspects of Chinese culture that they wanted to preserve and pass on to their children even while being committed to making a new life in the United States. This section examines three aspects of Chinese culture that participants most commonly sought to preserve in their attempt to remain Chinese while becoming American in the course of their acculturation experience.

China's rich musical culture. While many of the participants had trenchant criticisms of the Chinese approach to music education, there was a deep appreciation of the Chinese musical tradition itself and a clear desire to pass it on to their children. For instance, Victoria expressed her appreciation of the vast and varied Chinese ethnic musical traditions. Luke expected his daughter to learn to play as many Chinese instruments as possible. There was a general sense that the participants all were proud of their Chinese musical heritage and committed to 
preserving it. All of the parents suggested that early childhood music educators in the United States learn more about the rich musical culture of China and be sensitive in the ways they interact with their students and their families, noting that many Chinese families want to retain and even share their traditional culture and musical heritage. This rich musical heritage can serve as an authentic resource for early childhood music teachers.

The desire on the part of the participants that their Chinese musical heritage be better understood does not necessarily pose a problem in terms of the acculturation process. After all, as several of the participants explicitly stated, music is a universal language and need not be a barrier to cultural adaptation. Indeed, it often facilitates it. Cultural differences became more of an issue when the participants discussed aspects of their Chinese cultural heritage that are characteristically "Chinese" and perhaps not easily understood outside the Chinese cultural context, namely the Confucian concept of guan and the equally Confucian concept of music as an aspect of moral formation. While the participants were not unanimous in their views of the relative importance of guan or of the roles of the Confucian virtues of effort and persistence in music education, within the context of discussing these central concepts much of the criticism of American culture came to the fore, and some of the tensions between their appropriation of American culture and their commitment to preserve Chinese values became apparent.

Confucian concept of guan. A considerable amount has already been said in this study about the importance of the Confucian concept of guan. While guan has often been misunderstood as mere authoritarianism, as noted in Chapter 5 it is multi-faceted. The participants understood the concept primarily in terms of parental authority, parental nurturing of their children, and parents serving as role models. While some facets of this concept were 
criticized by some of the Chinese American participants in this study, clearly guan is a value that most wanted to preserve in some fashion.

It is worth mentioning that all three female participants emphasized the importance of guan in a child's early years and defended the Chinese approach to parenting. For example, Jean was convinced that guan is necessary, especially in early childhood education, and was convinced of the superiority of Chinese parenting in general. While Joan acknowledged that Chinese parenting is stricter, Joan asserted that indulging a child's every want is harmful and noted that children need guan to correct for their childish inexperience and to develop their full potential. Victoria also defended "tiger moms," noting that while this approach may be somewhat shocking to early childhood educators in the United States, in the context of Chinese culture it has its advantages and has proved effective. Victoria entirely attributes ethnic generalizations of Chinese immigrants as being so-called "model minorities" to the traditional Chinese parenting practices that stress educational attainment above all else. Rather than simply rejecting the "tiger mom" approach as a whole, Victoria urges teachers to identify aspects of it to incorporate into their own teaching.

Interestingly, the men in the study were less prone to defend the controlling facet of guan and tended to speak more about the importance of a child's freedom to discover on his or her own without being excessively “managed." This reveals another tension. In Steven's case, his wife insisted on the importance of guan as a mechanism of authority or control over their child and over Steven's objections. Steven stressed that in his private moments with his son, he allowed him autonomy in making decisions.

Moral function in music. Perhaps the most distinctively Chinese theme that emerged from the interviews was the role of music in moral cultivation. This theme was prominent in the 
interviews and was contrasted with values associated with music and music education in the United States. Although the female participants were more vocal in defending the concept of guan, with the male participants tending to be more critical of it, all participants clearly indicated that the moral function of music was an aspect of their Chinese tradition that had enduring value. For instance, Steven stated that he would be heartened if his son's teachers attempted to understand better his culture and values regarding the importance he assigns to music in development of his son's character. Jean also stressed that music education served to cultivate a person's character and considered this to be a distinctly Chinese virtue that she finds lacking in many of her American students.

The emphasis on the connection between music and moral cultivation may seem unusual to modern Western readers, many of whom are more prone to think of music in purely aesthetic terms. When morality and music are linked in the modern West, it is often to criticize the supposed negative effects of rock and roll (Bloom, The Closing of the American Mind, 1987). Nevertheless, the theme of music serving the moral good was consistent among the participants. While they differed considerably about their role as parents, they tended to agree that there was a significant moral dimension to the role of music in their children's lives. Several of the participants were well aware of the Confucian roots of this value, and accordingly regarded its Confucian roots as connecting them more profoundly to their Chinese heritage.

As noted in a previous chapter, underlying this view is the notion that human nature is perfectible. What lies between success and failure is education and the effort invested in it. The role of education, then, is to cultivate innate human potential, and music education is no exception. This view may help explain the criticisms voiced by some of the participants that Americans are too easy on their children, do not push them to make their best effort, and do not 
strive to be "tiger moms." Not to exert such pressure (i.e., not to guan a child) is to deprive the child of his or her full potential. Music education as a dimension of moral cultivation is a serious matter.

Tension arising through interplay of cultures. This review of the participants' critical assessments of both Chinese and American cultures reveals some of the tensions that they face in their personal journeys of becoming American while remaining Chinese. As I have shown, various dissatisfactions with Chinese culture were correlated with specific appropriations of American culture, and criticisms of other aspects of American culture were correlated with the wish to preserve yet other aspects of Chinese culture. One ends up with a number of valuessome American, others Chinese - all of which are all to be preserved and integrated into the lives of these Chinese American parents.

Tensions first become apparent when considering three sets of values that are difficult to reconcile. Participants emphasized the Chinese value of effort and hard work while also valuing the role of play in American education. Similarly, with differing degrees of emphasis they defended the Chinese tradition of guan while at the same time valuing the American emphasis on independence. Finally, they strongly supported the Chinese value of music education as a means of moral cultivation but also insisted, especially when thinking of their own children, that music should be primarily a form of creative self-expression. What becomes clear is the challenge to find a balance.

In each of these three situations there is a tension between two perspectives, one typically Chinese and one typically American, both of which are valued. As all participants were members of the Berry \& Sam (1997) "Integrated Quadrant” of acculturation, this tension comes as no surprise. According to Berry's and Sam's model of acculturation, people in this quadrant pursue 
values of the mainstream culture and maintain values of the culture of origin at the same time. This was evidenced repeatedly in the interviews, and specifically in the tensions between effort and play, guan and independence, and moral cultivation and creative self-expression as goals of music education.

Effort vs. play. Of all the participants it was Jean who most forcefully articulated the Chinese belief that children are innately strong and can take the pressure necessary to grow even stronger. Effort is a key Confucian value that all of the participants shared to some degree. Jean went so far as to say that causing her son to cry by insisting that he put sustained effort into his practice of the piano was perfectly acceptable. As already noted, a number of the participants (notably the women) were also in favor of the "tiger mom" ideal. On the other hand, even Jean admitted that since coming to the United States she had grudgingly come to acknowledge the value of play in education.

A similar value was apparent in the very different case of Steven, who did not share Jean's enthusiasm for guan and the imposition of strict practice habits on his son. Indeed he objected to his wife's "tiger mom" tactics. He said that he had come to value the use of play in education since coming to the United States, and explicitly mentioned the contrast between playbased education and the Chinese emphasis on discipline and hard work. At the same time, he also emphasized that educators in the United States would do well to understand that hard work is critical to success. Joan, who explicitly defended the Chinese approach of the "tiger mom," stated that it is appropriate for parents to override possible objections raised by their children to the effort required by their education. Nevertheless, Joan, too, has come to accept the value of play-based education, which she sees as teaching the valuable lessons of teamwork, sharing, cooperation, and communication. 
What emerges is a tension between two approaches to early childhood education, one emphasizing effort and the other emphasizing play. This tension is created by the fact that both approaches are valued. The challenge is not so much to choose between them as it is to find a way of balancing both.

Guan vs. independence. Another tension became apparent in the participants' assessments of the value of guan, calling for the careful (if loving) "management" of children, and the value of fostering children's independence and capacity for creativity. On some level parents were aware of the tension between these two values and the need to find a balance between them. Joan is self-consciously making an effort to integrate guan with her newly adopted American values. She admitted that too much guidance or oversight denies a child the freedom to make decisions and learn from his or her mistakes. She has sought to find a balance for her child by creating environments that as a whole are under her control as a parent, but also allow her child as much freedom to explore as possible. Victoria implicitly acknowledged that she has become more sensitive to and more tolerant of her daughter's behavior since coming to the United States. That is, she has learned to allow her daughter to make some of her own choices. The men in the study seemed less conflicted on this issue, more fully embracing the value of independence over traditional Chinese notions of parental control.

Moral cultivation vs. creative self-expression. The tension between music education as a means of moral cultivation and music education as a means of creative self-expression is closely related to the previous two tensions. Music education in China traditionally has been devoted to technical mastery of traditional instruments and performance mastery of musical genres from the past. This is true of Chinese "classical" music as well as the many ethnic musical traditions. In 
the modern West, by contrast, music is often understood as a form of creative self-expression. A high value is placed on originality, sometimes even for its own sake.

While the participants in this study strongly endorsed music as a form of moral cultivation, they also seemed to value music as a form of creative self-expression. While this view of music is not absent from the Chinese tradition, an emphasis on creativity, selfenrichment, and enjoyment with regard to music and music education seems related to a significant degree to their American acculturation experience.

\section{Seeking Balance}

The challenges these parents face are not those of choosing between the values they have inherited from the tradition of their birth and those they have encountered in the United States. Rather, they are matters of finding balance between these two sets of values. The parents are aware of these challenges; Joan in particular suggested how insights from the Chinese tradition itself could contribute to meeting them successfully. She regards her own approach to parenting as a synthesis of the Chinese approach, which she thinks can be too strict, and the American approach, which can be too permissive. She finds inspiration for her synthetic approach in the Chinese concept of zhongyong, or the "Doctrine of the Mean," which she says has been the key to success in creating a new life with her family in the United States.

Others have also sought a "mean" between their Chinese heritage and the culture of their newly adopted home, even if they have not articulated this in terms of zhongyong. For instance, George said that in raising his son he has intentionally tried to combine both approaches. And Jean, the most unapologetic in her defense of guan, has nevertheless attempted to integrate aspects of play into her child's education. However, it was Joan who articulated this need for a "Golden Mean" most directly, and her words on this matter are worth repeating: 
Zhongyong is a traditional Confucius concept that I use to guide my second life here. I'm interested in learning more about American concepts and approaches to education and combining them with the Chinese approaches that shaped my own childhood. I hope my son's American music teachers will likewise be willing to make the necessary effort to understand their Chinese students' families' cultural values and traditions. $\left(3^{\text {rd }}\right.$ interview, May 28, 2013)

\section{Implications for Early Childhood Music Education}

Educators in the United States need to be aware of the various tensions that Chinese Americans confront in their attempts to acculturate to American life and adapt to the values that inform approaches to music education in the United States. Whereas much of current early childhood music education in the United States is play-based, many Chinese American parents are ill-equipped to appreciate the value of this method because it seems to clash with the effortbased approach with which they are more familiar. The guan-based approach to parenting that continues to inform their actions as parents is in tension with the American emphasis on encouraging independence in their children. Finally, the Chinese emphasis on the moral dimension of music and music education can easily clash with dominant understandings of music in American culture as primarily a form of entertainment, and with the emphasis on the cultivation of creative self-expression in many early childhood music education programs in the United States.

The findings of this study may help early childhood music educators to communicate more effectively the values that inform what they do in the classroom. Just as the remarkable success of the Chinese American parenting model of guan is perplexing to American educators who view such methods as authoritarian, the pedagogical best practices of many childhood music 
education programs in the United States are sometimes as perplexing to Chinese American parents. There are misunderstandings on both sides. This study may bridge this "culture gap" and facilitate more effective collaboration between American educators and Chinese American parents.

Such collaboration between teachers and parents is very important (Andress, 1989). Teachers and parents must approach one another on the basis of mutual respect, cooperation, shared responsibility, and a willingness to negotiate conflicts. A reciprocal relationship between teachers and parents is important for the educational success of a young child. For this relationship to work, Chinese American parents must also have a better understanding of the guiding principles and practices of early childhood music education in the United States. It is the responsibility of the teachers to facilitate such understanding; their appreciation of the parents' perspectives may help teachers become more effective in explaining their pedagogy and suggesting ways to transform the inevitable challenges of cultural difference into opportunities for creativity and growth.

In this dialogue between teachers and parents, teachers who have become more familiar with the cultural backgrounds of their students and their parents will be better positioned to listen and learn more about them. Parents are the primary caregivers for young children and are the best resource for understanding their needs. However, care must be taken to avoid cultural misunderstandings. For example, many Chinese American parents do not use the term "play" in the same way as American teachers do. "Play" is a term that carries much more meaning in the American pedagogical context than parents are in a position to understand without guidance. Teachers need to educate parents in this regard. 
Chinese American parents are also likely unaware of western concepts such as developmentally appropriate music practice based on principles of child development and wellbeing. Music educators need to include parent education as part of an early childhood music education program and communicate program principles and goals as clearly as possible. Parents also need to be taught how musical play can be integrated into parenting. Such a collaborative relationship, built on a firm foundation of intercultural understanding, will make it possible to reach an important goal, namely broadening the vision of what early childhood music education can be in the multicultural world in which everyone lives.

\section{Directions for Future Research}

This study has been motivated by two needs that have helped identify a number of directions for future research. The first is that American music educators need to become more familiar with the values that Chinese American families bring with them from their home culture. Some of the most important of these values, such as the understanding of parenting as guan and the role of traditional moral values in the Chinese American approach to music education, have been clarified in this study. However, in the process of analyzing the interview data new questions arose that merit further study, in particular questions regarding the roles of gender and socioeconomic status as factors in shaping the participants' views on parenting and music education.

One issue that emerged was that Chinese American women in this study tended to be more conservative in their approaches to parenting and music education than were the Chinese American men. All three women defended the "tiger mom" approach to parenting to some extent, whereas the men tended to emphasize the cultivation of independence and took a more "handsoff" approach to parenting. Is this apparent gender difference a mere artifact of this particular 
study, or is this a pattern that would hold up more generally? One possible direction for future research is to look at this gender issue in more detail, selecting a diverse group of women from varying socioeconomic backgrounds and with different levels of musical accomplishment to see if the pattern persists in a more diverse group. A similar follow-up study could be conducted with Chinese American men, perhaps followed by a larger, comparative study of women and men together in a more diverse group.

Another interesting pattern that may warrant further study is the gender division associated with musical accomplishment. Are Chinese American women more likely to have received extensive musical education and to be more accomplished as amateur musicians than men? One recalls the tradition that women are expected to be accomplished on at least one instrument. Is this tradition still operative today? All three women participants studied the piano formally, and two of them became quite accomplished. By contrast, the men in the study all reported less than satisfactory experiences with their musical education in China and, with the exception of Luke, did not become accomplished musicians.

In addition to these questions of gender, another interesting issue that emerged was that none of the participants of this study, whatever their level of musical accomplishment, wanted their own child to become a professional musician. Why the strong valuing of music education but resistance to a career in music? Is this influenced by the devaluing of music as a career in traditional Chinese culture? What are the factors that affect parents' expectations for their child's career choice? Is this a purely socioeconomic matter, or does music education for the children of Chinese Americans fulfill a need independent of financial and career concerns? A future study could focus on the relationship between the role of socioeconomic status and career choice and include parents from more diverse socioeconomic backgrounds. 
The second need addressed in this study, namely to help Chinese American parents better understand the form of play-based music education that is offered to their children, raises a number of questions related to how music educators in the United States communicate their educational values to Chinese American parents. To what extent are music teachers educating parents about play-based experiences in ways that help parents find a balance between two sets of contrasting cultural and educational values? How do parents initially interpret the use of play in the classroom? What are parents' actual experiences with and perspectives on this educational approach? How well are music teachers responding with cultural sensitivity to families' needs and backgrounds?

More research seems to be indicated by these questions. As an example, a study involving Chinese American students and their parents attending an early childhood music program together might be designed to observe the interactions between parents and teachers, including a series of interviews with parents before and after encountering play-based education. A follow-up longitudinal study of these same participants to track the longer term outcomes of the acculturation process may be warranted, or perhaps a study comparing and contrasting this group of parents with parents who have spent a longer time in the United States. Have Chinese Americans succeeded in finding a "Golden Mean" and, if so, what does this look like?

A first step would be to identify exemplary play-based early childhood music programs that include parent education. A survey or a multiple case study could be conducted to determine the extent to which these programs are effectively educating Chinese American parents about the values of play-based education. If such model programs do not currently exist, then a future direction for the profession would involve a conversation about how early childhood music educators can more successfully communicate play-based pedagogical values and forge 
reciprocal relationships with Chinese American parents.

\section{Conclusion}

This dissertation has been an attempt to listen to the voices of Chinese American parents, who often have difficulty expressing the values that inform their views on parenting and early childhood music education in ways that can be understood and appreciated by educators in the United States. As a Chinese American myself, I can attest to the challenges faced by anyone who wishes to become American while remaining authentically Chinese. Values often appear to clash. Sometimes these differences are real and sometimes they are more the result of mutual misunderstandings. "Tiger moms" are understood to be "authoritarian," which has a negative connotation. The actual value that informs this style of parenting, guan, remains unarticulated due to barriers of language and culture. Best practices in early childhood music education in the United States, such as play-based instruction, are misunderstood as a waste of time by puzzled parents.

As part of acculturation in the United States, Chinese American parents often embrace new values that are in some tension with the traditional Chinese values they wish to maintain. While parents continue to value effort and hard work, they come to acknowledge at the same time the value of a play-based approach to early childhood education. While they continue to defend guan as a vital aspect of parenting, they also come to value the emphasis on independence that they find in parenting styles common in the United States. And while they can appreciate music as a form of creative self-expression, at the same time they insist that music is a deeply moral phenomenon and that music education is integral to the formation of a child's character. This interplay between seemingly opposing values can lead to tension, especially as parents face decisions about the education of their children in the United States. But even as they 
experience such tension they seek creative solutions, hoping, in the best of Chinese traditions, to find a "Golden Mean" that unites the best of both cultures. In this effort they deserve support. It is my hope that this dissertation contributes to a better understanding of the reasons for tensions created by this cultural gap, and provides early childhood music educators with tools to be more responsive to Chinese American students and their parents in the process of seeking a balance. For many of these parents the traditional Chinese values discussed in this study are still very real, but their commitment to become American and to embrace the "best practices" of their new home is no less real. Early childhood music educators in the United States are ideally positioned to help them succeed in finding the balance they seek for themselves and their children. Through the careful examination of factors involved in the acculturation experience of Chinese American parents - from both the Chinese and the American sides - this study contributes to an understanding of the importance of and need for reciprocal relationships between music educators in the United States and the Chinese American parents whose children they teach. 


\section{References}

Andress, B. (Ed.). (1989). Promising Practices: Prekindergarten Music Education. Reston, VA: Music Educators National Conference.

Barrett, M. (2003). Musical children, musical lives, musical worlds. In S. Wright (Ed.), Children, meaning-making and the arts (pp. 63-90). Frenchs Forest, Australia: Pearson.

Berger, A. A., \& Cooper, S. (2003). Musical play: A case study of preschool children and parents. Journal of Research in Music Education, 51, 151-165.

Berger, E. H. (1987). Parents as partners in education: The school and home working together ( $2^{\text {nd }}$ ed.). Columbus, OH: Merrill Publishing Company.

Berger, K. S. (2008). The developing person through the life span ( $7^{\text {th }}$ ed.). New York, NY: Worth Publishers.

Berry, J. W., \& Sam, D. L. (1997). Acculturation and adaptation. In J. W. Berry, M. H. Segall, \& C. Kagitcibasi (Eds.), Handbook of cross-cultural psychology, Vol. 3: Social behaviour and applications ( $2^{\text {nd }}$ ed., pp. 291-326). Boston, MA: Allyn \& Bacon.

Billiter, B. (1993, August 7). Learning in a new key: Pilot study finds training in music may help preschoolers' education [Letter to the editor]. The Los Angeles Times, p. A30.

Bloom, A. (1987). The closing of the American mind: How higher education has failed democracy and impoverished the souls of today's students. New York, NY: Simon \& Schuster.

Britton, L. (1992). Montessori play and learn: A parent's guide to purposeful play from two to six. New York, NY: Three Rivers Press.

Brock, A., Dodds, S., Jarvis, P., \& Olusoga, Y. (2009). Perspective on play: Learning for life. London, UK: Pearson Education. 
Bronfenbrenner, U. (1979). The ecology of human development. Cambridge, MA: Harvard University Press.

Bronfenbrenner, U., \& Morris, P. A. (1998). The ecology of developmental processes. In W. Damon \& R. M. Lerner (Eds.), Handbook of child psychology, Vol. 1: Theoretical models of human development (5 ${ }^{\text {th }}$ ed., pp. 993-1023). New York, NY: John Wiley and Sons, Inc.

Caldwell, B. (1986). The significance of parent-child interaction in children's development. In A. W. Gottfried \& C. C. Brown (Eds.), Play interactions: The contribution of play materials and parental involvement to children's development (pp. 305-310). Lexington, MA: D. C. Heath and Company.

Campbell, P. S. (1998). Songs in their heads: Music and its meaning in children's lives. New York, NY: Oxford University Press.

Campbell, P. S., \& Scott-Kassner, C. (2002). Music in childhood: From preschool through the elementary grades. Belmont, CA: Cengage Learning.

Cardany, A. A. (2004). Music education for preschool children: Perspectives and experiences of parents. Dissertation Abstracts International, 65(11), 4141. (UMI No. 3152384)

Chan, L. K. S., \& Moore P. J. (2006). Development of attributional beliefs and strategic knowledge in years 5-9: A longitudinal analysis. Educational Psychology, 26, 161-185.

Chao, R. K. (1994). Beyond parental control and authoritarian parenting style: Understanding Chinese parenting through the cultural notion of training. Child Development, 65(4), 1111-1119.

Chao, R. K. (1995). Beyond authoritarianism: A cultural perspective on Asian American parenting practices. Paper presented at the Annual Meeting of the American 
Psychological Association, New York, NY. (ERIC Document Reproduction Service No. ED 390952)

Chen, C., \& Uttal, D. H. (1988). Cultural values, parents' beliefs, and children's achievement in the United States and Canada. Human Development, 31, 351-358.

Chen, H. (2001). Parents' attitudes and expectations regarding science education: Comparisons among American, Chinese American, and Chinese families. Adolescence, 36, 305-313.

Chen, Y. (2004). Invisible historical players: Uncovering the meanings and experiences of children in early Asian American history. In B. Tong (Ed.), Asian American children: A historical guide (pp. 3-23). Westport, CT: Greenwood Press.

Cheung, C., \& McBride-Chang, C. (2008) Relations of perceived maternal parenting style, practices, and learning motivation to academic competence in Chinese children. MerrillPalmer Quarterly, 54(1), 1-22.

Chiu, L. H. (1987). Child-rearing attitudes of Chinese, Chinese American, and Anglo-American mothers. Journal of Social Psychology, 128, 411-413.

Chua, A. (2011a, January 8). Why Chinese mothers are superior. Wall Street Journal. Retrieved from http://online.wsj.com/article/SB10001424052748704111504576059713528698754.html Chua, A. (2011b). Battle hymn of the tiger mother. New York, NY: Penguin Press.

Conrad, C., Neumann, A., Haworth, J. G., \& Scott, P. (1993). Qualitative research in higher education: Experiencing alternative perspectives and approaches. Needham Heights, MA: Ginn Press.

Cook, S. (1995a). Unity and diversity in the musical thought of Warring States China. Retrieved from ProQuest Digital Dissertations. (AAI9610102) 
Cook, S. (1995b). Yue Ji: Record of music: Introduction, translations, notes, and commentary. Asian Music, 26(2), 1-96.

Cook, S. (1997). Xun Zi on ritual and music. Monumenta Serica, 45, 1-38.

Creswell, J. W. (2007). Qualitative inquiry and research design: Choosing among the five approaches $\left(2^{\text {nd }}\right.$ ed.). Thousand Oaks, CA: Sage Publications.

Creswell, J. (2009). Research Design: Qualitative, quantitative, and mixed methods approaches $\left(3^{\text {rd }}\right.$ ed.). Thousand Oaks, CA: Sage Publications.

Crosswhite, J. E. (1996). Effect of music instruction on language development of preschool children. Dissertation Abstracts International, 57(12), 5092A. (UMI No. 9715590)

Crystal, D. S., Chen, C., Fuligni, A. J., Stevenson, H. W., Hsu, C., Ko, H., ... Kimura, S. (1994). Psychological maladjustment and academic achievement: A cross-cultural study of Japanese, Chinese, and American high school students. Child Development, 65(3), 738-753.

Csikszentmihalyi, M. (2002). Flow. London, UK: Rider.

Custodero, L. A. (2006). Singing practices in 10 families with young children. Journal of Research in Music Education, 54(1), 37-56.

Denney, K. (2000). Kindermusik: Spotlight on early childhood music education. Reston, VA: Music Educators National Conference.

Denzin, N. K. (1978). The research act: A theoretical introduction to sociological methods. New York, NY: McGraw-Hill.

Duffy, B. (2006). Supporting creativity and imagination in the early years. Maidenhead, UK: Open University Press. 
Early Head Start National Resource Center. (2005). Early head start program strategies.

Retrieved from http://www.ehsnrc.org/101/menu/pdfs/EHSProgramStratEnglish/psmentalhealth.pdf

Eisner, E. W. (1998). The enlightened eye: Qualitative inquiry and the enhancement of educational practice. Upper Saddle River, NJ: Prentice-Hall.

Flohr, J. W. (2005). The musical lives of young children. Upper Saddle River, NJ: Pearson Education.

Follari, L. M. (2007). Foundation and best practices in early childhood education: History, theories and approaches to learning. Upper Saddle River, NJ: Pearson Education.

Fox, D. B. (1989). MusicTIME and music times two: The Eastman infant-toddler music programs. In B. Andress (Ed.), Promising practices: Prekindergarten music education (pp. 12-23). Reston, VA: Music Educators National Conference.

Frost, J. F., Wortham, S. C., \& Reifel, S. (2008). Play and child development (3 ${ }^{\text {rd }}$ ed.). Upper Saddle River, NJ: Prentice Hall/Merrill.

Gardner, H. (1983). Frames of mind. New York, NY: Basic Books.

Gelfand, M. J., Higgins, M., Nishii, L. H., Raver, J. L., Dominguez, A., Murakami, F., ... Toyama, M. (2002). Culture and egocentric biases of fairness in conflict and negotiation. Journal of Applied Psychology, 87, 833-845. doi:10.1037/0021-9010.87.5.833

Glesne, C. (2010). Becoming qualitative researchers: An introduction (4 ${ }^{\text {th }}$ ed.). New York, NY: Addison Wesley Longman.

Gordon, E. E. (1995). The role of music aptitude in early childhood music. Early Childhood Connections, Winter 1995, 2-9. 
Gordon, E. E. (1997). A music learning theory for newborn and young children. Chicago, IL: GIA Publications.

Gorman, J. C. (1998). Parenting attitudes and practices of immigrant Chinese mothers of adolescents. Family Relations, 47(1), 73-80.

Graves, T. D. (1967). Psychological acculturation in a tri-ethnic community. Southwestern Journal of Anthropology, 23, 338-350.

Grätzer, D. P. D. (1999). Can music help to improve parent-child communication? International Journal of Music Education, 34, 47-56.

Ho, M. K. (1976). Social work with Asian Americans. Social Casework, 57(3), 195-201.

Ho, D. Y. F. (1989). Continuity and variation in Chinese patterns of socialization. Journal of Marriage and the Family, 51, 149-163.

Hsu, F. L. K. (1971). Psychological homeostasis and ren: Conceptual tools for advancing psychological anthropology. American Anthropologist, 73, 23-44.

Huang, C. C. (1997). The analects of Confucius (Lunyu). Oxford, UK: Oxford University Press.

Huang, H. (2012). Why Chinese people play western classical music: Transcultural roots of music philosophy. International Journal of Music Education, 30 (2), 161-176. doi:10.1177/0255761411420955

Ilari, B. (2005). On musical parenting of young children: Musical beliefs and behaviors of mothers and infants. Early Child Development and Care, 175(7-8), 647-660.

Jacobi-Karna, K. (2007). The role of play in early childhood education. Orff Echo, 40(1), 13-16.

Janesick, V. J. (1999). A journal about journal writing as a qualitative research technique: History, issues, and reflections. Qualitative Inquiry, 5, 505-524. doi:10.1177/107780049900500404 
Johnson, J. E., Christie, J. F., \& Yawkey, T. D. (1999). Play and early childhood development ( $2^{\text {nd }}$ ed.). New York, NY: Longman.

Katz, L. G. (1986). Current perspectives on child development. Bulletin of the Council for Research in Music Education, 86, 1-9.

Koops, L. H. (2011). Perceptions of current and desired involvement in early childhood music instruction. Visions of Research in Music Education, 17. Retrieved from http://www-usr.rider.edu/vrme /

Lai, K. (2003). Confucian moral cultivation: Some parallels with musical training. In K. C. Chong, S. H. Tan, \& C. L. Ten (Eds.), The moral circle and the self: Chinese and western approaches (pp. 107-139). Peru, IL: Open Court.

Li, J. (2001). Expectations of Chinese immigrant parents for their children's education: The interplay of Chinese tradition and the Canadian context. Canadian Journal of Education, 26(4), 477-494.

Lin, K. M. (2004). Virtuous transcendence: Holistic self-cultivation and self-healing in elderly Korean immigrants. Transcultural Psychiatry, 41(2), 296-298.

Lincoln, Y. S., \& Guba, E. G. (1985). Naturalistic inquiry. New York, NY: Sage.

Littleton, D. (1991). Influence of play settings on preschool children's music and play behaviors. Retrieved from ProQuest Digital Dissertations. (AAI9990652)

Littleton, D. (1998). Music learning and child's play. General Music Today, 12(1), 8-15.

Mallett, C. A. (2000). An examination of parent/caregiver attitudes toward music instruction, the nature of the home musical environment, and their relationship to the developmental music aptitude of preschool children. Dissertation Abstracts International, 61(04), 1335A. 
Maslin, J. (2011, January 20). But will it all make 'tiger mom' happy? [Review of the book Battle hymn of the tiger mother, by Amy Chua]. The New York Times, pp. C1.

Maxwell, J. A. (2004). Qualitative research design: An interactive approach (2 ${ }^{\text {nd }}$ ed.) Thousand Oaks, CA: Sage Publications.

McElwee, G. (2004). It's never too early. Library Information Update, 3(11), 23-25.

Merriam, A. P. (1964). The anthropology of music. Evanston, IL: Northwestern University Press.

Merriam, S. B. (1988). Case study research in education: A qualitative approach. San Francisco, CA: Jossey-Bass.

Merriam, S. B. (1998). Qualitative research and case study applications in education. San Francisco, CA: Jossey-Bass.

Miranda, M. (2009). Developmentally appropriate practice: Historic roots and evolving paradigms. In L. K. Thompson \& M. R. Campbell (Eds.), Research perspectives: Thought and practice in music education (pp. 7-35). Charlotte, NC: Information Age Publishing.

Montessori, M. (1964). The Montessori method (A. E. George, Trans.). New York, NY: Schoken Books. (Original work published 1912)

Morse, J. M., \& Field, P. A. (1995). Qualitative research methods for health professionals $\left(2^{\text {nd }}\right.$ ed.). Thousand Oaks, CA: Sage.

Moyers, B. (Producer). (2003, March 1). Becoming American: The Chinese experience [Television broadcast]. Arlington, VA: Public Broadcasting Service.

Moyles, J. (1995). The excellence of play. Buckingham, UK: Open University Press. 
National Association for the Education of Young Children. (2009). Developmentally appropriate practice in early childhood programs serving children from birth through age 8. Retrieved from http://www.naeyc.org/files/naeyc/file/positions/PSDAP. pdf

National Head Start Association (2013). Policy agenda. Retrieved from http://www.nhsa.org/advocacy/advocacy/policy_agenda

Nelson, D. A., Hart, C. H., Yang, C., Olsen, J. A., \& Jin, S. (2006) Aversive parenting in China: Associations with child physical and relational aggression. Child Development, 77, 554572.

Niland, A. (2009). The power of musical play: The value of play-based, child-centered curriculum in early childhood music education. General Music Today, 23 (1), 17-21.

Onchwari, G., Onchwari, J. A., \& Keegwe, J. (2008). Teaching the immigrant child: Application of child development theories. Journal of Early Childhood Education, 36, 267-273.

Patton, M. Q. (1990). Qualitative evaluation and research methods $\left(2^{\text {nd }}\right.$ ed). Thousand Oaks, CA: Sage Publications.

Pestalozzi, J. (1951). The education of man, aphorisms. (H. Norden \& R. Norden, Trans.). New York, NY: Philosophical Library.

Ponick, F. S. (1999). What's happening in early childhood music education? Teaching Music, 7(2), 30-37.

Pong, W. Y., \& Chow, J. C. S. (2002). On the pedagogy of examinations in Hong Kong. Teaching and Teacher Education, 18(2), 139-149.

QSR NVivo (Version 10) [Software]. (2012). QSR International. Retrieved from http://www.qsrinternational.com/products_nvivo.aspx 
Reimer, B. (2002). A philosophy of music education: Advancing the vision ( $3^{\text {rd }}$ ed.). Upper Saddle River, NJ: Pearson.

Rogers, S. (2011). Rethinking play and pedagogy in early childhood education: Concepts, contexts and cultures. New York, NY: Routledge.

Roopnarine, J. L., \& Johnson, J. E. (2000). Approaches to early childhood education ( $3^{\text {rd }}$ ed.). Upper Saddle River, NJ: Merrill/Prentice Hall.

Saracho, O. N., \& Spodek, B. (1998). Preschool children's cognitive play: A factor analysis. International Journal of Early Childhood Education, 3, 67-76.

Schuman, D. (1982). Policy analysis, education, and everyday life. Lexington, MA: Heath. Seidman, I. (1998). Interviewing as qualitative research: A guide for researchers in education and the social sciences ( $2^{\text {nd }}$ ed.). New York, NY: Teachers College Press.

Silverman, L. K. (1992). How parents can support gifted children. Reston, VA: Council for Exceptional Children. Retrieved from http://www.ericdigests.org/1993/parents.htm

Smith, D. C. (Ed.). (1991). The Confucian continuum: Educational modernization in Taiwan. New York, NY: Praeger.

Smithrim, K. L. (1997). Free musical play in early childhood. Canadian Music Educator, 38(4), $17-22$.

Stake, R. E. (1995). The art of case study research. Thousand Oaks, CA: Sage Publications.

Stake, R. E. (2000). Case studies. In N. K. Denzin \& Y. S. Lincoln (Eds.), Handbook of qualitative research ( $2^{\text {nd }}$ ed., pp. 435-454). Thousand Oaks, CA: Sage.

Stake, R. E. (2006). Multiple case study analysis. New York, NY: Guilford Press.

Stevenson, H. W., \& Lee, S. Y. (1990). Contexts of achievement. Monographs of the Society for Research in Child Development, 55(1-2), Serial No. 221. 
Stevenson, H. W., \& Stigler, J. W. (1992). The learning gap: Why our schools are failing and what we can learn from Japanese and Chinese education. Toronto, Canada: Summit Books.

Stewart, S. M., Rao, N., Bond, M. H., McBride-Chang, C., Fielding, R., \& Kennard, B. D. (1998). Chinese dimensions of parenting: Broadening Western predictors and outcomes. International Journal of Psychology, 33(5), 345-358.

Stewart, S. M., Bond, M. H., Kennard, B. D., Ho, L.M., \& Zaman, R. M. (2002). Does the Chinese construct of guan export to the West? International Journal of Psychology, 37(2), 74-82. doi:10.1080/00207590143000162

Szabo, M. (1999). Early music experience and musical development. General Music Today, 12(3), 17-19.

Taggart, C. C. (2000). Developing musicianship through musical play. In Spotlight on early childhood music education (pp. 23-26). Reston, VA: Music Educators National Conference.

Taggart, C. C. (2003). Child-centered play in music: Developmentally appropriate practice. Early Childhood Connections, 9(2), 15-23.

Tarnowski, S. M. (1999). Musical play and young children. Music Educators Journal, 86, 26-29.

Tarnowski, S. M., \& Barrett, J. R. (1997). The beginnings of music for a lifetime: Survey of musical practices in Wisconsin preschools. Update: Applications of Research in Music Education, 15(2), 6-12.

Thomas, T. N. (1995). Acculturative stress in the adjustment of immigrant families. Journal of Social Distress and the Homeless, 4(2), 131-142

Tobin, J. J., Wu, D. Y. H., \& Davidson, D. H. (1989). Preschool in three cultures. New 
Haven, CT: Yale University Press.

Trollinger, V. L. (2003). Relationships between pitch-matching accuracy, speech fundamental frequency, speech range, age, and gender in American English-speaking preschool children. Journal of Research in Music Education, 51, 78-94.

Tweed, R. G., \& Lehman, D. R. (2002). Learning considered within a cultural context: Confucian and Socratic approaches. American Psychologist, 57(2), 89-99.

United States Census Bureau. (2011, March). Population distribution and change: 2000 to 2010: 2010 Census Briefs. (C2010BR-01). Retrieved from http://www.census.gov/prod/cen2010/briefs/c2010br-01.pdf

Vandermaas-Peeler, M., King, C., Clayton, A., Holt, M., Kurtz, K., Maestri, L., ... Woody, E. (2001). Parental scaffolding during joint play with preschoolers. In J. L. Roopnarine (Ed.), Conceptual, social-cognitive, and contextual issues in the fields of play (Play \& Culture Studies, Volume 4) (pp. 165-181). West Mifflin, PA: PlumCircle.

Verna, M. A., \& Campbell, J. R. (1998). The differential effects of family processes and SES on academic self-concepts and achievement of gifted Asian American and gifted Caucasian high school students. Paper presented at the Annual Meeting of the American Educational Research Association, San Diego, CA. (ERIC Document Production Service No. ED419025)

Vygotsky, L. S. (1987). Thinking and speech. (N. Minick, Trans.). In R. W. Riber \& A. S. Carton (Eds.), Problems of general psychology (Vol. 1, pp. 39-285). New York, NY: Plenum Press. (original work published 1934) 
Wang, Y. (1900). Elementary Chinese: San tzu ching. (H. A. Giles, Trans.). Shanghai, China: Kelly \& Walsh. Retrieved fromhttp://www.archive.org/details/elementarychines00wangrich (Original work dates from $13^{\text {th }}$ century C.E.)

Wolcott, H. F. (1990). Writing up qualitative research. London, UK: Sage Publications.

Wong, M. G. (1995). The education of White, Chinese, Filipino, and Japanese students: A look at "High School and Beyond." In D. T. Nakanishi \& T. Y. Nishida (Eds.), The Asian American educational experience: A source book for teachers and students (pp. 221-234). New York, NY: Routledge.

Wu, E. H. (2006). Nurture over nature: A reflective review of Confucian philosophy on learning and talented performance. Gifted Education International, 21, 181-189.

Wu, Sung-Mei. (2005). A survey of Taiwanese parents' attitudes toward early childhood music education and their participation in music activities at home. Dissertation Abstracts International, 66 (06), 2098. (UMI No. 3180371)

Wu, P., \& Hart, C. H. (2002). Similarities and differences in mothers' parenting of preschoolers in China and the United States. International Journal of Behavioral Development, 26, $481-491$.

Yang, W., \& Zhou, W. (2008). What accounts for Chinese American children's high academic performance: A literature review of parental influences and home environment. Gifted Education International, 24(1), 88-104.

Yax-Fraser, M. J. (2007). A balancing act: The cultural choices and processes of cross-cultural mothering. Retrieved from ProQuest Digital Dissertations. (AAI9990560)

Yin, R. K. (1993). Applications of case study research. Newbury Park, CA: Sage Publishing. 
Yin, R. K. (2003). Case study research: Design and methods ( $3^{\text {rd }}$ ed.). Thousand Oaks, CA: Sage Publications.

Yin R. K. (2009). Case study research: Design and methods $\left(4^{\text {th }}\right.$ ed.). London, UK: Sage Publications.

Yue, J. (2008). Confucius on music education. Nebula, 5(1), 128-133.

Zhongyong. (2014). In Encyclopaedia Britannica online. Retrieved from http://www.britannica.com/EBchecked/topic/117001/Zhongyong 


\section{Dear Parents,}

\section{Appendix A \\ Letter of Invitation}

I am currently a doctoral student in Music Education at West Virginia University. I am conducting a dissertation research study, "Understanding Chinese American Parents: The Interplay of Chinese Tradition and the American Context in Early Childhood Music Education," under the supervision of Dr. Janet Robbins. The purpose of my study is to gain a better understanding of the acculturation experience of first-generation Chinese American parents and the values that inform their expectations for their young children's early childhood music education. A primary goal is to gain a deeper understanding of the interplay of Chinese traditional culture and American early childhood music education. Your participation is voluntary.

Knowing what music means to Chinese American parents for their children's education and the role that music education plays in traditional Chinese culture will help early childhood music educators better understand Chinese American parents and their children, as well as help build reciprocal relationships necessary for bridging any "cultural gaps" that may exist between teachers and parents. A deeper understanding of the role that music has played in traditional Chinese culture will help teachers truly appreciate the values that inform Chinese American parents' perspectives on their children's music education. Such an appreciation will make teachers more perceptive in their attempts to explain their own methods to parents and has the potential to transform the inevitable challenges of cultural difference into opportunities for creativity and growth.

I would like to invite you to join my study. Your participation would involve a series of three interviews. I hope to conduct these three interviews in the next three months. Each interview will be conducted in Chinese and will last for 90 minutes, and could take place either at Saint Joseph's University where I teach, or at a location more convenient for you.

Your confidentiality will be highly respected. You will not be identified by name in the dissertation. The content will be used only for the purpose of this dissertation, and will not be shared with others. No permanent records of the interview will be kept. You are free to withdraw from the project at any time. West Virginia University Institutional Review Board acknowledgement of this project is on file.

I look forward to talking to you about your child and music soon. If you are interested in participating, please contact me at 304-216-6868 or by email at jyu@ sju.edu.

Sincerely,

\section{Juan Julie Yu}

Supervisor Contact Information:

Dr. Janet Robbins, Professor of Music

School of Music

West Virginia University

Morgantown, West Virginia

304.293.4540 


\title{
Appendix B \\ Institutional Review Board Approval Letter
}

\author{
WestVurginiaUniversity. \\ Office of Research Integrity and Compliance \\ Acknowledgement Letter - Exempt - Initial Protocol Review \\ To: \\ From: \\ Approval Period: \\ Subject: \\ Protocol Tracking\#: \\ Title: \\ Janet Robbins \\ WVU Office of Research Integrity and Compliance \\ 04/29/2013 Expiration Date: 04/28/2016 \\ Acknowledgement Letter - Exempt - Initial Protocol Review \\ 1303027845 \\ Understanding Chinese American Parents: The Interplay of Chinese Tradition and \\ Early Childhood Music Education in the United States
}

The above-referenced study was reviewed by the West Virginia University Institutional Review Board (IRB) and was granted exemption in accordance with 45 CFR 46.101 (1-6).

- This research study was granted an exemption because the Research involves educational tests, survey procedures, interview procedures or observation of public behavior and (i) information obtained is recorded in such a manner that human subjects cannot be identified, directly or through identifiers linked to the subjects; and (ii) any disclosure of the human subjects responses outside the research could not reasonably place the subjects at risk of criminal or civil liability or be damaging to the subject?s financial standing, employability, or reputation [45 CFR 46.101(2)]. All exemptions are only good for three years. If this research extends more than three years beyond the approved date, then the researcher will have to request another exemption. The following documents have been acknowledged for use in this study and are available in the WVU+kc system:

- Yu_Cover Letter_Revised.docx

- letter of support for translation.jpg

- Attachment for Questionnaires_revised.docx

- Final_Interview Protocal_English_April 4.docx

- Final_Interview Protocal_Chinese_April 4.docx

If you have any questions, please contact the IRB at (304) 293-7073.

Thank you.

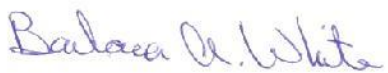


Board Designee: Barbara White

Letter Sent By: Barbara White on 04/29/2013 at 09:27:08-04:00

Once you begin your human subject research, the following regulations apply:

1. Any modifications to the study protocol must be reviewed and acknowledged by the IRB prior to implementation.

2. You may not use a modified form until it has been acknowledged by the IRB. 


\section{Appendix C \\ Interview Protocol in English and Chinese}

\section{Interview \#1: Focused Life History}

1. Tell me about your memories of music classes at school when you were young.

2. Tell me about any musical activities you recall taking place outside of school. Why were you involved?

3. Tell me about any musical activities that took place in your home when you were growing up.

4. How were your parents involved in your music education when you were growing up?

5. What do you recall about your parents' expectations for your music education?

6. What do you value most about Chinese musical culture?

7. How do you think growing up in China shaped your view of music and music education?

\section{Interview \#2: Details of Experience}

1. Tell me about the musical activities you and your child do at home.

2. Tell me about any music classes and/or lessons your child is involved in at school.

3. Tell me about any music classes and/or lessons your child is involved in outside of school.

4. What are some specific things your child is learning in music at school and/or outside of school?

5. Tell me about your child's music teacher(s)? How closely have you worked with him/her.

6. What does your child seem to like most about the music classes and/or lessons?

7. What does your child seem to like least about the music classes and/or lessons? 
8. What influenced your decision to enroll your child in music classes and/or lessons?

9. What do you want most for your child's music education?

10. Are the classes and/or lessons meeting your expectations? Please explain and give examples if possible.

11. What role(s) do you believe you should play in your child's music education?

12. In what ways is your child's musical experience in the United States different from your musical experience growing up in China?

\section{Interview \#3: Reflection on the Meaning}

1. As a parent, what role do you think music should play in your child's life?

2. Do you find that music is valued differently in the United States than it is in China? If so, can you give some examples?

3. How are your expectations for your child's music education similar to those of your parents?

4. How are your expectations for your child's music education different from those of your parents?

5. As a parent, what challenges have you faced regarding your child's music education?

6. How do you think your upbringing has influenced your approach to parenting and your decisions regarding your child's music education?

7. How has your understanding of your role as a parent in your child's music education changed since coming to the United States?

8. How has your understanding of early childhood music education changed since coming to the United States? 
9. How do you negotiate cultural differences between your Chinese heritage and your new American identity as a parent directing your child's music education?

10. What specific aspects of Chinese musical culture are the most important for music teachers in the United States to understand? 


\section{Interview questions in Chinese:}

\section{Interview \#1:}

1. 请你说一说你小时候记忆中的音乐课。

2. 你小时候参加过哪些课外音乐活动? 你为什么会参加?

3. 在你的成长过程中, 在你的家里会有哪些音乐活动?

4. 你的父母在你的音乐是怎样参与你的音乐教育的?

5. 你父母对你的音乐教育有哪些期望?

6. 你认为中国音乐文化里最有价值的是什么?

7. 中国文化从哪些方面影响了你的音乐价值观?

\section{Interview \#2:}

1. 请说说您和您的孩子之间在家的音乐互动活动。

2. 请说说你的孩子在学校的音乐课以及/或者音乐班。

3. 请告诉我你的孩子在校外参加的音乐课或者音乐辅导班。

4. 你的孩子在学校和校外的音乐课中都学了些什么?

5. 请说一说你孩子的音乐老师。你和他/她是怎么互动的?

6. 您的孩子最喜欢音乐课的哪些方面？

7. 您的孩子最不喜欢音乐课的哪些方面?

8. 什么影响了你让孩子参加音乐培训的决定?

9. 你最希望你的孩子从音乐教育中获得什么?

10. 您的孩子的音乐课达到了您的预期吗? 为什么? 请举例说明。

11. 你认为家长对于孩子的音乐教育应该扮演什么角色? 
12. 在哪些方面您孩子在美国的音乐学习经历和您在中国的音乐学习经历有什么不

同?

Interview \#3:

1. 作为家长, 你为什么音乐在孩子的生活中有什么作用?

2. 你认为音乐价值在美国和中国一样吗? 请举例说明。

3. 你对你的孩子在音乐教育上的期望跟您的父母对您的有什么相同之处?

4. 你对你的孩子在音乐教育上的期望跟您的父母对您的有什么不同之处?

5. 作为家长, 你面对孩子的音乐教育, 遇到过的最大的挑战是什么?

6. 你的父母那一辈是如何影响你对孩子的教育和在音乐学习上的决定的?

7. 来美国以后, 你对于家长在孩子音乐教育中的作用的理解有什么改变?

8. 来美国以后，你对于早期儿童音乐教育的理解有了什么改变?

9. 作为家长, 你是怎么协调你的传统文化跟你所吸收的美国文化在儿童音乐教育 方面的差异的?

10. 你认为美国音乐教师最需要了解中国音乐文化的哪些方面? 